Prepared in cooperation with the National Park Service

\title{
Synthesis and Interpretation of Surface-Water Quality and Aquatic Biota Data Collected in Shenandoah National Park, Virginia, 1979-2009
}

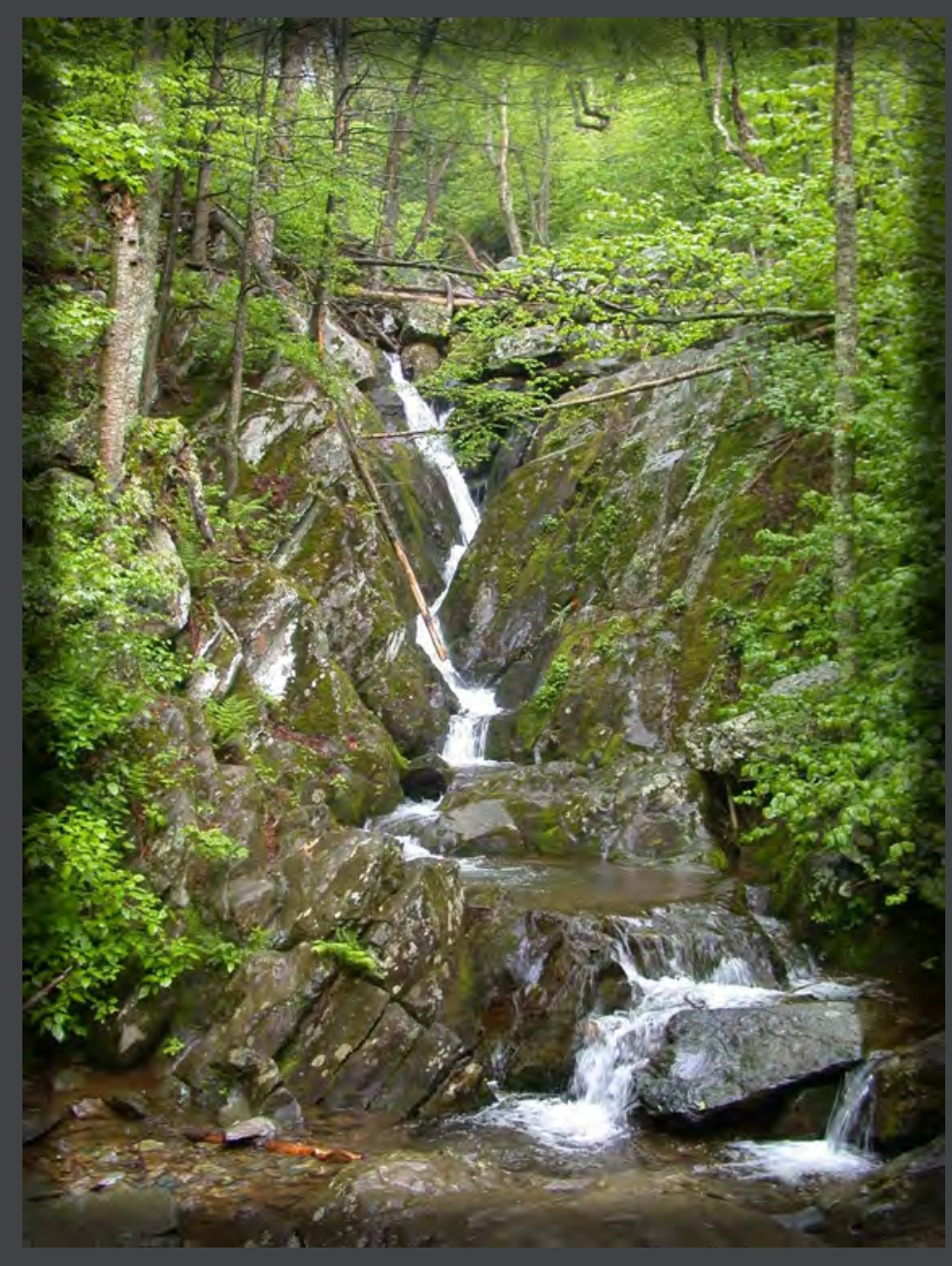

Scientific Investigations Report 2013-5157

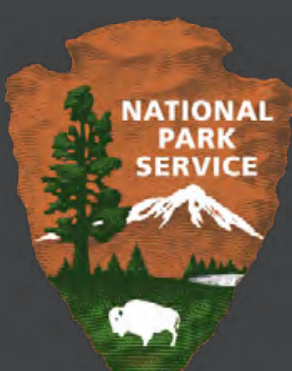

U.S. Department of the Interior

U.S. Geological Survey 
Cover. Falls on Hogcamp Branch, Shenandoah National Park. 


\section{Synthesis and Interpretation of Surface-Water Quality and Aquatic Biota Data Collected in Shenandoah National Park, Virginia, 1979-2009}

By John D. Jastram, Craig D. Snyder, Nathaniel P. Hitt, and Karen C. Rice

Prepared in cooperation with the National Park Service

Scientific Investigations Report 2013-5157 


\title{
U.S. Department of the Interior SALLY JEWELL, Secretary
}

\section{U.S. Geological Survey Suzette M. Kimball, Acting Director}

\author{
U.S. Geological Survey, Reston, Virginia: 2013
}

For more information on the USGS - the Federal source for science about the Earth, its natural and living resources, natural hazards, and the environment, visit http://www.usgs.gov or call 1-888-ASK-USGS.

For an overview of USGS information products, including maps, imagery, and publications, visit http://www.usgs.gov/pubprod

To order this and other USGS information products, visit http://store.usgs.gov

Any use of trade, product, or firm names is for descriptive purposes only and does not imply endorsement by the U.S. Government.

Although this report is in the public domain, permission must be secured from the individual copyright owners to reproduce any copyrighted materials contained within this report.

Suggested citation:

Jastram, J.D., Snyder, C.D., Hitt, N.P., and Rice, K.C., 2013, Synthesis and interpretation of surface-water quality and aquatic biota data collected in Shenandoah National Park, Virginia, 1979-2009: U.S. Geological Survey Scientific Investigations Report 2013-5157, 77 p., http://pubs.usgs.gov/sir/2013/5157/. 


\section{Acknowledgments}

Jeb Wofford, National Park Service, provided detailed information on history, methods, and objectives of the aquatic macroinvertebrate and fish monitoring efforts in Shenandoah National Park, and his extensive feedback on the analyses presented resulted in numerous improvements to the report. Alan Williams, National Park Service, provided monitoring data and spatial data collected by the park, and was extremely helpful in providing background information on how data were historically collected and stored by park staff.

The compilation of the comprehensive NPSTORET database and the spatial data was performed by USGS employee Tom Burley, whose efforts to restructure the datasets in order to incorporate unprecedented data volumes into NPSTORET were vital to the success of the data compilation component of this study.

Four thorough reviews were provided by James Webber, Melissa Riskin, Ellen Porter, and Tamara Blett, whose comments greatly improved the clarity and continuity of the report. 



\section{Contents}

Acknowledgments ..................................................................................................................ii

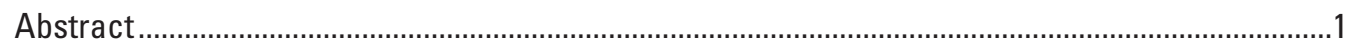

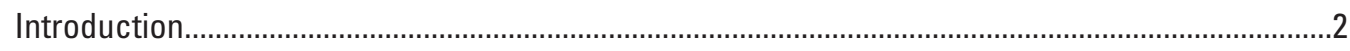

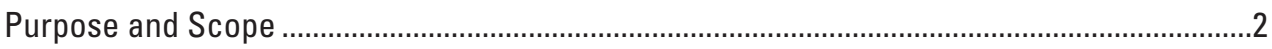

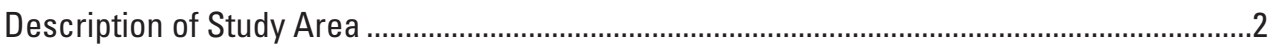

Aquatic-Resource Concerns ...........................................................................................

Aquatic Monitoring Datasets.......................................................................................

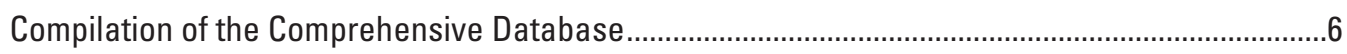

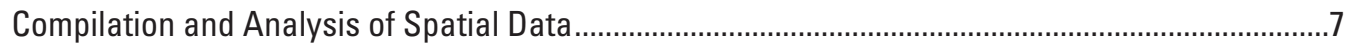

General Approach of Analysis of Spatial Patterns and Temporal Trends in Water Quality, Aquatic Macroinvertebrates, and Fish ..........................................................

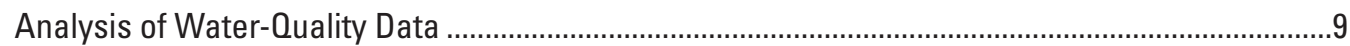

Water-Quality Data Structure and Analysis .............................................................................

Accounting for Streamflow in Water-Quality Trend Assessments .........................................11

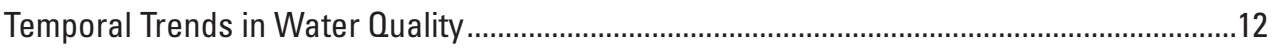

Determination of Appropriate Trend-Model Formulations...............................................14

Temporal Trends in Water-Quality Constituents ...............................................................15

Practical Significance of Trend Analyses............................................................18

Temporal Trends in Water Temperature ........................................................................19

Comparison of Water-Temperature Trends and Air-Temperature Trends.......................23

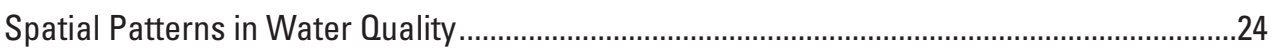

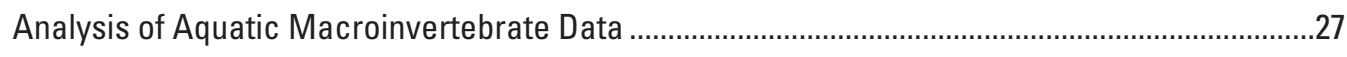

Aquatic Macroinvertebrate Data Structure and Analysis .......................................................27

Aquatic Macroinvertebrate Community Characteristics ....................................................29

Spatial Patterns in Aquatic Macroinvertebrates .................................................................

Temporal Trends in Aquatic Macroinvertebrates ..............................................................39

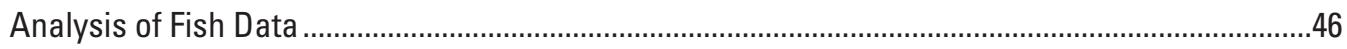

Fish Data Structure and Analysis......................................................................................

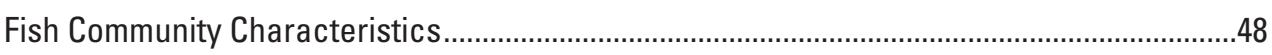

Temporal Trends and Spatial Patterns in Fish Communities ................................................49

Temporal Trends and Spatial Patterns in Brook Trout Population............................................54

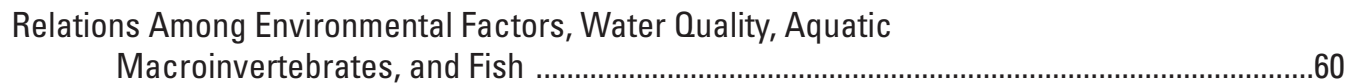

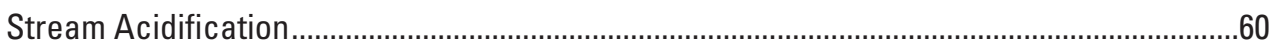

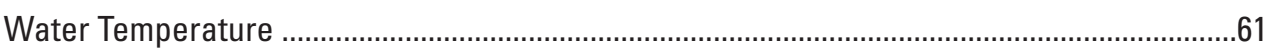

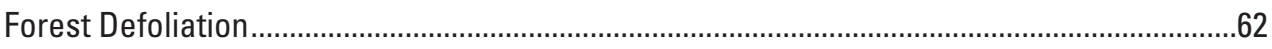

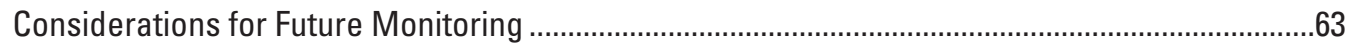

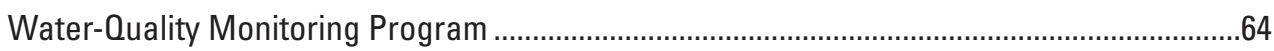

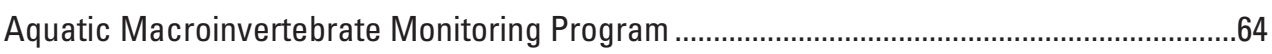

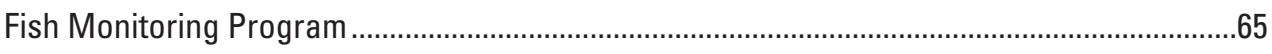

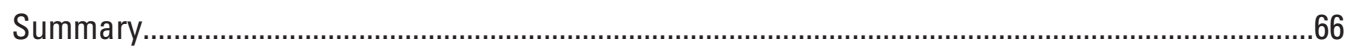

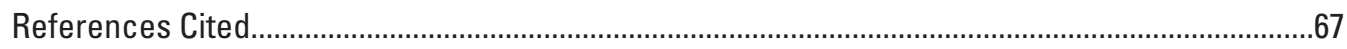

Appendix 1. Macroinvertebrate taxa collected at 24 Long Term Ecological Monitoring

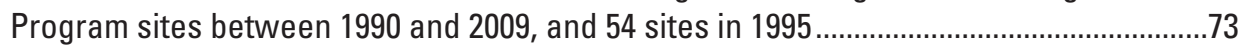




\section{Figures}

1-3. Maps showing-

1. Location of Shenandoah National Park in Virginia ...................................................

2. Water-quality monitoring stations used for Shenandoah Watershed Study, Shenandoah National Park Aquatic Monitoring Program, and the Springs and Headwater Streams Study, with underlying geology

3. Monitoring stations used for temporal trend analysis of water-quality constituents.

4-11. Graphs showing-

4. Cumulative distribution frequency of daily mean streamflow from five streamgages used in Shenandoah Watershed Study in Shenandoah National Park

5. Relations between concentration trend slope and flow-adjusted trend slope for acid neutralizing capacity, $\mathrm{pH}$, and sulfate ..

6. Trend-slope $p$-values for 4-season sampling definition against $p$-values for 12-season sampling definition.

7. Acid neutralizing capacity trend slopes and significance by geologic category and analysis period

8. $\mathrm{pH}$ trend slopes and significance by geologic category and analysis period ..........17

9. Sulfate trend slopes and significance by geologic category and analysis period..

10. Trend slopes and significance of annual water-temperature characteristics by analysis period .

11. Time series of mean, minimum, and maximum annual water temperature for 14 sites, with period of defoliation indicated by vertical dotted lines.

12. Map showing U.S. Geological Survey streamgages used in water-temperature trend analysis.

13. Graphs showing annual water-temperature trend slopes and significance for nine U.S. Geological Survey streamgages.

14. Graphs showing annual air-temperature characteristics at the Big Meadows and Luray meteorological stations, and annual mean water temperature at the Shenandoah River at Lynnwood, Virginia, streamgage, with trend lines

15. Maps showing spatial patterns in $\mathrm{pH}$, acid neutralizing capacity, sulfate, and specific conductance, and underlying geology, in Shenandoah National Park

16. Scatterplot of principal component axes against water-quality variables, with significant correlations highlighted.

17. Map showing macroinvertebrate sampling sites in Shenandoah National Park ............28

18-27. Graphs showing-

18. Watershed area of macroinvertebrate sampling sites used for temporal and spatial analyses, by geologic class.

19. Taxonomic and trophic composition of aquatic macroinvertebrates by sample year computed from samples collected from 24 sites 
20. Aquatic macroinvertebrate metric values by geologic class for 12 metrics significantly influenced by geology....

21. Percent abundance of Leuctra relative to the overall community, the Ephemeroptera, Plecoptera, and Trichoptera assemblage, the intolerant taxa assemblage, and the shredder assemblage by watershed type

22. Relations between aquatic macroinvertebrate metrics and watershed area for the six metrics significantly influenced by watershed area

23. Shredder\% computed with Leuctra, and without Leuctra, against watershed area, by geologic class.

24. Trend slopes for the seven aquatic macroinvertebrate metrics with trends independent of geology and watershed area (park-wide) by time period

25. Trend slopes by geologic class for the seven metrics with long-term trend slopes indicating significant geologic effects

26. Trend slope as a function watershed area for selected aquatic macroinvertebrate metrics.

27. The number of years required to detect a statistically significant change in metric means for metrics that showed significant trends park-wide, and metrics with trends dependent on geology.

28. Map showing all fish sampling site locations, and those selected for brook trout analyses and community analyses, within Shenandoah National Park

29-38. Graphs showing-

29. The temporal variation in average abundance of species within Shenandoah National Park community focal sites

30. The temporal variation in fish species richness for community focal sites by National Park Service site code

31. Distributions of mean fish richness by geologic class and against watershed area for three time periods analyzed

32. Fish richness trend slope as functions of geologic class and watershed area for the three time periods analyzed

33. Distributions of brook trout young-of-year mean abundance by geologic class and against watershed area for three time periods analyzed

34. Brook trout young-of-year abundance trend slopes by geologic class and against watershed area for three time periods analyzed.

35. Distributions of brook trout adult mean abundance by geologic class and against watershed area for three time periods analyzed.

36. Brook trout adult abundance trend slopes by geologic class and against watershed area for three time periods analyzed

37. Per capita rate of increase for adult brook trout at 32 focal sites

38. Z-scores of mean annual temperature and abundance of the genus Leuctra for sites with records spanning the entire monitoring period, grouped by Shenandoah National Park district 


\section{Tables}

1. Spatial attributes determined for monitoring stations and associated watersheds and the sources of those data.

2. Results of principal component analysis on environmental factors for monitored watersheds.

3. Shenandoah Watershed Study monitoring stations, periods of record, years of record, and number of water-quality results contained in the dataset used for trend analysis

4. Watershed area, geology, and period of record for five streamgages in Shenandoah National Park used to determine streamflow statistics

5. Correlation coefficients for non-exceedance probabilities from the five Shenandoah Watershed Study (SWAS) streamgages and the mean non-exceedance probability computed from those five streamgages

6. Statistics for regression models using various flow statistics to estimate acid-neutralizing capacity, by site...

7. Watershed area, mean watershed elevation, and period of record for U.S. Geological Survey streamgages used for water-temperature trend analysis.........20

8. Years in which samples were collected for 24 Long Term Ecological Monitoring sites used in temporal trend analysis

9. Site information, watershed area, predominant geology, and site elevation for sites used in analysis of temporal trends and spatial patterns in aquatic macroinvertebrates

10. Description of the 14 macroinvertebrate community metrics evaluated

11. Factor loadings from principal components analysis of aquatic macroinvertebrate metrics for data used in the spatial and temporal analyses of aquatic macroinvertebrate communities.

12. Partial coefficients of determination for variables found to be statistically significant predictors for each metric, and overall model $R^{2}$, from interactive stepwise general linear modeling used to assess the effects of geology and watershed area on spatial variation in macroinvertebrate metrics

13. Description of temporal trends of 14 aquatic macroinvertebrate metrics......................40

14. Number of fish community sampling events per month from 1996 to 2009

15. Fish species and abundances reported from 1996 to 2009 from 3-pass backpack electrofishing surveys at 107 sites

16. Stepwise general linear model results for effects of geology and watershed area on stream fish community richness, brook trout young-of-year abundance, and brook trout adult abundance among time periods of 5, 10, and 14 years. 


\section{Conversion Factors}

\begin{tabular}{lcl}
\hline \multicolumn{1}{c}{ Multiply } & By & \multicolumn{1}{c}{ To obtain } \\
\hline centimeter $(\mathrm{cm})$ & Length & \\
micrometer $(\mu \mathrm{m})$ & 0.3937 & inch (in.) \\
meter $(\mathrm{m})$ & 0.003937 & inch (in.) \\
kilometer $(\mathrm{km})$ & 3.281 & foot $(\mathrm{ft})$ \\
kilometer $(\mathrm{km})$ & 0.6214 & mile (mi) \\
meter $(\mathrm{m})$ & 0.5400 & mile, nautical $(\mathrm{nmi})$ \\
& 1.094 & yard $(\mathrm{yd})$ \\
\hline hectare $($ ha) & Area & \\
square kilometer $\left(\mathrm{km}^{2}\right)$ & 2.471 & acre \\
hectare $($ ha) & 247.1 & acre \\
square kilometer $\left(\mathrm{km}^{2}\right)$ & 0.003861 & square mile $\left(\mathrm{mi}^{2}\right)$ \\
& 0.3861 & square mile $\left(\mathrm{mi}^{2}\right)$ \\
\hline cubic meter per second $\left(\mathrm{m}^{3} / \mathrm{s}\right)$ & 35.31 & \\
\hline
\end{tabular}

Temperature in degrees Celsius $\left({ }^{\circ} \mathrm{C}\right)$ may be converted to degrees Fahrenheit $\left({ }^{\circ} \mathrm{F}\right)$ as follows:

${ }^{\circ} \mathrm{F}=\left(1.8 x^{\circ} \mathrm{C}\right)+32$

Horizontal coordinate information is referenced to the North American Datum of 1983 (NAD 83).

Specific conductance is given in microsiemens per centimeter at 25 degrees Celsius ( $\mu \mathrm{S} / \mathrm{cm}$ at $25^{\circ} \mathrm{C}$ ).

Concentrations of chemical constituents in water are given in microequivalents per liter ( $\mu \mathrm{eq} / \mathrm{L}$ ). 


\section{Abbreviations}

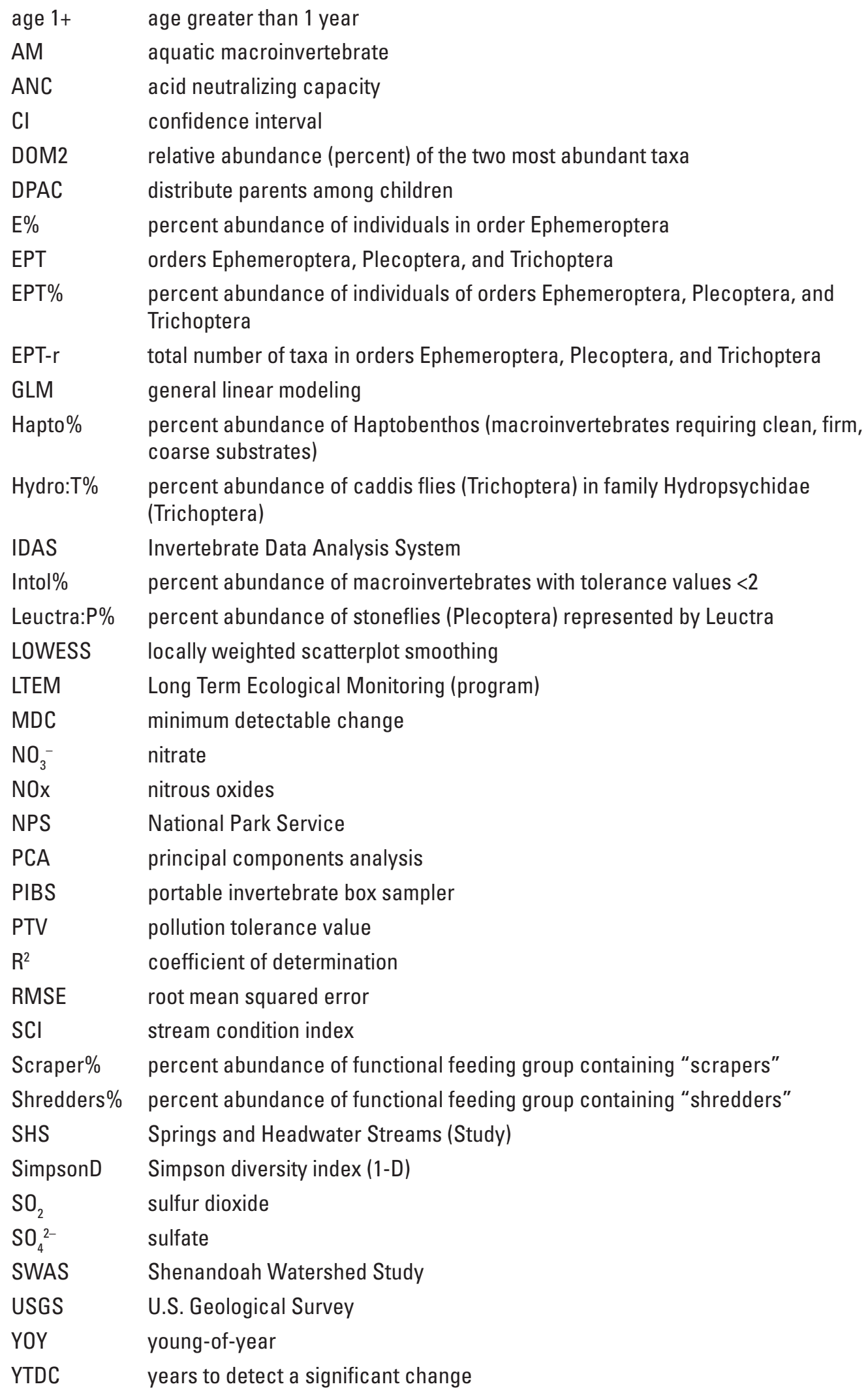




\title{
Synthesis and Interpretation of Surface-Water Quality and Aquatic Biota Data Collected in Shenandoah National Park, Virginia, 1979-2009
}

\author{
By John D. Jastram, Craig D. Snyder, Nathaniel P. Hitt, and Karen C. Rice
}

\section{Abstract}

Shenandoah National Park in northern and central Virginia protects 777 square kilometers of mountain terrain in the Blue Ridge physiographic province and more than 90 streams containing diverse aquatic biota. Park managers and visitors are interested in the water quality of park streams and its ability to support healthy coldwater communities and species, such as the native brook trout (Salvelinus fontinalis), that are at risk in the eastern United States. Despite protection from local stressors, however, the water quality of streams in the park is at risk from many regional stressors, including atmospheric pollution, decline in the health of the surrounding forests because of invasive forest pests, and global climate change. In 2010, the U.S. Geological Survey, in cooperation with the National Park Service, undertook a study to compile, analyze, and synthesize available data on water quality, aquatic macroinvertebrates, and fish within Shenandoah National Park. Specifically, the effort focused on creating a comprehensive water-resources database for the park that can be used to evaluate temporal trends and spatial patterns in the available data, and characterizing those data to better understand interrelations among water quality, aquatic macroinvertebrates, fish, and the landscape.

Data from three primary sources, namely the Shenandoah Watershed Study, the Shenandoah National Park Aquatic Macroinvertebrate Monitoring Program, and the Springs and Headwater Streams Study, were compiled and loaded into the National Park Service's NPSTORET database. This effort yielded a comprehensive database containing nearly 1.3 million measurements of habitat characteristics, approximately 442,000 measurements of water-quality characteristics, and over 438,000 measurements of biological taxa (fish and aquatic macroinvertebrates), collected across 673 sites over a period of more than 30 years.

Temporal trends in water quality indicate conflicting patterns in terms of acidity. Long-term (20- and 30-year) trends in acid-neutralizing capacity (ANC) and $\mathrm{pH}$ may indicate some improvement (decreasing acidity), but short-term (5-year) trends suggest increasing acidity. The long-term increase in $\mathrm{pH}$ occurred park-wide, although the increases were minimal in watersheds having siliciclastic bedrock. The long-term increases in ANC were mostly limited to watersheds with basaltic bedrock. Trends in concentrations of stream-water sulfate, another constituent of atmospheric deposition, indicated long-term improvements (declines in concentration) in watersheds having basaltic bedrock, long-term increases in concentration in watersheds having granitic bedrock, but no trend in watersheds with siliciclastic bedrock. Park-wide increases in mean, median, and maximum water temperatures were detected over the last 20 years. The average annual increase in mean water temperature park-wide was $0.04{ }^{\circ} \mathrm{C}$, which equates to about $1.2{ }^{\circ} \mathrm{C}$ over the last 30 years. Short-term trends generally coincided with long-term trends but were more variable. Water temperatures generally tracked air temperatures, and additional analyses of longer-term (greater than 80 years) regional air-temperature data showed that the most recent increases in air temperature are not unprecedented.

Analysis of spatial patterns in water quality demonstrated that watersheds with higher mean elevations, lower land-surface gradients, and greater proportions of basaltic and carbonate geology are least affected by acidification and tend to be improving over time. Watersheds having greater proportions of siliciclastic and granitic geology, with smaller watershed areas and higher minimum watershed elevation tend to be affected by acidification and are experiencing continued degradation in water quality. There was no apparent spatial pattern in the water-temperature trends.

Benthic macroinvertebrate community metrics were found to be highly correlated with geology and, to a lesser extent, watershed area. Temporal trends in benthic macroinvertebrates showed evidence of change in community structure over time, which in most cases indicated declines in stream condition. Although the overall condition of park streams would be considered by most measures to be relatively healthy, streams in siliciclastic watersheds, in particular, have been and continue to be affected by acidic deposition. In addition, park streams have warmed significantly over the last 20 years and evidence indicates that benthic macroinvertebrate communities have responded to the warming trend.

Analysis of temporal trends in fish-community metrics revealed increasing species richness from 1996 to 2010, with the greatest increases observed in the larger streams. 
Furthermore, increases in fish richness were detected only in watersheds underlain by granitic and basaltic geology; no trend in richness was detected in siliciclastic watersheds, which also had the lowest richness values. The low richness values and lack of improvement over time in siliciclastic watersheds further suggests that recovery from acidification is not yet occurring in these areas. Increases in richness may partially be due to increased water temperatures.

Analysis of brook-trout population data indicated a response to acidification in siliciclastic watersheds, as mean abundances of young-of-year (YOY) and adult (age greater than 1 year; age 1+) fish were consistently lower in these watersheds than in others. Long-term (15-year) increases were detected, however, in adult abundances in the siliciclastic watersheds, although YOY abundances showed a declining trend during this same period. Despite observed demographic and environmental variation, brook trout population growth rates were stable throughout the study area between 1996 and 2009.

Although the current monitoring design in the park is spatially and temporally robust, specifically in terms of the ability to detect changes in water quality and aquatic fauna, and to understand processes related to stream acidification, multiple potential improvements to the monitoring programs were identified. Potential changes that would allow for more efficient accomplishment of monitoring objectives or more complete representation of water-resources and aquatic fauna conditions include reducing the frequency of water-quality trend monitoring to quarterly sampling, operating additional streamgages within the park, and co-locating monitoring stations used for water-quality, aquatic macroinvertebrate, and fish monitoring programs. Although these changes would potentially reduce monitoring costs or improve the datasets, the current dataset was found to be sufficient to satisfy multiple objectives, including objectives or data analysis for which the monitoring program was not originally designed, such as water-temperature trend analysis.

\section{Introduction}

Shenandoah National Park is located within the Blue Ridge physiographic province in northern and central Virginia and protects 777 square kilometers $\left(\mathrm{km}^{2}\right)$ of mountain terrain in the Blue Ridge physiographic province. The mountain-top location of the park affords protection of more than 90 streams containing diverse aquatic biota. Park managers and visitors are interested in the water quality of streams in the park, in particular, its ability to support healthy populations of native brook trout that are at risk in the eastern United States. Despite protection from local stressors, however, the water quality of streams in the park is at risk from various stressors, including atmospheric pollution, declines in the health of the surrounding forests because of invasive forest pests, and global climate change.
In 2010, the U.S. Geological Survey (USGS), in cooperation with the National Park Service (NPS), initiated a study to examine three separate databases that contain data collected within Shenandoah National Park, which contain water-quality data, aquatic macroinvertebrate (AM) data, and fish data. The purpose of this study was to analyze the three existing databases, synthesize the databases, and interpret the data in the context of the effect of water quality on the distribution of biota in park streams. More specifically, the objectives of this study were to:

1. Determine whether relations exist among aquatic faunal distribution and abundance and water quality in park streams and assess the relation of those data to ecosystem data;

2. Determine whether the monitoring programs are adequate to characterize the status and trends in water quality of streams and aquatic biota across the spectrum of acid sensitivity within the park; and

3. Analyze and improve the park's water-resources monitoring database.

\section{Purpose and Scope}

The purpose of this report is to describe aquatic resource data that have been collected in Shenandoah National Park over the last three decades, and to describe a recent effort to compile and analyze those data. The data, which include measures of water quality, aquatic macroinvertebrates, and fish, were collected by multiple entities to satisfy varied objectives, and the analyses reported herein are the result of the first time these disparate datasets have been analyzed collectively. This report provides an understanding of how water quality, aquatic macroinvertebrates, and fish have changed over the period of the study and how they vary spatially within the park. Additionally, this report presents analyses of the interrelations among the temporal and spatial patterns observed in water quality, aquatic macroinvertebrates, and fish.

\section{Description of Study Area}

Shenandoah National Park is a narrow strip of NPS land 169 kilometers $(\mathrm{km})$ in length, located in northern Virginia (Va.) (fig. 1). Of the $777 \mathrm{~km}^{2}$ protected within the park boundary, about 40 percent $\left(311 \mathrm{~km}^{2}\right)$ is designated as wilderness. The park is mostly forested, containing a mix of deciduous and coniferous trees. The climate is humid temperate, with mean annual air temperatures ranging from 9 degrees Celsius $\left({ }^{\circ} \mathrm{C}\right)$ at higher elevations to $12{ }^{\circ} \mathrm{C}$ at lower elevations, with a mean annual rainfall of 100 to 150 centimeters $(\mathrm{cm})$ per year (National Park Service, 2012).

Water resources in the park include over $1,000 \mathrm{~km}$ of stream channels contained within about 90 perennial streams (National Park Service, 1998) that ultimately drain into Chesapeake Bay through three rivers: the Rappahannock River, the 


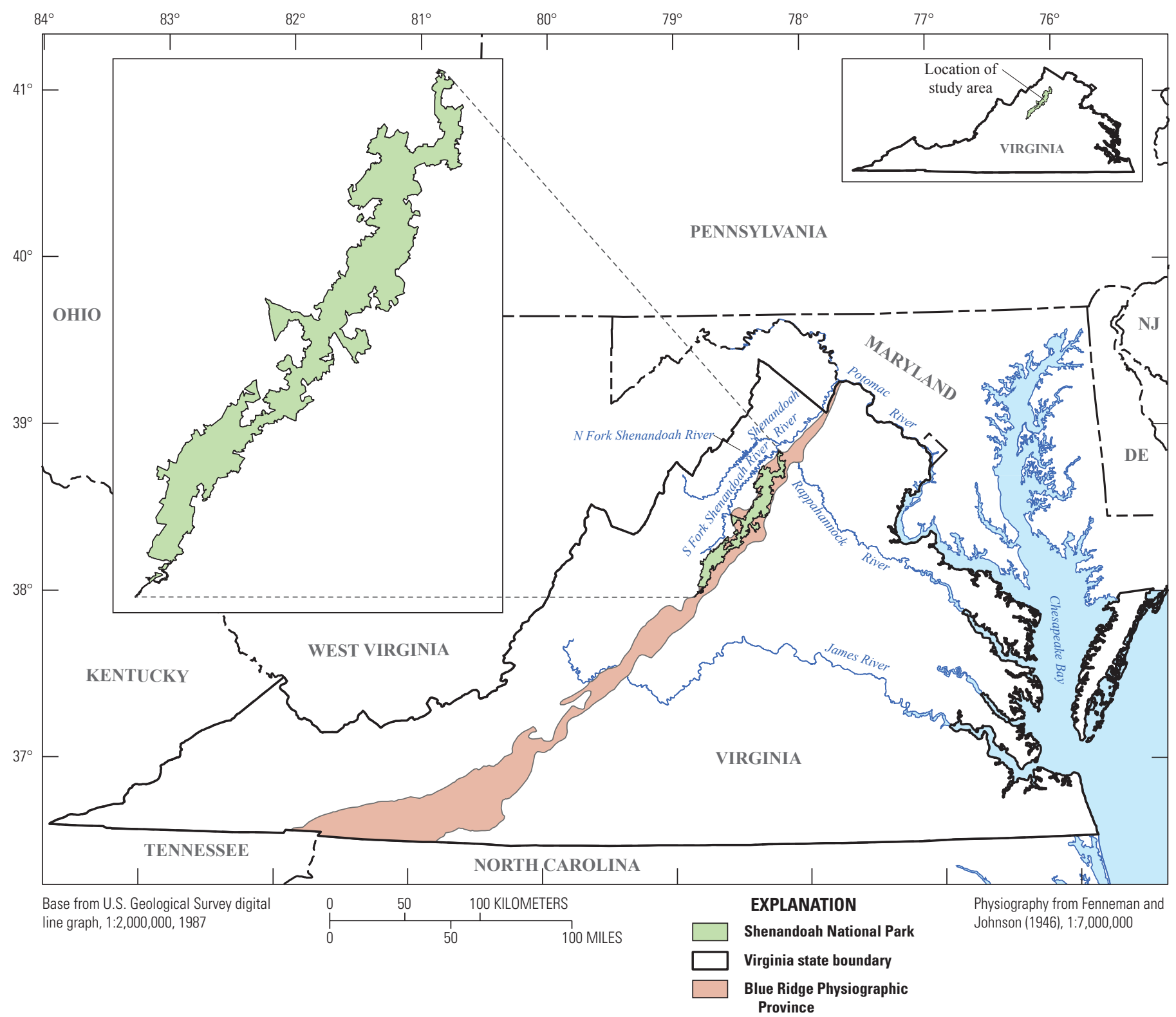

Figure 1. Location of Shenandoah National Park in Virginia.

Potomac River, and the James River. These aquatic habitats, along with their associated riparian areas, constitute unique and important resources in the park, providing irreplaceable habitat for many aquatic and terrestrial species.

Eleven geologic formations have been identified in the park (Virginia Division of Mineral Resources, 2003; Southworth and others, 2009). For the purpose of this study, the 11 formations were grouped into three classes - siliciclastic, granitic, and basaltic — based on their ability to neutralize acidic inputs. Each of the three classes represent approximately one-third of the area within the park. The siliciclastic class is found mainly in the westernmost parts of the park, the basaltic class crops out in the central region of the park, and the granitic class is present along the eastern margins of the park (fig. 2).
The bedrock control on stream-water quality has long been recognized in the Blue Ridge physiographic province (Bricker and Rice, 1989) and within the Shenandoah National park in particular (Cosby and others, 2006; Deviney and others, 2006; Rice and others, 2007). In general, watersheds developed on siliciclastic bedrock have streams with very low ionic-strength waters and little acid-neutralizing capacity (ANC). Watersheds developed on basaltic bedrock have streams with the highest ionic-strength and ANC values in the park, and watersheds developed on granitic bedrock have streams with ionic-strength and ANC values intermediate between those developed on siliciclastic and basaltic bedrock. Thus, there is a gradient in sensitivity to inputs by acidic deposition across streams in the park that is strongly controlled by the type of bedrock that underlies the watershed. 


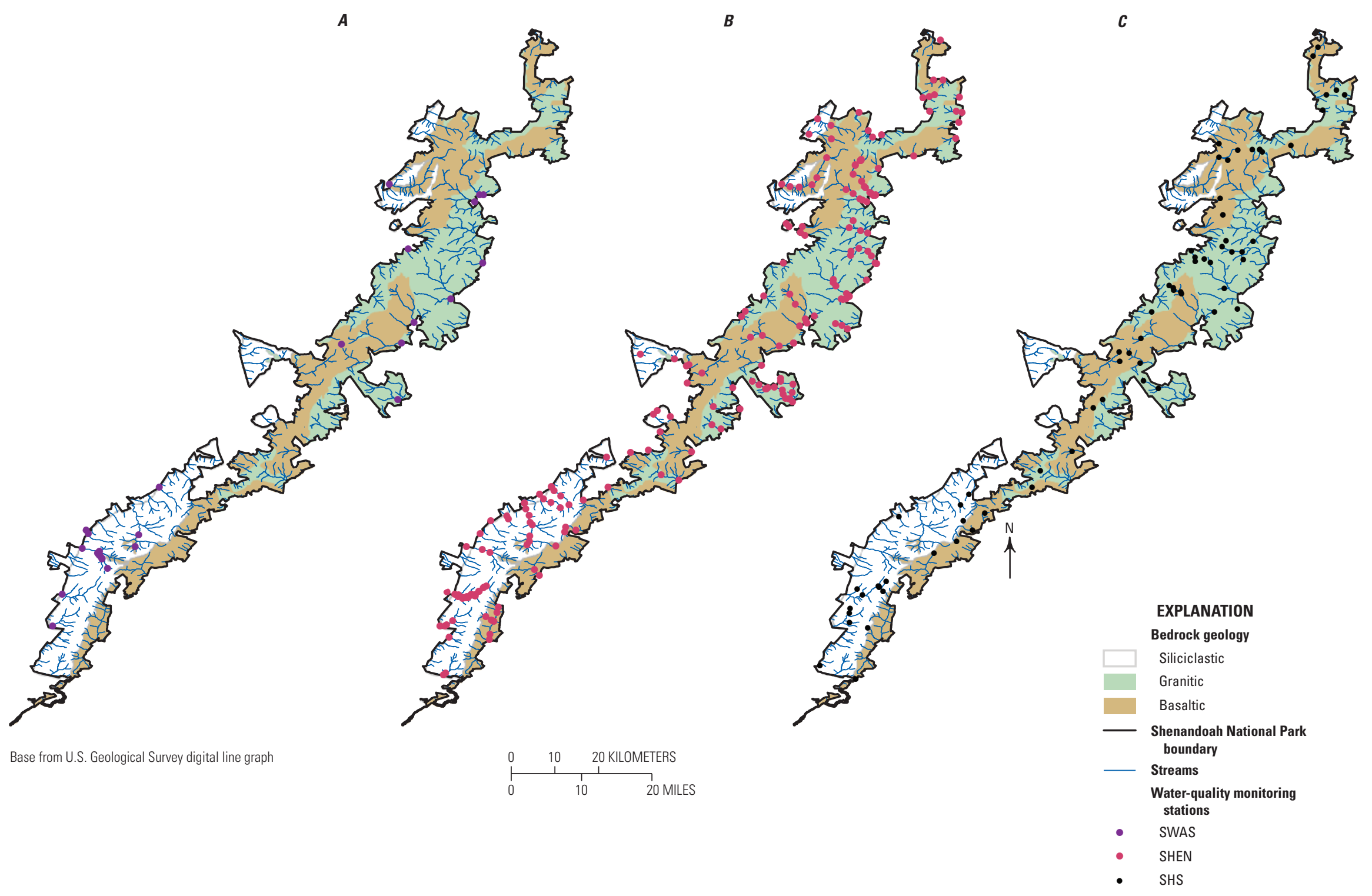

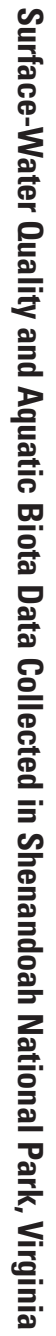

Figure 2. Water-quality monitoring stations used for $A$, Shenandoah Watershed Study (SWAS), $B$, Shenandoah National Park Aquatic Monitoring Program (SHEN), and $C$, the Springs and Headwater Streams Study (SHS), with underlying geology. Location of study area provided in figure 1. 


\section{Aquatic-Resource Concerns}

Pristine water quality is essential to the park's ecosystems, as well as to the hundreds of thousands of people in the surrounding lowlands who rely on water that originates in the park for their domestic water supply. The park's legislative history speaks of "beautiful cascading streams" and the critical importance of wildlife, recreation, and mountain scenery to the establishment of the park (U.S. Department of the Interior, 1932). The park's brook trout habitat is widely recognized as being among the best in the middle Appalachians, and streams in the park collectively provide habitat for at least 38 fish species (National Park Service, 2013) and approximately 240 macroinvertebrate species (National Park Service, 2008). As a result, water quality and the effects of degraded water quality on the park's aquatic ecosystems are some of the most significant resource-management issues at the park.

Currently, one of the largest resource-management problems that resource managers at the park face is air quality, specifically acidic deposition, and its effects on stream-water quality in the park. Acidic deposition and its effects on aquatic ecosystems have been major scientific and public policy issues for nearly 30 years, because of the potential for large-scale and long-term changes in water quality and the resulting loss of aquatic biota. Previous studies (Cosby and others, 1991, and references therein) have noted that streams in large areas of the southeastern United States are vulnerable to acidification, and the park has received some of the highest levels of acid deposition in the country. Acid deposition has declined since implementation of the Clean Air Act's Acid Rain Program in 1990; however, recovery of many acidified lakes and streams is not likely without further reductions in acid deposition (Burns and others, 2011). The Shenandoah National Park Resources Management Plan (National Park Service, 1998) contains 7 project statements on acidic deposition and its effects on the environment, and 13 additional project statements concerning other aspects of air-quality management (out of 168 total project statements), showing the importance of this issue to the park. Characterizing the link between air quality and water quality related to acidic deposition, contaminants, soil conditions, and forest health is a high priority for research in Shenandoah National Park.

In addition to acidic deposition, park managers are contending with other issues relevant to aquatic resources, including managing potential effects of climate change, preservation of native brook trout, introduction of exotic fish, and forest defoliation by insect pests. Climate change threatens to alter the temperature and precipitation regimes of the park, which in turn could disrupt the balance of the cool- and cold-water ecosystems in headwater streams of the park. Many of the aquatic organisms that inhabit these streams, including the native brook trout, require cool water temperatures to complete their life cycles; therefore, warming of park streams poses a risk to these unique communities. Warming stream temperatures also may increase the abundance of exotic organisms in park streams as water-temperatures increase to levels more acceptable to such organisms, creating an additional stress for native species. Changes in the precipitation regime as a result of climate change could also threaten these ecosystems as disturbances such as floods and droughts may occur more frequently, with greater duration and greater intensity.

Forest defoliation by the gypsy moth (Lymantria dispar) has been an important resource-management issue in the park over the last three decades. The most noticeable effects of defoliation occur in the terrestrial ecosystems, but there are potential cascading effects on water quality and aquatic biota, centered around changes in the aquatic food web. In-stream nutrient concentrations may increase, and the type of available food sources may change, as uptake of nutrients by trees is decreased and inputs to the stream from leaf fall are decreased. These changes, potentially exacerbated by increased light levels, could possibly shift the trophic composition of the AM community from organisms that consume leaf material deposited in the stream to those that consume algae growing on stream substrates.

\section{Aquatic Monitoring Datasets}

Multiple long-term and (or) spatially extensive aquatic data-collection efforts were identified as primary data sources for this study. Although this collection of datasets is not inclusive of all aquatic data collected in the park, it is believed to represent the most temporally and spatially extensive datasets containing data pertinent to the objectives of this study.

Recognizing the potential threat of acidic deposition, the NPS initiated the Shenandoah Watershed Study (SWAS) in 1979 in cooperation with researchers from the University of Virginia. The goal of SWAS has been to monitor and assess the acid-base chemistry in park streams in order to better understand the effects of acidic deposition on stream resources. SWAS data include stream discharge, water temperature, and several water-quality parameters relevant to acidic deposition (specific conductance, $\mathrm{pH}, \mathrm{ANC}$, and the concentrations of major cations and anions). Since the inception of SWAS, water-quality data have been collected at least quarterly at sites in 14 watersheds (fig. $2 A$ ), and multiple samples have been collected during individual storm events at sites in 3 watersheds. The SWAS data analyzed for this report include records from 20 of the 29 sites in the complete SWAS dataset, although the number of years sampled varies considerably among sites. This dataset contains nearly 195,000 individual water-quality results collected during nearly 11,000 sampling events, with over 150,000 of those results collected at 6 of the 20 sites.

In addition to SWAS data, the NPS has collected waterquality data as part of their biological monitoring efforts. These monitoring data were intended to provide context for the fisheries and AM data, and include measurements of water temperature, dissolved oxygen, specific conductance, $\mathrm{pH}$, and total dissolved solids. The dataset provided for this study includes over 9,000 water-quality results from 204 sites (fig. $2 B$ ), dating back to 1986, with the majority of the results coming from approximately one-third of the sites. 
Incorporation of biological endpoints into the aquatic monitoring program began in 1982 with the start of the Shenandoah National Park Fisheries Monitoring Program. The initial focus of the program was on monitoring the status of the brook trout fishery within the park, although the scope of the program was expanded in 1995 to include the occurrence and abundance of all fish species and associated fish community metrics (J.E.B. Wofford, National Park Service, written commun., 2011). In total, the fish data include over 370,000 records from over 1,600 sampling events across 211 sites.

The AM monitoring program for the park was initiated in 1984 when the park was designated as a prototype for the Long-Term Ecological Monitoring (LTEM) Program of the NPS. The objectives of the AM monitoring program are to use AM community and habitat metrics to characterize status and trends in stream condition. The AM dataset provided for this study contains approximately 65,000 results for 346 measures (taxa counts) from 737 sampling events across 114 sites.

The Springs and Headwater Streams (SHS) Study was conducted by staff from the USGS Leetown Science Center from 2007 through 2008. This study was initiated because of a lack of water-quality data collected from headwater streams and springs in the park. In addition, the Water Resources Scoping Report for the park (Vana-Miller and Weeks, 2004) suggested that the SWAS program, which was focused on sampling at low elevations in the watersheds, needed to consider expansion to sampling water quality higher in the watersheds. Therefore, the goal of this study was to characterize the physical, chemical, and biological characteristics in headwater streams and springs in the park in order to determine if current monitoring activities adequately characterize the range of aquatic habitat in the park. This goal was achieved through sampling water quality and AM communities at 23 headwater streams, 40 springs, and 9 LTEM stream sites (fig. 2C). Waterquality data collected for this effort include the same list of constituents as those collected for the SWAS program. This effort resulted in the collection of nearly 2,500 water-quality measurements and approximately 5,750 biological measures (taxa counts) from 140 sampling efforts across the sites.

\section{Compilation of the Comprehensive Database}

The comprehensive database, consisting of fish and AM monitoring data collected by Shenandoah National Park, water-quality data collected by SWAS, and AM and waterquality data collected by the SHS Study, was compiled in the NPSTORET framework of the NPS. This framework was selected for consistency with NPS protocols for data storage, and to facilitate data upload to the U.S. Environmental Protection Agency's STORET database. Water-quality data collected by as part of the SWAS program, as well as water data collected in the park for numerous other studies, already existed in an NPSTORET database. This existing NPSTORET database was used as the foundation to which the other datasets were added.

Water-quality data and site information from the SHS study were previously loaded in the NPSTORET database; therefore, only the AM data collected as part of that study remained to be loaded into the NPSTORET database. Counts of AM taxa per sampling event, as provided by the study authors, were reformatted into row-major format and loaded into NPSTORET.

Water-quality, AM, fish, and habitat data collected by the NPS are maintained by the NPS in a Microsoft Access database. Prior to loading the data into NPSTORET, these data required extensive reformatting to collapse the multiple column-major tables, originally linked by one-to-many relationships, into fewer row-major tables, while still maintaining the integrity of relationships used to link data to the appropriate sampling event and location. The resultant NPSTORET database contained nearly 1.3 million measurements of habitat characteristics, approximately 442,000 water-quality measurements, and over 438,000 measurements of biological taxa (AM and fish data) collected across 673 sites. This comprehensive database formed the foundation for the analyses presented in this report, and it is expected to become the primary database for archival and analysis of all historic and future aquatic monitoring data collected in the park.

Concentration units of water-quality constituents were standardized for storage in NPSTORET such that concentrations are stored in units of microequivalents per liter $(\mu \mathrm{eq} / \mathrm{L})$. Therefore, concentrations of chemical constituents are presented in $\mu \mathrm{eq} / \mathrm{L}$ throughout this report. 


\section{Compilation and Analysis of Spatial Data}

In addition to the water-quality and biological (AM and fish) data just described, a suite of other environmental variables were used as covariates in spatial and temporal trend analyses in order to determine the extent to which spatial patterns and temporal trends in water quality and biological measures depend on local habitat or landscape setting. The selected environmental variables included those known or expected to influence water quality and biota, such as geology, elevation, and watershed area, as well as variables for which data were readily available and that may be of interest in the current study or potential future studies (for example, forest vegetation composition, location of roads and trails, and stream order).
Environmental data were compiled from various sources including published datasets specific to the park, published datasets with Nation-wide coverage, and datasets maintained by park staff (table 1). Local site conditions were characterized for all sites, and a subset of the watersheds was also characterized to determine the landscape attributes associated with each site. The subset characterized consisted of those watersheds that had sites with sufficient monitoring data for trend analysis.

The datasets just described were manipulated using ArcGIS 9.3.1 to calculate and assign attributes to the sampling points or watershed areas draining sampling points. In addition, watershed boundaries were delineated and attributes derived for all unmonitored streams leaving the boundaries of the park to provide a basis for extrapolating analyses to unmonitored watersheds should that objective be part of any future work. The resulting collection of spatial data was compiled into an ArcGIS 9.3.1 geodatabase (table 1).

Table 1. Spatial attributes determined for monitoring stations and associated watersheds and the sources of those data.

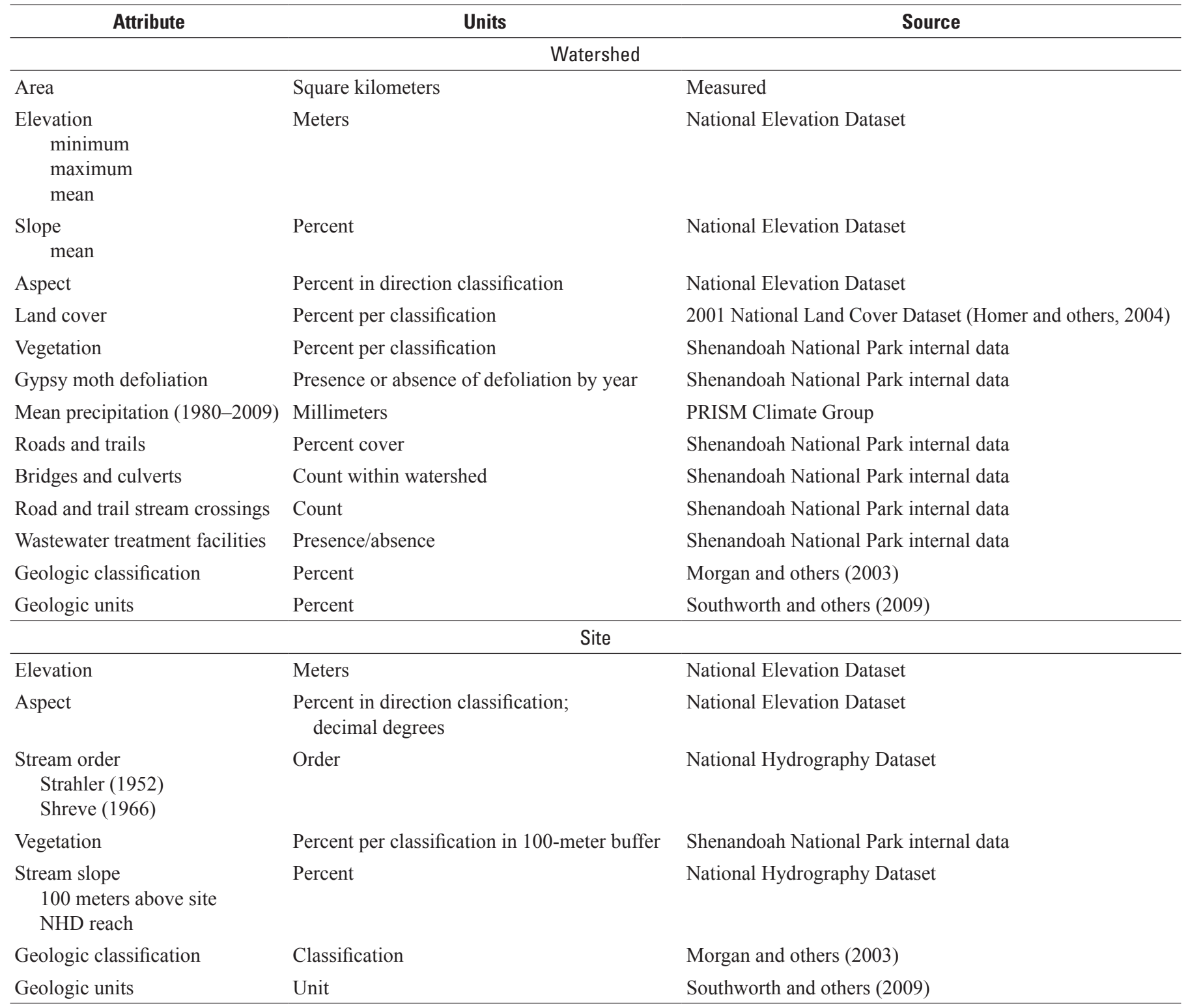




\section{General Approach of Analysis of Spatial Patterns and Temporal Trends in Water Quality, Aquatic Macroinvertebrates, and Fish}

The fish and AM monitoring data collected by park staff have not been previously analyzed for long-term trends. In addition, there has been no prior synthesis or analysis of these data in conjunction with the SWAS water-quality data or the SHS Study. The combination of these datasets facilitated an integrated assessment of status and trends in aquatic resources and provided a basis to generate hypotheses regarding the effects of regional anthropogenic stressors on stream condition.

A consistent analysis approach was used to evaluate spatial patterns and temporal trends in water quality, AM, and fish. Specific characteristics of the individual datasets (water quality, AM, and fish), however, required that different statistical techniques be applied to each dataset. The specific methods of analysis, therefore, are presented in the respective sections of this report to maintain clarity in how the analyses were performed.

There were several discrepancies among the three data types (water quality, AM, and fish) that prevented a fully integrated data analysis. Specifically, the location of sample sites varied among monitoring programs, as did the timing and frequency of sampling, preventing direct assessment of relations between different data types. Therefore, the general analytical approach taken was to assess spatial patterns and temporal trends for each data type individually and subsequently look for commonalities in short-term and long-term trends in order to derive hypotheses regarding causal explanations for observed patterns. In particular, temporal trends were assessed in the context of acidic deposition, forest defoliation caused by the gypsy moth, and climate change - the three stressors most likely to influence stream conditions in the park.

Numerous response variables were assessed for each data type. Water-quality response variables included mean, maximum, and minimum values for water temperature, and numerous water-quality constituents known to be important to drivers of water quality in the park, including $\mathrm{pH}, \mathrm{ANC}$, sulfate $\left(\mathrm{SO}_{4}{ }^{2-}\right)$, and nitrate $\left(\mathrm{NO}_{3}^{-}\right)$. Aquatic macroinvertebrate response variables included 15 metrics that describe the diversity and structure of AM communities and often are used to infer stream condition. Fish response variables included 3 measures of the abundance and demography of brook trout as well as 22 measures of the diversity and composition of the overall fish community.

Spatial patterns and temporal trends were assessed through a multiple regression modeling approach that related each individual response variable to a suite of potential predictor variables. For analysis of spatial patterns, it was not feasible to evaluate the relations among the large number of site and watershed characteristics and the suite of response measures. There were numerous correlations among the lists of environmental variables; therefore, principal components analysis (PCA; Shaw, 2003) was used to reduce the list of predictor variables to a smaller number of uncorrelated multivariate gradients. The PCA results showed that environmental factors can be reduced to 3 statistically significant $(p<0.10)$ dimensions that collectively describe nearly 62 percent of the variability in the environmental characteristics of these watersheds (table 2). The first PCA axis explains over 35 percent of the variation and is highly correlated with the proportion of siliciclastic geology in the watershed and mean watershed slope. The second PCA axis explains an additional 14 percent of the variation and is most strongly correlated with watershed area and minimum elevation. The third PCA axis explains an additional 12 percent of the variation and positively correlates with the proportion of granitic geology in the watershed and negatively correlates with the proportion of basaltic geology. The strong correlations between vegetation characteristics and individual principal components is understood to be a result of the correlation between those vegetation characteristics and other physical attributes (such as geology and elevation), and therefore the vegetation characteristics would be expected to have associative relations, as opposed to causative relations, with water quality, fish, and AM measures. Thus, geology and watershed area, and their interaction, were used as predictor variables in spatial analyses.

Temporal trend analyses focused on changes in response measures through time, using time (in years) as the primary predictor variable. Trend analyses were performed for four periods; namely, the most recent 20-year period (1990-2009), 14-year period (1996-2009), 10-year period (2000-2009), and 5-year period (2005-2009). These periods were selected to represent changes over time that have led to currently observed conditions. Selection of different time periods and (or) start/end dates could possibly yield different results. The analysis of fish data was limited to collections made after 1995 because of concerns about the comparability of sampling methods over time, hence the 14 -year period instead of a 15-year period consistent with the 5-year interval of the other analyses. Aquatic macroinvertebrate and fish data were collected at an annual time step; therefore, simple linear regression was used to evaluate changes in response measures over time. Monthly water-temperature data were summarized as annual statistics, and those annual statistics were analyzed similarly to AM and fish data. Water-quality data were collected more frequently and therefore were analyzed using the Seasonal Kendall Trend Test (Helsel and Hirsch, 2002). Multiple linear regression was subsequently used to evaluate the importance of watershed characteristics (geology, watershed area, and the interaction between geology and watershed area) on temporal changes in response variables (that is, regression slopes) for each time period. In general, the analytical approach just described was used to assess spatial and temporal trends in response to water-quality, AM, and fish variables. 
Table 2. Results of principal component analysis on environmental factors for monitored watersheds.

$[\%$, percent; <, less than; m, meter; NHD, National Hydrography Dataset]

\begin{tabular}{|c|c|c|c|}
\hline $\begin{array}{l}\text { Percentage of variance } \\
\text { explained and p-value }\end{array}$ & $\begin{array}{c}\text { Principal } \\
\text { component } 1\end{array}$ & $\begin{array}{c}\text { Principal } \\
\text { component } 2\end{array}$ & $\begin{array}{c}\text { Principal } \\
\text { component } 3\end{array}$ \\
\hline Individual & 35.544 & 14.178 & 12.08 \\
\hline Cumulative & 35.544 & 49.723 & 61.803 \\
\hline p-value & $<0.0001$ & $<0.0001$ & $<0.0001$ \\
\hline \multicolumn{4}{|c|}{ Correlation } \\
\hline Watershed area & 0.12 & -0.71 & 0.04 \\
\hline $\begin{array}{l}\text { Mean watershed } \\
\text { elevation }\end{array}$ & 0.85 & 0.39 & 0.18 \\
\hline $\begin{array}{l}\text { Maximum watershed } \\
\text { elevation }\end{array}$ & 0.79 & -0.20 & 0.35 \\
\hline $\begin{array}{l}\text { Minimum watershed } \\
\text { elevation }\end{array}$ & 0.41 & 0.77 & -0.02 \\
\hline Precipitation & 0.58 & -0.10 & 0.47 \\
\hline Mean watershed slope & -0.85 & -0.04 & 0.32 \\
\hline Siliciclastic & -0.87 & 0.38 & 0.03 \\
\hline Granitic & 0.41 & -0.27 & 0.69 \\
\hline Basaltic & 0.55 & -0.14 & -0.74 \\
\hline Carbonate & -0.25 & 0.10 & 0.03 \\
\hline Developed, open space & 0.69 & 0.25 & -0.18 \\
\hline Black locust & 0.43 & -0.23 & -0.68 \\
\hline Open space & 0.39 & 0.40 & -0.31 \\
\hline Chestnut oak & -0.91 & 0.20 & 0.11 \\
\hline Yellow poplar & 0.36 & -0.67 & 0.28 \\
\hline Cove hardwood & 0.44 & -0.39 & -0.42 \\
\hline Pine & -0.69 & 0.34 & -0.01 \\
\hline Red oak & 0.82 & 0.28 & 0.01 \\
\hline Hemlock & 0.66 & 0.37 & 0.33 \\
\hline Aspect & -0.26 & 0.09 & -0.34 \\
\hline Channel slope $100 \mathrm{~m}$ & 0.39 & 0.23 & 0.29 \\
\hline NHD reach slope & 0.44 & 0.52 & 0.02 \\
\hline
\end{tabular}

\section{Analysis of Water-Quality Data}

Water-quality data were compiled and analyzed to evaluate temporal trends and spatial patterns in water-quality constituents related to stream acidification. The temporal trend analysis was developed in a manner that provides an understanding of shortterm and long-term temporal trends. Spatial pattern analysis were developed to provide an understanding of potential relations between the typical values of water-quality constituents and the physical setting of the watershed represented by the monitoring station, as well as the relations between observed temporal trends and respective watershed characteristics.

\section{Water-Quality Data Structure and Analysis}

Water-quality sampling for the SWAS program was conducted by program personnel. Grab samples were collected and delivered to the SWAS laboratory at the University of Virginia for analysis of chemical constituents. Standard laboratory procedures, including the use of stand-alone meters, titrations, atomic absorption spectrophotometers, and ion chromatographs, were used as appropriate for the various analyses. Details of the method used for each analysis are maintained in the NPSTORET database. Sample collection and analysis for the SHS study were performed similarly to the SWAS program, although USGS staff were responsible for the collection of samples. Water-quality measurements made in association with the Shenandoah National Park AM and Fisheries Monitoring Programs did not include any sample collection. For these efforts, only field measurements of physical parameters (water temperature, $\mathrm{pH}$, specific conductance, and dissolved oxygen) were taken. These measurements were made using sensors placed in the stream at the time of data collection.

Of the water-quality data compiled in the comprehensive database, only the SWAS program data have been collected for a sufficient time period and at a sufficient temporal resolution to support trend analysis. The dataset used for temporal trend analysis of water quality, therefore, consisted of data from 15 sites (fig. 3) spanning a range of time periods, with the longest spanning over 30 years (table 3 ). 


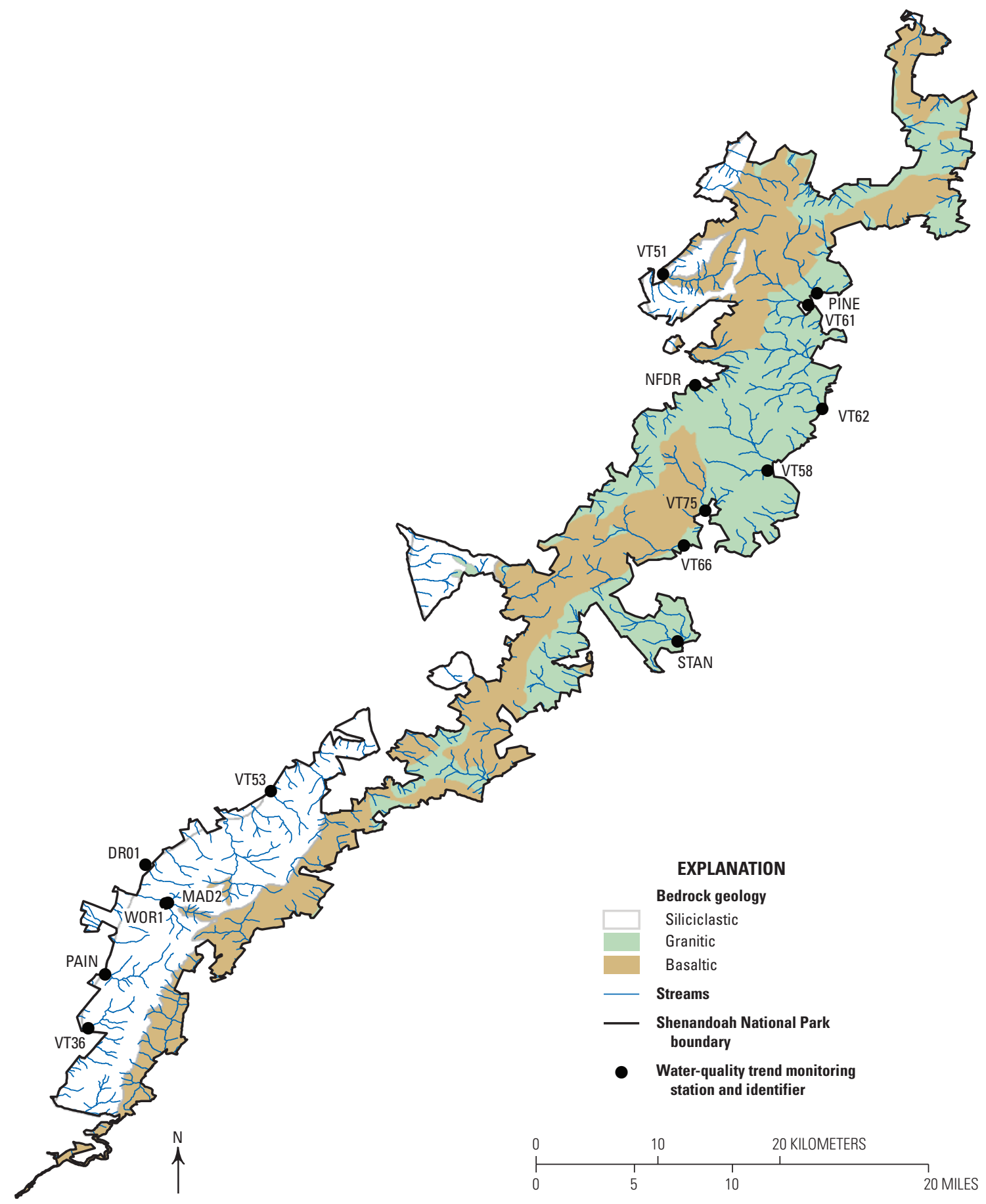

Figure 3. Monitoring stations used for temporal trend analysis of water-quality constituents. Location of study area provided in figure 1. 
Table 3. Shenandoah Watershed Study (SWAS) monitoring stations, periods of record, years of record, and number of waterquality results contained in the dataset used for trend analysis.

\begin{tabular}{|c|c|c|c|c|}
\hline $\begin{array}{c}\text { Site } \\
\text { identifier }\end{array}$ & Site name & $\begin{array}{l}\text { Period of } \\
\text { record }\end{array}$ & $\begin{array}{l}\text { Years of } \\
\text { record }\end{array}$ & $\begin{array}{c}\text { Number of } \\
\text { results }\end{array}$ \\
\hline DR01 & Deep Run & $\begin{array}{c}11 / 02 / 1979- \\
12 / 20 / 2010\end{array}$ & 31.2 & 25,842 \\
\hline MAD2 & $\begin{array}{l}\text { Madison Run } \\
\quad \text { (upper) }\end{array}$ & $\begin{array}{c}03 / 31 / 1981- \\
07 / 26 / 2010\end{array}$ & 29.3 & 10,835 \\
\hline NFDR & $\begin{array}{l}\text { North Fork Dry } \\
\text { Run }\end{array}$ & $\begin{array}{c}03 / 12 / 1987- \\
12 / 21 / 2010\end{array}$ & 23.8 & 23,107 \\
\hline PAIN & Paine Run & $\begin{array}{c}08 / 14 / 1987- \\
12 / 20 / 2010\end{array}$ & 23.4 & 30,265 \\
\hline PINE & Piney River & $\begin{array}{c}10 / 21 / 1995- \\
12 / 21 / 2010\end{array}$ & 15.2 & 26,172 \\
\hline STAN & Staunton River & $\begin{array}{c}09 / 04 / 1996- \\
12 / 21 / 2010\end{array}$ & 14.3 & 18,909 \\
\hline WOR1 & White Oak Run & $\begin{array}{c}11 / 02 / 1979- \\
12 / 20 / 2010\end{array}$ & 31.2 & 26,896 \\
\hline VT36 & Meadow Run & $\begin{array}{c}08 / 16 / 1987- \\
10 / 28 / 2010\end{array}$ & 23.2 & 2,041 \\
\hline VT51 & Jeremy's Run & $\begin{array}{c}04 / 25 / 1987- \\
10 / 28 / 2010\end{array}$ & 23.5 & 1,923 \\
\hline VT53 & Twomile Run & $\begin{array}{c}08 / 14 / 1987- \\
10 / 28 / 2010\end{array}$ & 23.2 & 2,085 \\
\hline VT58 & $\begin{array}{l}\text { Brokenback } \\
\text { Run }\end{array}$ & $\begin{array}{c}08 / 12 / 1987- \\
10 / 29 / 2010\end{array}$ & 23.2 & 2,005 \\
\hline VT61 & $\begin{array}{l}\text { N.F. Thornton } \\
\text { River }\end{array}$ & $\begin{array}{c}04 / 26 / 1987- \\
10 / 28 / 2010\end{array}$ & 23.5 & 1,923 \\
\hline VT62 & Hazel River & $\begin{array}{c}04 / 26 / 1987- \\
10 / 28 / 2010\end{array}$ & 23.5 & 1,934 \\
\hline VT66 & Rose River & $\begin{array}{c}04 / 25 / 1987- \\
10 / 29 / 2010\end{array}$ & 23.5 & 1,935 \\
\hline VT75 & $\begin{array}{l}\text { White Oak } \\
\text { Canyon Run }\end{array}$ & $\begin{array}{c}07 / 31 / 1990- \\
10 / 29 / 2010\end{array}$ & 20.3 & 1,728 \\
\hline
\end{tabular}

Spatial variability in water-quality conditions throughout the park was evaluated using graphical and statistical techniques. Graphical analyses consisted of deriving spatially interpolated maps from median constituent values for every monitoring station from every monitoring program with such data. These analyses provide reasonable information about general water-quality patterns throughout the park, because sites containing water-quality data are well distributed within the park. In general terms, the interpolated maps are intended to depict the spatial distribution of water-quality conditions, but additional fine-scale variability is probably not represented well by these generalizations because these simple interpolations are based on site proximity. Statistical analyses included analysis of correlations between water-quality trend slopes and median values and the principal component axes for watershed characteristics identified earlier herein at those sites where trend analyses were performed. These correlation analyses were performed using the SWAS program data that were used in the analysis of temporal trends.
Spatial patterns in water quality, or associations with spatially variable watershed characteristics, were evaluated statistically using correlation analysis (Kendall's tau) of the waterquality medians and trend slopes with the principal component axes that represent the physical characteristics of the monitored watersheds. Additionally, scatterplots were generated and bestfit lines were drawn to better characterize the relation between the principal components and water-quality variables.

\section{Accounting for Streamflow in Water-Quality Trend Assessments}

Variability in streamflow often is chiefly responsible for variability in measurements of water quality, as water contributions from various sources may be masked or enhanced depending on the flow regime. Changes in streamflow can result in the dilution or concentration of water-quality constituents, and removal of this variability can improve the power to detect trends (Schertz and others, 1991). Because of these dependencies on hydrologic conditions, it was necessary to characterize the hydrologic conditions that existed at the time of sample collection. Although some of the data-collection efforts within the park included measurements of streamflow or some general characterization of flows or water levels, the water-quality samples used for trend analysis did not. Therefore, it was necessary to develop a representative characterization of flow conditions for all sampling events across the park.

The SWAS program operates streamgages on five streams in the park to generate long-term continuous timeseries records of streamflow (table 4). These five streamgages represent a range of watershed sizes and geologic characteristics (table 4), and therefore, differing distributions of streamflow (fig. 4) believed to collectively represent hydrologic conditions throughout the park.

Daily mean streamflow data from the five SWAS streamgages were used to compute an approximation of hydrologic conditions across the park. The approximation was developed by first evaluating the distribution of measured daily mean streamflow values available for the period of record for each gaged site. From the cumulative distribution frequency (fig. 4) for each site, the non-exceedance probability was computed for each daily mean streamflow value. The mean of the collection of non-exceedance probabilities for each day in the study period was then computed and used as a representation of hydrologic conditions, as needed for the statistical analyses of water quality and aquatic biota that follow.

To confirm the approximation just described was representative of actual hydrologic conditions, overall mean non-exceedance values were compared to site-specific non-exceedance values and site-exclusive non-exceedance values (overall mean non-exceedance computed excluding the site of interest). Additionally, concentration-streamflow relations were compared with concentration-streamflow relations using the overall mean non-exceedance probabilities, the site-specific non-exceedance probabilities, and the siteexclusive non-exceedance probabilities instead of streamflow. 
Table 4. Watershed area, geology, and period of record for five streamgages in Shenandoah National Park used to determine streamflow statistics.

$\left[\mathrm{km}^{2}\right.$, square kilometer]

\begin{tabular}{llrlcc}
\hline $\begin{array}{c}\text { Station } \\
\text { identifier }\end{array}$ & \multicolumn{1}{c}{ Stream name } & $\begin{array}{c}\text { Watershed } \\
\text { area } \\
\left(\mathbf{k m}^{2}\right)\end{array}$ & $\begin{array}{c}\text { Predominant } \\
\text { geology }\end{array}$ & $\begin{array}{c}\text { Record begin } \\
\text { date }\end{array}$ & $\begin{array}{c}\text { Record } \\
\text { end date }\end{array}$ \\
\hline WOR1 & White Oak Run & 5.1 & Siliciclastic & $11 / 01 / 1979$ & $01 / 17 / 2011$ \\
NFDR & North Fork Dry Run & 2.3 & Granitic & $10 / 01 / 1987$ & $03 / 01 / 2011$ \\
STAN & Staunton River & 10.7 & Granitic & $09 / 02 / 1992$ & $02 / 14 / 2011$ \\
PINE & Piney River & 12.4 & Basaltic & $09 / 30 / 1992$ & $02 / 15 / 2011$ \\
PAIN & Paine Run & 12.7 & Siliciclastic & $10 / 01 / 1992$ & $02 / 07 / 2011$ \\
\hline
\end{tabular}

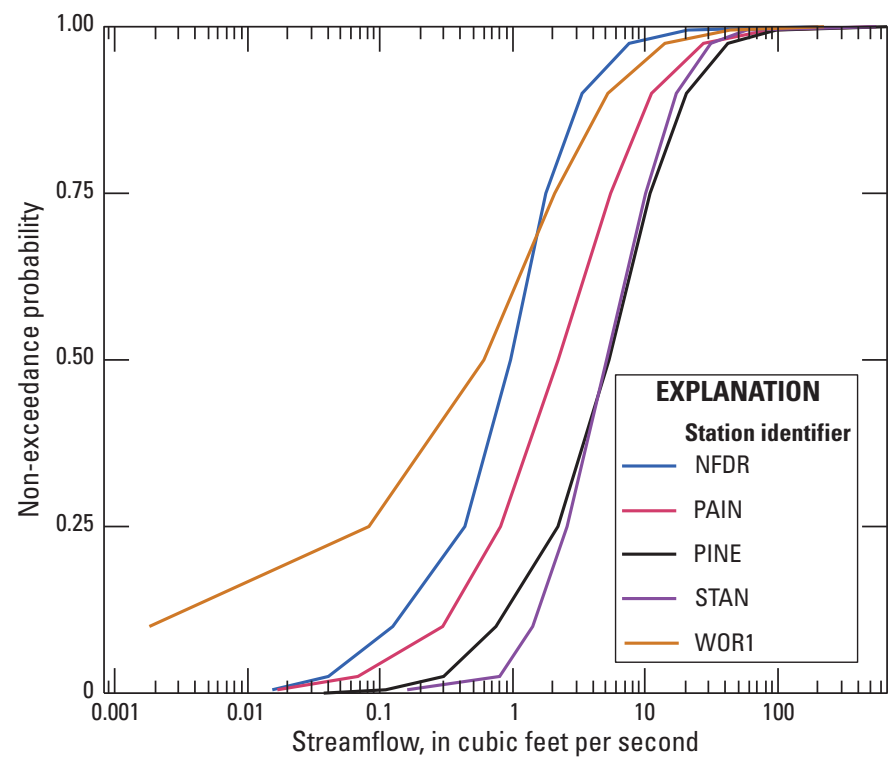

Figure 4. Cumulative distribution frequency of daily mean streamflow from five streamgages used in Shenandoah Watershed Study in Shenandoah National Park.

Correlations of streamflow non-exceedance probabilities between gaged sites indicated that, although the magnitude of flow varied among sites, the non-exceedance probabilities of the daily values were strongly correlated, indicating that the mean non-exceedance probabilities can be used as a representative approximation of hydrologic conditions throughout the park (table 5).

Relations between the computed flow statistics and ANC were evaluated using linear regression to evaluate the appropriateness of the statistic for flow normalization of water-quality data. Regressions of ANC and the overall mean non-exceedance probabilities, the site-specific non-exceedance probabilities, and the site-exclusive non-exceedance probabilities were evaluated to determine if the use of the mean nonexceedance probability effectively reproduced the site-specific concentration-streamflow relation. Consistency across the models in the amount of variability in ANC explained by the flow statistics, determined from the coefficient-of-determination $\left(\mathrm{R}^{2}\right)$ and the root mean squared error (RMSE), demonstrated that the mean probability describes variability in waterquality constituents at a level consistent with the site-specific relations (table 6). Furthermore, overlap of the 95-percent confidence intervals (CI) for the intercepts and slopes of the models for 4 of the 5 sites demonstrates that regression lines from each of the flow statistics are generally not significantly different (table 6).

\section{Temporal Trends in Water Quality}

Temporal trends in water quality were evaluated using the Seasonal-Kendall trend test (Hirsch and Slack, 1984) as programmed in S-ESTREND (Slack and others, 2003), a version of EStimateTREND (ESTREND; Schertz and others, 1991) written in the S programming language (Venables and Ripley, 2000). The Seasonal-Kendall test is a non-parametric test of monotonic trend based upon the Mann-Kendall test (Mann, 1945; Kendall, 1975) that accounts for seasonal variability by comparing data collected within the same season. The Seasonal-Kendall trend test was used because of its ability to efficiently handle multiple statistical challenges common to trend analysis of environmental data, including non-normality, seasonality (serial correlation), streamflow dependence, and the violation of statistical assumptions for parametric analysis (Schertz and others, 1991; Zipper and others, 2002).

Trend analyses of water-quality constituents pertaining to acidic deposition and acidification of stream water, including $\mathrm{pH}, \mathrm{ANC}, \mathrm{NO}_{3}^{-}$, and $\mathrm{SO}_{4}{ }^{2-}$, were performed. Trend analyses were conducted at all monitoring stations within the park for which the minimum criteria of 5 years of data collection with a sample count greater than 10 (Schertz and others, 1991) was satisfied. Time periods of 5, 10, 14, 20, and 30 years, all ending in 2009, were used to evaluate short-term (recent) to long-term trends in the constituents of interest. 
Table 5. Correlation coefficients (Pearson's r) for non-exceedance probabilities from the five Shenandoah Watershed Study (SWAS) streamgages and the mean non-exceedance probability computed from those five streamgages.

[All coefficients significant for $\alpha=0.01$. —, value not shown; N/A, not applicable]

\begin{tabular}{|c|c|c|c|c|c|c|c|}
\hline $\begin{array}{c}\text { Station } \\
\text { identifier or } \\
\text { statistic }\end{array}$ & NFDR & PAIN & PINE & STAN & WOR1 & Mean & $\begin{array}{c}\text { Site- } \\
\text { exclusive } \\
\text { mean }\end{array}$ \\
\hline NFDR & 1.000 & - & - & - & - & - & 0.870 \\
\hline PAIN & 0.857 & 1.000 & - & - & - & - & 0.935 \\
\hline PINE & 0.880 & 0.888 & 1.000 & - & - & - & 0.923 \\
\hline STAN & 0.832 & 0.862 & 0.868 & 1.000 & - & - & 0.893 \\
\hline WOR1 & 0.831 & 0.927 & 0.860 & 0.844 & 1.000 & - & 0.885 \\
\hline Mean & 0.937 & 0.959 & 0.952 & 0.932 & 0.962 & 1.000 & $\mathrm{~N} / \mathrm{A}$ \\
\hline
\end{tabular}

Table 6. Statistics for regression models using various flow statistics to estimate acidneutralizing capacity, by site.

[ANC, acid-neutralizing capacity; RMSE, root mean squared error; $\mathrm{R}^{2}$, coefficient of determination; \%, percent; CI, confidence interval]

\begin{tabular}{|c|c|c|c|c|c|c|c|}
\hline \multirow{3}{*}{$\begin{array}{c}\text { Non-exceedance } \\
\text { probability }\end{array}$} & \multirow{3}{*}{$\begin{array}{l}\text { Mean } \\
\text { ANC }\end{array}$} & \multirow{3}{*}{ RMSE } & \multirow{3}{*}{$\mathbf{R}^{2}$} & \multirow{2}{*}{\multicolumn{2}{|c|}{$\begin{array}{c}\text { Slope } \\
\text { Lower } 95 \% \text { Upper } 95 \%\end{array}$}} & \multicolumn{2}{|c|}{ Intercept } \\
\hline & & & & & & Lower $95 \%$ & Upper 95\% \\
\hline & & & & Cl & Cl & Cl & Cl \\
\hline \multicolumn{8}{|c|}{ NFDR } \\
\hline Site exclusive & 63.48 & 25.58 & 0.28 & -62.85 & -52.17 & 89.73 & 95.92 \\
\hline Mean & 63.48 & 25.30 & 0.30 & -65.34 & -54.63 & 90.75 & 96.91 \\
\hline Site specific & 63.34 & 26.21 & 0.24 & -55.71 & -45.08 & 85.43 & 91.55 \\
\hline \multicolumn{8}{|c|}{ PAIN } \\
\hline Site exclusive & 6.15 & 3.92 & 0.56 & -17.02 & -15.20 & 13.82 & 14.87 \\
\hline Mean & 6.15 & 3.86 & 0.57 & -17.17 & -15.37 & 13.93 & 14.97 \\
\hline Site specific & 6.15 & 3.87 & 0.57 & -16.41 & -14.67 & 13.61 & 14.63 \\
\hline \multicolumn{8}{|c|}{ PINE } \\
\hline Site exclusive & 233.05 & 41.68 & 0.67 & -230.87 & -210.72 & 338.90 & 350.46 \\
\hline Mean & 233.05 & 41.19 & 0.68 & -231.09 & -211.25 & 338.89 & 350.26 \\
\hline Site specific & 233.15 & 44.16 & 0.63 & -208.45 & -188.65 & 326.39 & 337.84 \\
\hline \multicolumn{8}{|c|}{ STAN } \\
\hline Site exclusive & 84.50 & 15.00 & 0.35 & -43.37 & -36.43 & 102.76 & 106.77 \\
\hline Mean & 84.50 & 14.97 & 0.35 & -43.80 & -36.83 & 102.99 & 107.01 \\
\hline Site specific & 84.40 & 15.16 & 0.31 & -38.48 & -31.74 & 100.33 & 104.29 \\
\hline \multicolumn{8}{|c|}{ WOR1 } \\
\hline Site exclusive & 28.37 & 14.63 & 0.44 & -53.32 & -46.43 & 53.25 & 57.37 \\
\hline Mean & 28.89 & 13.47 & 0.50 & -56.53 & -50.82 & 56.64 & 60.09 \\
\hline Site specific & 28.89 & 13.46 & 0.50 & -54.91 & -49.37 & 56.06 & 59.44 \\
\hline
\end{tabular}


Some of the variability in water quality often can be attributed to seasonal variations resulting from phenomena such as biological activity, changes in constituent source, or changes in the predominant water source, and such variability can mask temporal trends if not removed (Hirsch and others, 1982; Schertz and others, 1991). The Seasonal-Kendall trend test reduces the seasonal effect by grouping the data into seasons and then comparing data collected within the same season (Hirsch and Slack, 1984). The selection of the number of seasons to use in a given trend test was based on either (1) an understanding of seasonal variability in the constituent of interest, or (2) the number of annual samples collected according to a consistent sampling frequency (Schertz and others, 1991). For this study, the sampling frequency was generally biweekly, monthly, or quarterly. Because of the potentially confounding effects of serial correlation among frequently collected samples, and because seasonal differences rarely occur on a scale finer than 1 month, the S-ESTREND program does not allow for seasonal definitions finer than 12 per year (monthly; Schertz and others, 1991). Consequently, quarterly seasonal definitions were used for all sites, and, where possible, monthly seasonal definitions were used in order to compare the effects of different sampling frequencies on the ability to detect trends.

Trend analyses were conducted on both constituent concentrations and streamflow-adjusted concentrations. Streamflow adjustment was accomplished using the stagewise method (Hirsch and others, 1982) in which a regression of streamflow versus concentration is developed and the trend test is performed on the residuals of the regression. In this case, the residual equals the observed concentration minus the predicted concentration. The flow-concentration regression was performed in this study using LOESS models, a procedure similar to LOcally WEighted Scatterplot Smoothing (LOWESS). LOESS is a robust approach for flow adjustment when regression assumptions are violated and (or) when thorough evaluation of model fit is not feasible because of the large number of possible models generated when working with numerous constituent/site combinations (Schertz and others, 1991; Slack and others, 2003). Streamflow data were not available for all monitoring stations where waterquality data were collected; therefore, estimations of hydrologic conditions, as described in the previous section, were used in the flow-adjusted trend models. All default settings for seasonal periods, minimum data requirements, and flow adjustment within the S-ESTREND program were utilized. Alpha $(\alpha)=0.10$ was specified as the cutoff value for statistical significance of the trend slopes.
Trend analyses were furthered by evaluating the significance of trends park-wide and grouped by major geologic classification. The intent of this analysis was to evaluate the potential for geologic effects on water-quality trends and to provide a general overview of the direction of change in water-quality constituents throughout the park. This was accomplished using a 2-sided one-sample $t$-test on all trend slopes for a given constituent and time period. The $t$-test is used to test the null hypothesis that the trend slope is equal to zero. A significant result from the $t$-test indicates that the mean trend slope is significantly different from zero, thereby indicating the presence of a geology class-wide trend, regardless of the significance of the individual trend results. Similar analyses to evaluate the potential effects of watershed area, given the importance of this factor in the PCA, were intended but not completed because of disparities in the distributions of watershed areas within geologic classes.

\section{Determination of Appropriate Trend-Model Formulations}

Comparisons of slopes for concentration trends with flow-adjusted concentration trends indicated that the two approaches yielded consistent patterns for $\mathrm{ANC}, \mathrm{pH}$, and $\mathrm{SO}_{4}^{2-}$ concentrations. That is, the magnitude and significance of trend slopes were similar whether concentration or flowadjusted concentration was used in the analyses (fig. 5). Therefore, subsequent analyses focus on concentration-only trends for ease of interpretation and because trends in concentration are more pertinent in evaluating the effects of water quality on aquatic biota.

The SWAS program has collected water-quality data at various frequencies across sites and over time. As described earlier, only the monthly and quarterly data are appropriate for use in analyses of temporal trends. To evaluate the effect of sampling frequency on the results of temporal trend analysis, the trend analyses were computed at the sites where monthly data were collected using both monthly and quarterly seasonal definitions. This evaluation was accomplished by comparing the statistical significance of the computed concentration trend slopes using the 4-season and 12-season definitions (fig. 6). Generally, the significance $(\alpha=0.1)$ of the computed trend slope was similar between the 4 -season and 12-season definitions, and the use of the 4-season definition allows trend analyses to be conducted at a greater number of sites; therefore, the temporal trends in concentration (not flow adjusted) presented hereafter are based upon the 4-season definition (quarterly sampling). 


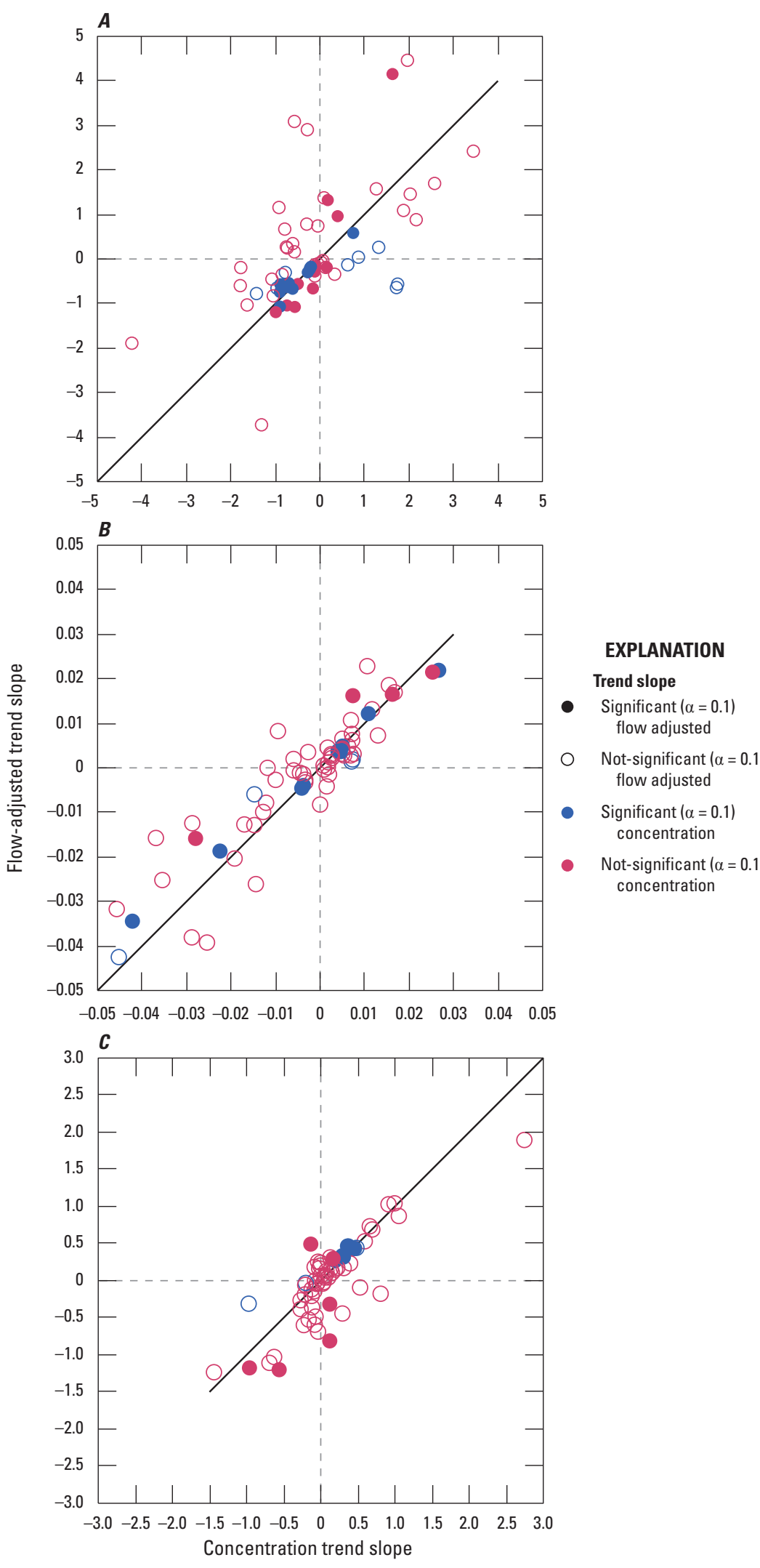

Figure 5. Relations between concentration trend slope and flow-adjusted trend slope for $A$, acid neutralizing capacity (ANC), $B$, $\mathrm{pH}$, and $C$, sulfate $\left(\mathrm{SO}_{4}{ }^{2-}\right)$.

\section{Temporal Trends in Water-Quality Constituents}

Trends in $\mathrm{ANC}, \mathrm{pH}$, and $\mathrm{SO}_{4}{ }^{2-}$ were analyzed using methods just detailed. Evaluation of trends in $\mathrm{NO}_{3}^{-}$was unsuccessful because of the high proportion of censored results; greater than 40 percent of $\mathrm{NO}_{3}{ }^{-}$results were below the reporting limit of the laboratory analysis. The statistical methods employed within S-ESTREND can effectively detect trends in datasets having a small proportion of censored values, but once that proportion exceeds about 5 percent, the results are impaired (Schertz and others, 1991).

Temporal trends in ANC were strongly correlated with median ANC values, which were strongly related to the underlying geology of the watershed (fig. 7). These relations were most obvious when comparing trend slopes and median ANC values between siliciclastic and basaltic watersheds. Most negative trend slopes in ANC were observed in siliciclastic watersheds, which also had the lowest median ANC values. These patterns suggest that streams draining siliciclastic watersheds were not only more acidic than streams in watersheds of other geologic types, but also showed stronger evidence of being increasingly affected by acidic deposition over time, especially in the more recent time periods (5 and 10 years). Although these negative trend slopes are small, on the order of $-1 \mu \mathrm{eq} / \mathrm{L}$ per year, these results may be biologically relevant because median ANC values in these streams are only about $12 \mu \mathrm{eq} / \mathrm{L}$, making the proportional change per year relatively large. Furthermore, decreasing ANC trends were statistically significant geology-class-wide only for streams in siliciclastic watersheds (for the 5-, 10-, and 14-year periods), and class-wide significant increasing ANC trends were observed only in basaltic watersheds (for the 20-year period). Longterm significant trends and short-term non-significant trends in the basaltic watersheds indicate improving conditions, because ANC is increasing in these watersheds. The degree of improvement is relatively small, however, because the median representative value of ANC in these watersheds is nearly $200 \mu \mathrm{eq} / \mathrm{L}$ and the significant long-term trends have slopes of 1 to $2 \mu \mathrm{eq} / \mathrm{L}$ per year. ANC trends in the granitic watersheds show a distinct pattern of change, with trends split proportionately between increasing and decreasing slopes, only two of which are statistically significant. No class-wide significant ANC trends were observed in granitic watersheds. 


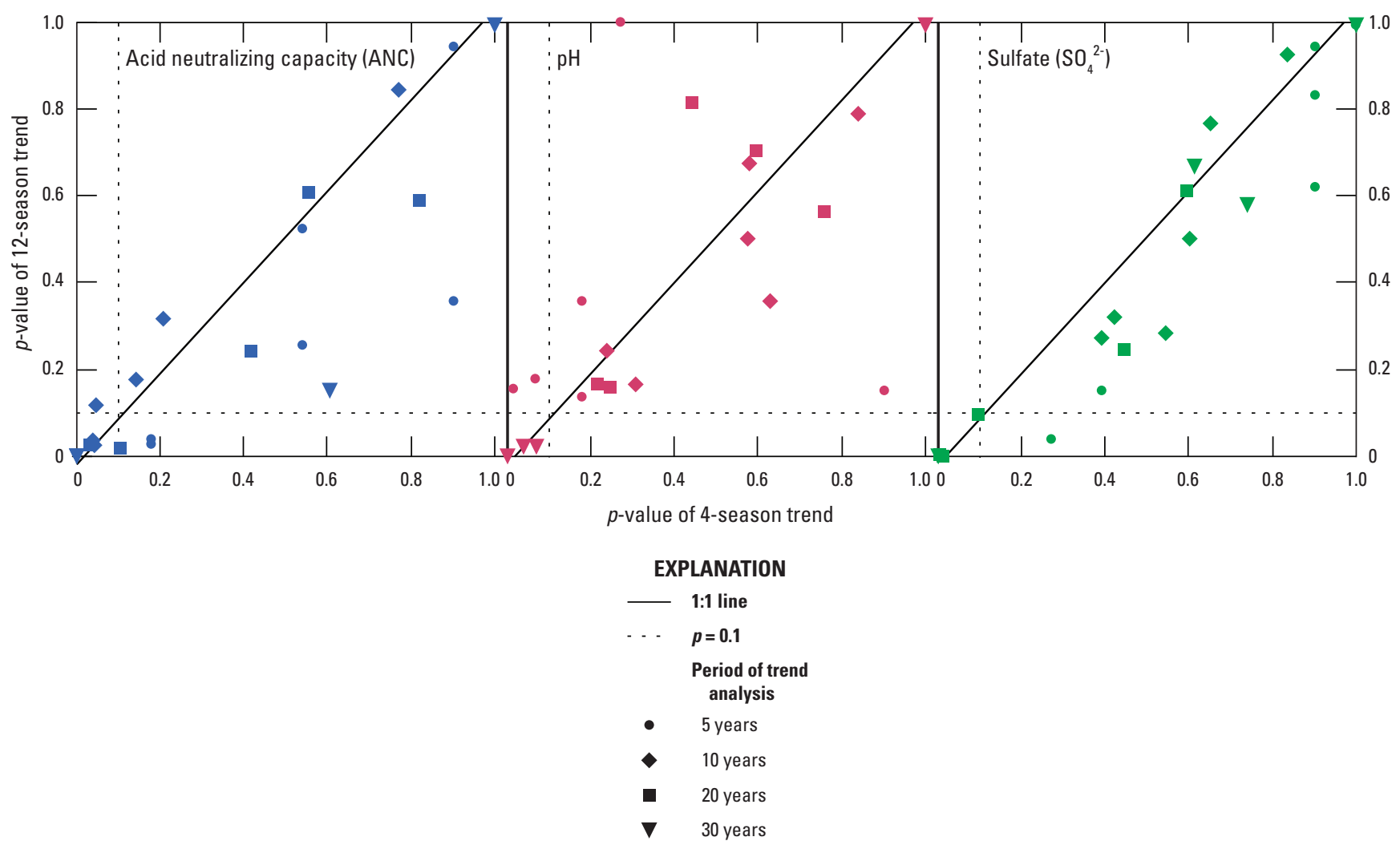

Figure 6. Trend-slope $p$-values for 4-season sampling definition against $p$-values for 12-season sampling definition.

Trends in $\mathrm{pH}$ were more variable and less indicative of relations with underlying geology than ANC trends (fig. 8). Long-term trends (10-, 14-, and 20-years) across all geologic categories generally indicated increasing $\mathrm{pH}$ values, or recovery from acidification, with significant class-wide trends in the granitic watersheds (10- and 20-year trends), basaltic watersheds (10-, 14-, and 20-year trends), and siliciclastic watersheds (14-year trends). Significant long-term trends were detected for trend slopes of less than 0.01 to more than 0.03 unit. Although these trend slopes are small, they equate to increases of 0.2 to $0.3 \mathrm{pH}$ unit over the 10 - to 30 -year duration of the periods evaluated, which could be biologically meaningful.

Short-term trends ( 5 year) in $\mathrm{pH}$ exhibit uncharacteristic declines compared to the longer-term trends, and these trends were significant class-wide for each of the three geologic classes. Short-term trends are highly susceptible to the effects of climatic variability and were probably affected by dry conditions early in the trend period, followed by wet conditions later in the period. Such climatic conditions would result in a decreasing trend in $\mathrm{pH}$ as greater volumes of acidic deposition were delivered to the watershed during the latter part of the 5-year period. This effect also is apparent in the short-term ANC trends in siliciclastic watersheds, where ANC values are very low, but was not detected in the basaltic and granitic watersheds where background ANC is much higher, exemplifying the sensitivity of the streams underlain by siliciclastic geology.

Trends in $\mathrm{SO}_{4}^{2-}$ show variability similar to the trends in $\mathrm{pH}$ (fig. 9). Significant long-term $\mathrm{SO}_{4}^{2-}$ trends in the siliciclastic and granitic watersheds had slopes of approximately $0.5 \mu \mathrm{eq} / \mathrm{L}$ per year, which yields a long-term increase of approximately $10 \mu \mathrm{eq} / \mathrm{L}$ over the 20 -year period. Only the 14- and 20-year trends in the granitic class, however, yielded a significant increasing class-wide trend. In contrast, longterm $\mathrm{SO}_{4}{ }^{2-}$ trends in the basaltic watersheds revealed declining $\mathrm{SO}_{4}{ }^{2-}$ concentrations in those watersheds, with trend slopes as great as approximately $-1 \mu \mathrm{eq} / \mathrm{L}$ per year, yielding an approximately $20-\mu \mathrm{eq} / \mathrm{L}$ decline over the 20 -year period. The 10 -year trend results for the basaltic class yielded a significant classwide decreasing trend, as did the 14-year trend in the siliciclastic class. Although the short-term trends in $\mathrm{SO}_{4}{ }^{2-}$ exhibit greater variability than the long-term trends, the overall pattern indicates increasing $\mathrm{SO}_{4}{ }^{2-}$ concentrations in the granitic watersheds, decreasing $\mathrm{SO}_{4}^{2-}$ concentrations in the basaltic watersheds, and mixed results in the siliciclastic watersheds. With the exception of the highly variable 5-year trends, these results appear to indicate decreasing trends in recent years. 


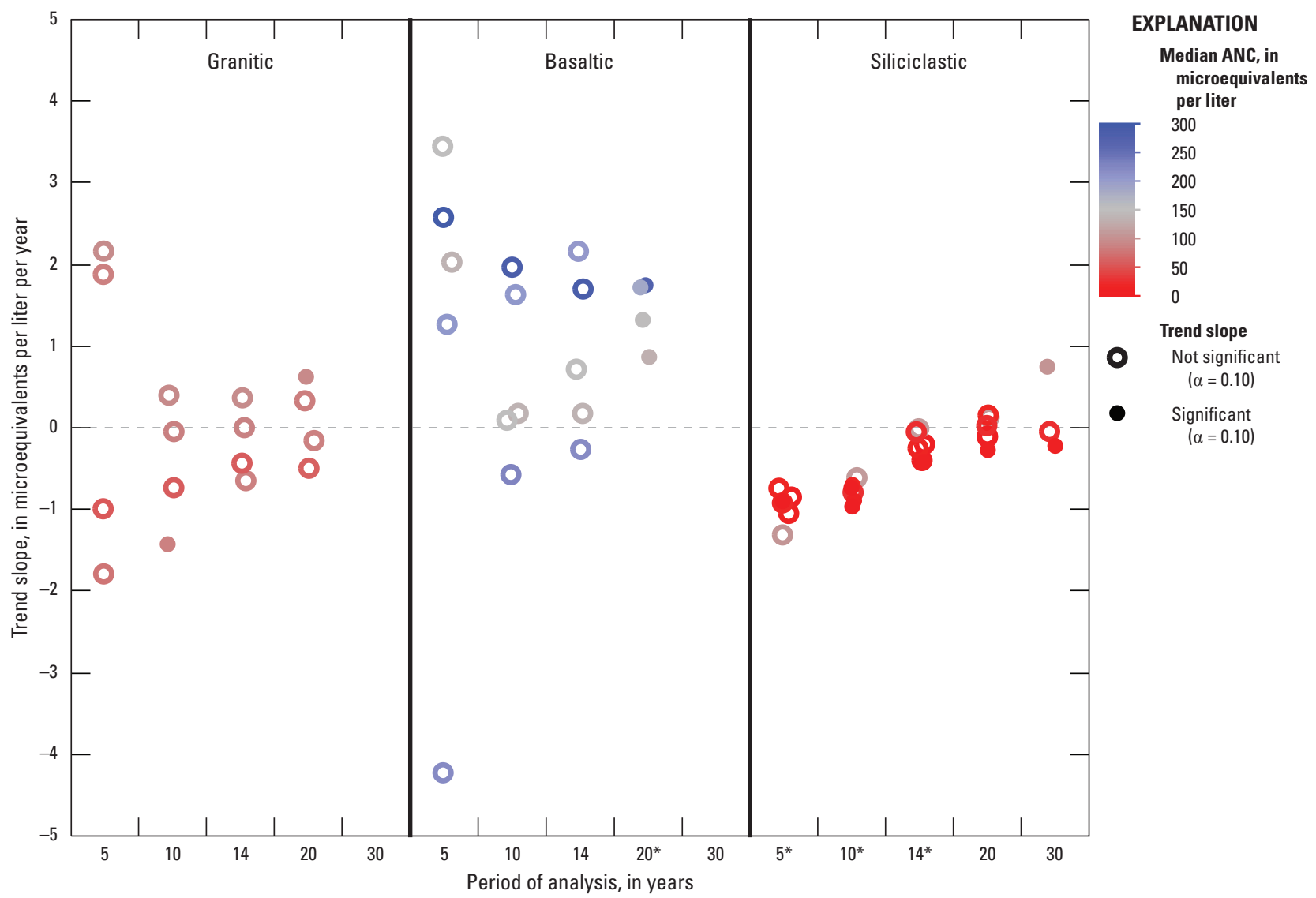

Figure 7. Acid neutralizing capacity (ANC) trend slopes and significance by geologic category and analysis period. Years with significant (alpha $=0.10$ ) class-wide trends are denoted with an asterisk.

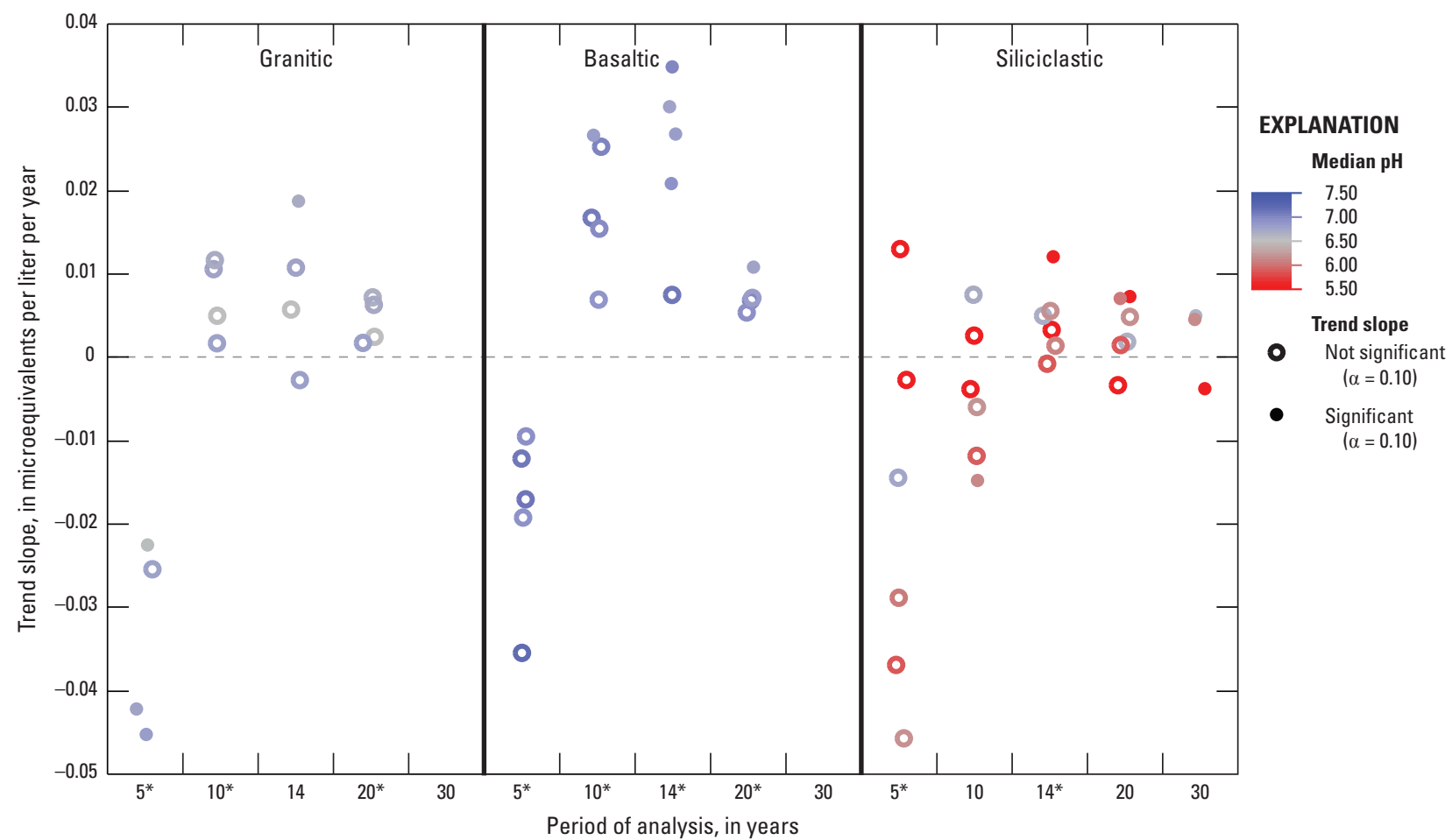

Figure 8. pH trend slopes and significance by geologic category and analysis period. Years with significant (alpha $=0.10$ ) class-wide trends are denoted with an asterisk. 


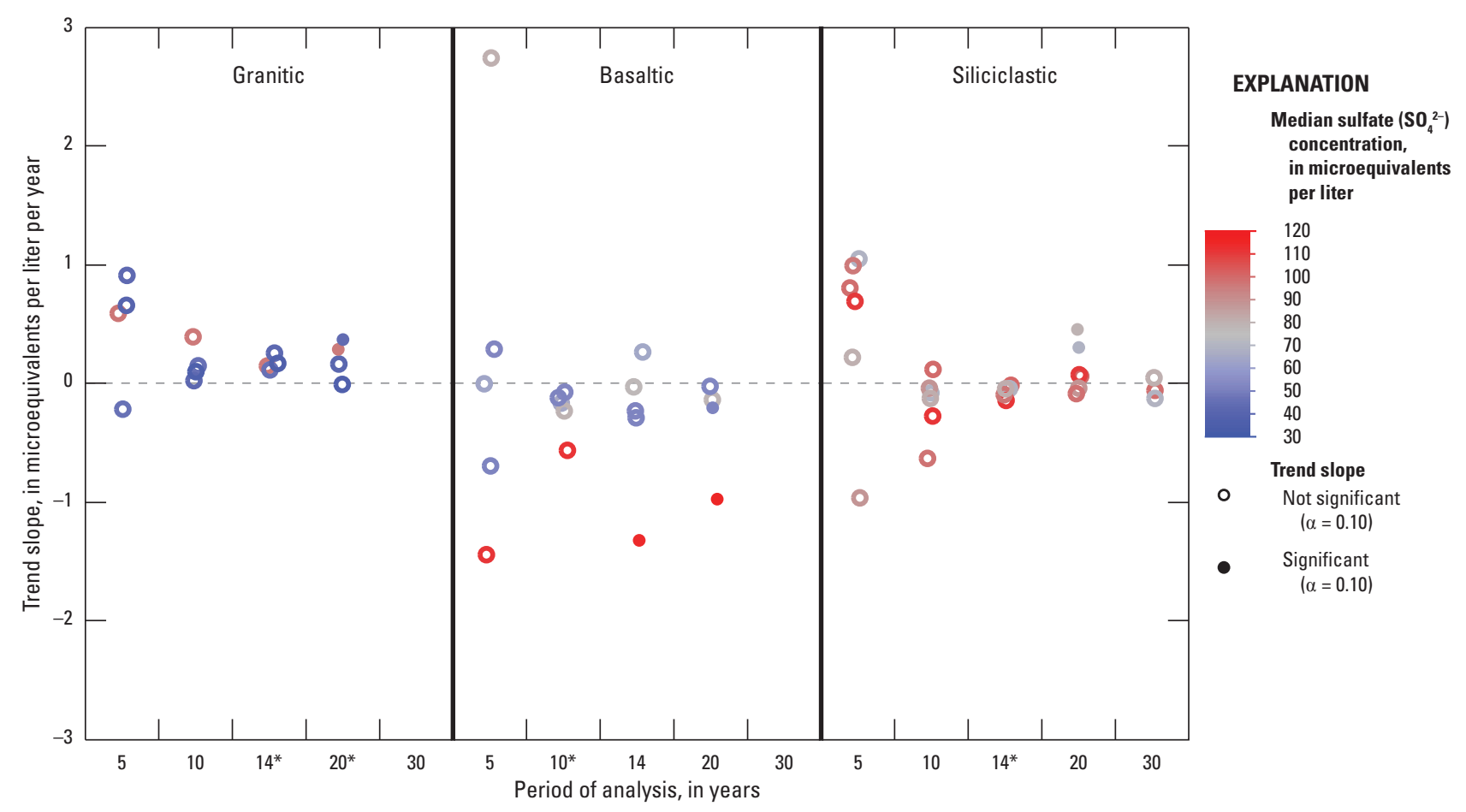

Figure 9. Sulfate $\left(\mathrm{SO}_{4}{ }_{4}^{2-}\right)$ trend slopes and significance by geologic category and analysis period. Years with significant (alpha $=0.10$ ) class-wide trends are denoted with an asterisk.

\section{Practical Significance of Trend Analyses}

It is often desirable to statistically evaluate the power of a given analysis, or to determine what the smallest detectable change is for a given sampling design. Although a formal power analysis was not performed, insight may be gained as to the power of these trend analyses by evaluating the practical significance of the smallest detected significant trends for each constituent.

Significant trends in ANC were detected in 15 of the 62 trend analyses performed (fig. 7). The mean absolute value of the significant trend slopes for ANC was approximately $0.9 \mu \mathrm{eq} / \mathrm{L}$ per year, whereas the minimum absolute value of the significant trend slopes was approximately $0.2 \mu \mathrm{eq} / \mathrm{L}$ per year. These trends slopes were smallest at sites having median long-term ANC values less than $5 \mu \mathrm{eq} / \mathrm{L}$, or those sites most affected by acidification. These results indicate that the quarterly sampling scheme produces sufficient data to detect long-term ANC trends of practical significance.

Significant trends in $\mathrm{pH}$ were detected in 17 of the 62 trend analyses performed (fig. 8). The mean absolute value of the significant trend slopes for $\mathrm{pH}$ was approximately 0.02 units per year, whereas the minimum absolute value of the significant trend slopes was approximately 0.003 units per year. The trend slopes were smallest at sites having the lowest median long-term $\mathrm{pH}$, or those sites that are most degraded in terms of $\mathrm{pH}$. The magnitude of these trends is extremely small and probably well below the level of practical significance. It is valuable to be able to detect such small changes over time, however, because minor changes in $\mathrm{pH}$ may ultimately lead to the crossing of toxic thresholds for aquatic biota, in either the recovery or degradation direction (for example, see Deviney and others, 2012). These results indicate that the quarterly sampling scheme produces sufficient data to detect long-term $\mathrm{pH}$ trends of practical significance, particularly at the most degraded sites.

Significant trends in $\mathrm{SO}_{4}{ }^{2-}$ were detected in 7 of the 62 trend analyses performed (fig. 9). The mean absolute value of the significant trend slopes for $\mathrm{SO}_{4}{ }^{2-}$ was approximately $0.6 \mu \mathrm{eq} / \mathrm{L}$ per year, whereas the minimum absolute value of the significant trend slopes was approximately $0.2 \mu \mathrm{eq} / \mathrm{L}$ per year. These trend slopes all represent trends of less than 1 percent per year when evaluated in terms of the median $\mathrm{SO}_{4}^{2-}$ concentration. The detection of such small changes in $\mathrm{SO}_{4}^{2-}$ indicate that the quarterly sampling scheme produces sufficient data to detect long-term $\mathrm{SO}_{4}{ }^{2-}$ trends of practical significance. 


\section{Temporal Trends in Water Temperature}

Water-temperature trends, particularly warming trends, in the park are of interest because of the potential implications for cool- and cold-water organisms, such as brook trout, that are native to park waters and prefer water temperatures below $17^{\circ} \mathrm{C}$ (Cherry and others, 1977). Significant increases in stream-water temperature were detected at numerous sites in the park, predominantly during the 10 -year period (fig. 10). Increasing trend slopes in the annual median, mean, and maximum water temperature were often large, ranging from 0.14 to $0.76{ }^{\circ} \mathrm{C}$ per year, with a median of $0.32{ }^{\circ} \mathrm{C}$ per year. The longer-term trend results (14-year and 30-year) also indicate rising water temperatures, particularly annual maximums. Only one site (WOR1) had sufficient data to support evaluation of the 30-year trend in water temperature, and the results for that site indicated a small but statistically significant increase in annual mean, median, and maximum water temperature for the 30 -year period ending in 2009. The trend slope for mean annual water temperature over this period was approximately $0.04{ }^{\circ} \mathrm{C}$ per year, which equates to an increase of $1.2{ }^{\circ} \mathrm{C}$ over the 30 -year period. As with the 5 -year trends in water quality, the 5-year trends in water temperature were highly variable.

One explanation for the observed increases in streamwater temperatures in the park is that they were due to increased solar radiance associated with forest defoliation from gypsy moth infestation. For this hypothesis to be consistent with the data, water temperatures would be expected to increase during the period of defoliation, followed by decreasing water temperatures, as canopy cover was reestablished and streams were once again shaded. In many cases, increasing water temperatures were observed prior to, during, and after the period of most intense defoliation in the park (1990-95; fig. 11). Thus, the observed patterns do not support the hypothesis that gypsy moth defoliation is responsible for increased water temperatures.

An alternative hypothesis for observed increases in water temperatures in the park is that air temperature has increased in association with climate change. In order to test the climate-change hypothesis, changes in water temperature were evaluated over larger spatial and longer temporal scales. For these analyses, long-term water-temperature records were obtained from nine USGS streamgages located within and near the park (fig. 12). These data represent a range of watershed areas, from small watersheds similar in size to those in the park, to much larger watersheds that incorporate the drainages of the park. The period of record for these sites is sufficiently long to examine trends at a temporal scale relevant to climate change (table 7). White Oak Run, one of the streams for which water-temperature trends were computed from the SWAS dataset, also had a USGS streamgage that was operated at a separate location. Measurements at the White Oak Run USGS streamgage were made independently from the SWAS efforts, and therefore represent an independent verification of the water-temperature trends observed in the SWAS dataset.

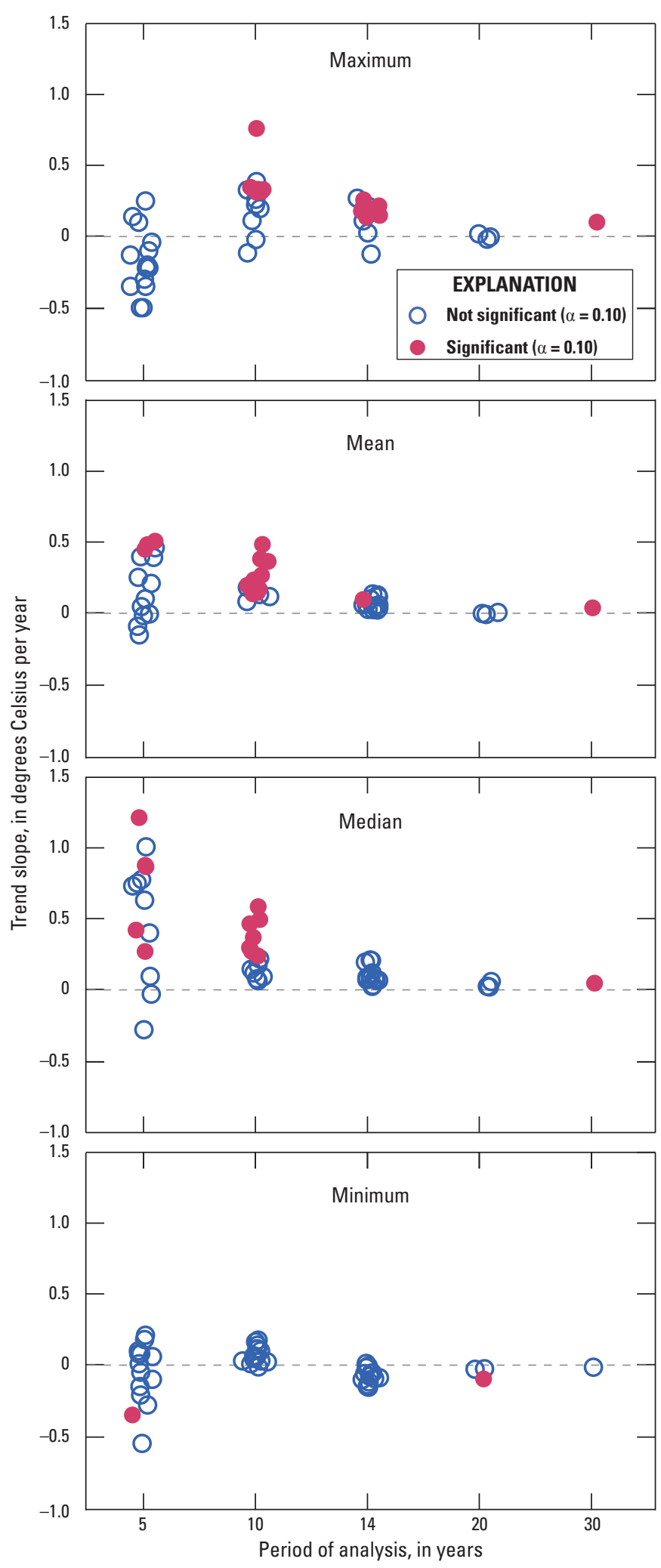

Figure 10. Trend slopes and significance of annual water-temperature characteristics by analysis period. 


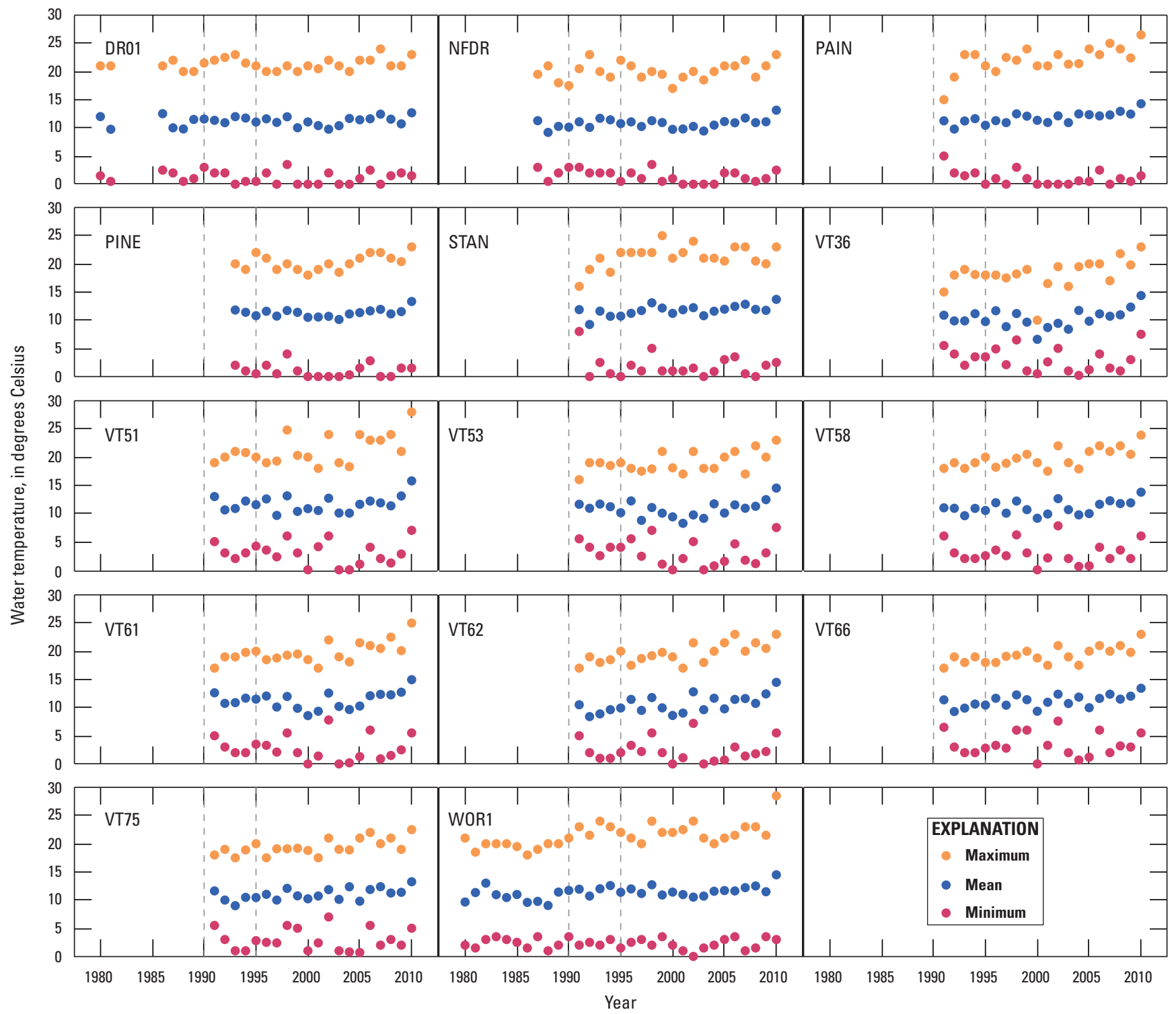

Figure 11. Time series of mean, minimum, and maximum annual water temperature for 14 sites, with period of defoliation indicated by vertical dotted lines.

Table 7. Watershed area, mean watershed elevation, and period of record for U.S. Geological Survey (USGS) streamgages used for water-temperature trend analysis.

$\left[\mathrm{km}^{2}\right.$, square kilometer; $\mathrm{m}$, meter]

\begin{tabular}{llrrrr}
\hline $\begin{array}{c}\text { Station } \\
\text { identifier }\end{array}$ & \multicolumn{1}{c}{ Station name } & $\begin{array}{c}\text { Watershed } \\
\text { area } \\
\left(\mathbf{k m}^{2}\right)\end{array}$ & $\begin{array}{c}\text { Mean watershed } \\
\text { elevation } \\
(\mathbf{m})\end{array}$ & $\begin{array}{c}\text { Period of } \\
\text { record }\end{array}$ & $\begin{array}{c}\text { Years of } \\
\text { record }\end{array}$ \\
\hline 01620500 & North River Near Stokesville, Va. & 45 & 972 & $1941-2011$ & 70 \\
01621050 & Muddy Creek At Mount Clinton, Va. & 37 & 617 & $1993-2011$ & 18 \\
01627500 & South River At Harriston, Va. & 548 & 756 & $1925-2011$ & 86 \\
01628060 & White Oak Run Near Grottoes, Va. & 5 & 709 & $1978-1996$ & 18 \\
01628500 & S.F. Shenandoah River Near Lynnwood, Va. & 2,795 & 826 & $1930-2011$ & 81 \\
01629500 & S.F. Shenandoah River Near Luray, Va. & 3,554 & 781 & $1925-2011$ & 86 \\
01631000 & S.F. Shenandoah River At Front Royal, Va. & 4,233 & 743 & $1930-2011$ & 81 \\
01662800 & Battle Run Near Laurel Mills, Va. & 67 & 466 & $1958-2011$ & 53 \\
01665500 & Rapidan River Near Ruckersville, Va. & 297 & 650 & $1989-2011$ & 22 \\
\hline
\end{tabular}




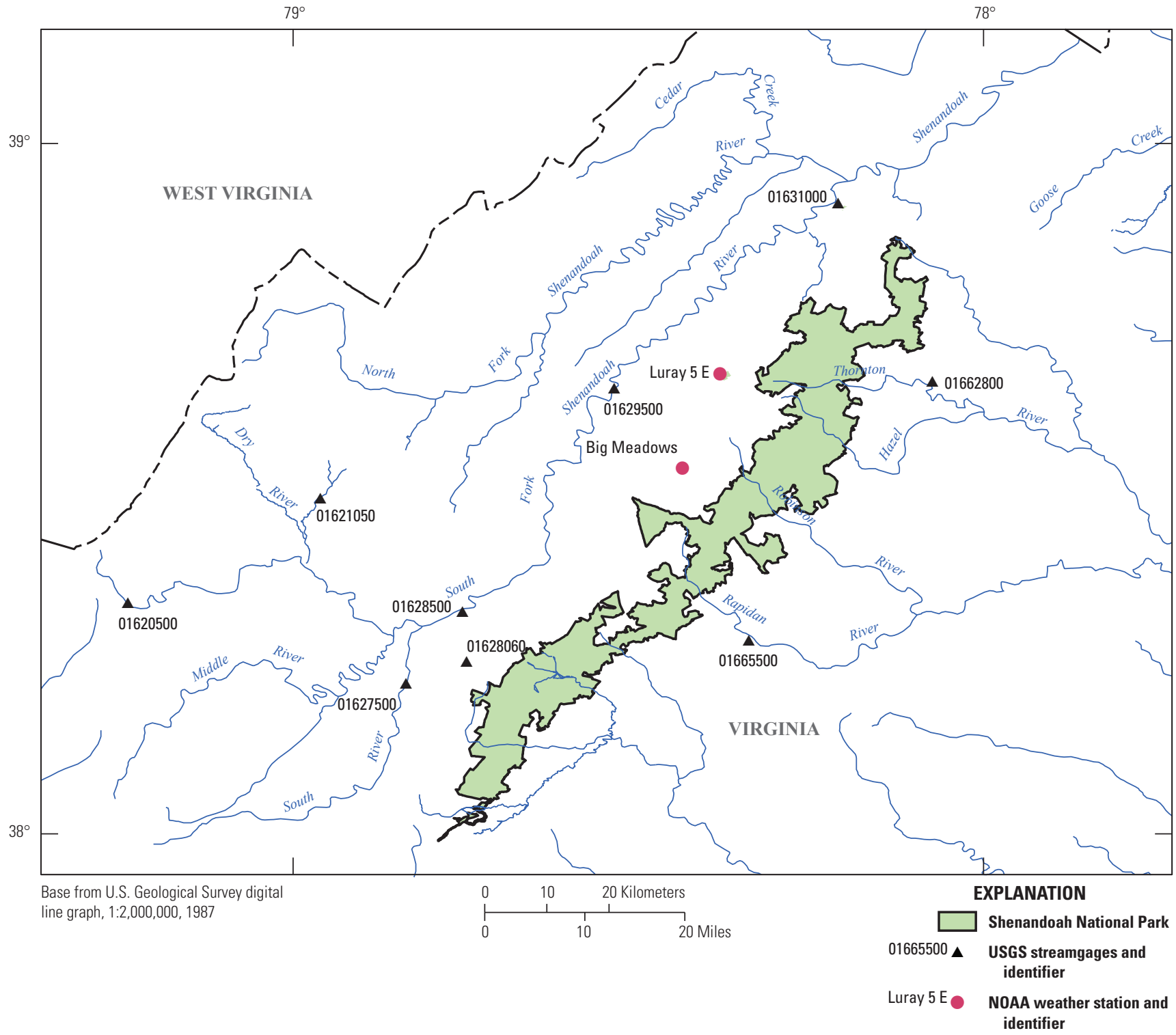

Figure 12. U.S. Geological Survey (USGS) streamgages used in water-temperature trend analysis. Location of study area provided in figure 1. NOAA is National Oceanic and Atmospheric Administration.

Air-temperature records from two meteorological stations within the park (Luray 5E and Big Meadows) were used to evaluate long-term trends in air temperature. These air-temperature data were retrieved from the National Climatic Data Center website (National Oceanic and Atmospheric Administration, 2012) as monthly mean air temperature, monthly mean maximum air temperature, and monthly mean minimum air temperature. The monthly mean values were averaged over each calendar year to generate annual mean air temperatures, annual mean minimum air temperatures, and annual mean maximum air temperatures for use in the trend analyses. Data included records for the period 1941-2011 at the Luray site and 1935-2011 at the Big Meadows site; however, recent data were incomplete for both sites, so the trend analysis for each was performed only through 2001. Trend analyses for air temperature were performed using simple linear regression (1) for the entire period of the analysis dataset to evaluate long-term trends, and (2) from 1979 to the end of the period of analysis dataset for comparison with the maximum period of record for water temperature in SHEN streams.

Significant water-temperature trends of similar magnitude to those observed in the park were detected at six of the nine USGS streamgages in and around the park (fig. 13). Significant water-temperature trends were most common at stations having a period of record similar to the period of record of the SWAS sites, and at stations with the smallest watershed area (table 7; fig. 13). Furthermore, water-temperature trends observed at the USGS streamgage on White Oak Run near Grottoes, Va., over a period of record that overlaps the SWAS dataset are of similar magnitude to the water-temperature 


\section{Surface-Water Quality and Aquatic Biota Data Collected in Shenandoah National Park, Virginia}

trends observed in the SWAS dataset (fig. 13). Lastly, a more moderate increasing trend was observed over the much longer period of record at the larger South Fork Shenandoah River near Lynnwood, Va. streamgage compared to the trends observed in the park, suggesting that increases in water temperature were not limited to the small mountainous watersheds such as those in the park. The increasing water-temperature trends observed in the small, mountainous, streams of the park (fig. 10) exceed the magnitude of water-temperature trends documented by other studies using similar methods (Kaushal and others, 2010). The lesser magnitude trend at the larger Lynnwood, Va. Streamgage, compared to the trends observed in the park streams, is consistent with those reported in the literature, which tend to focus on larger river systems (Kaushal and others, 2010).

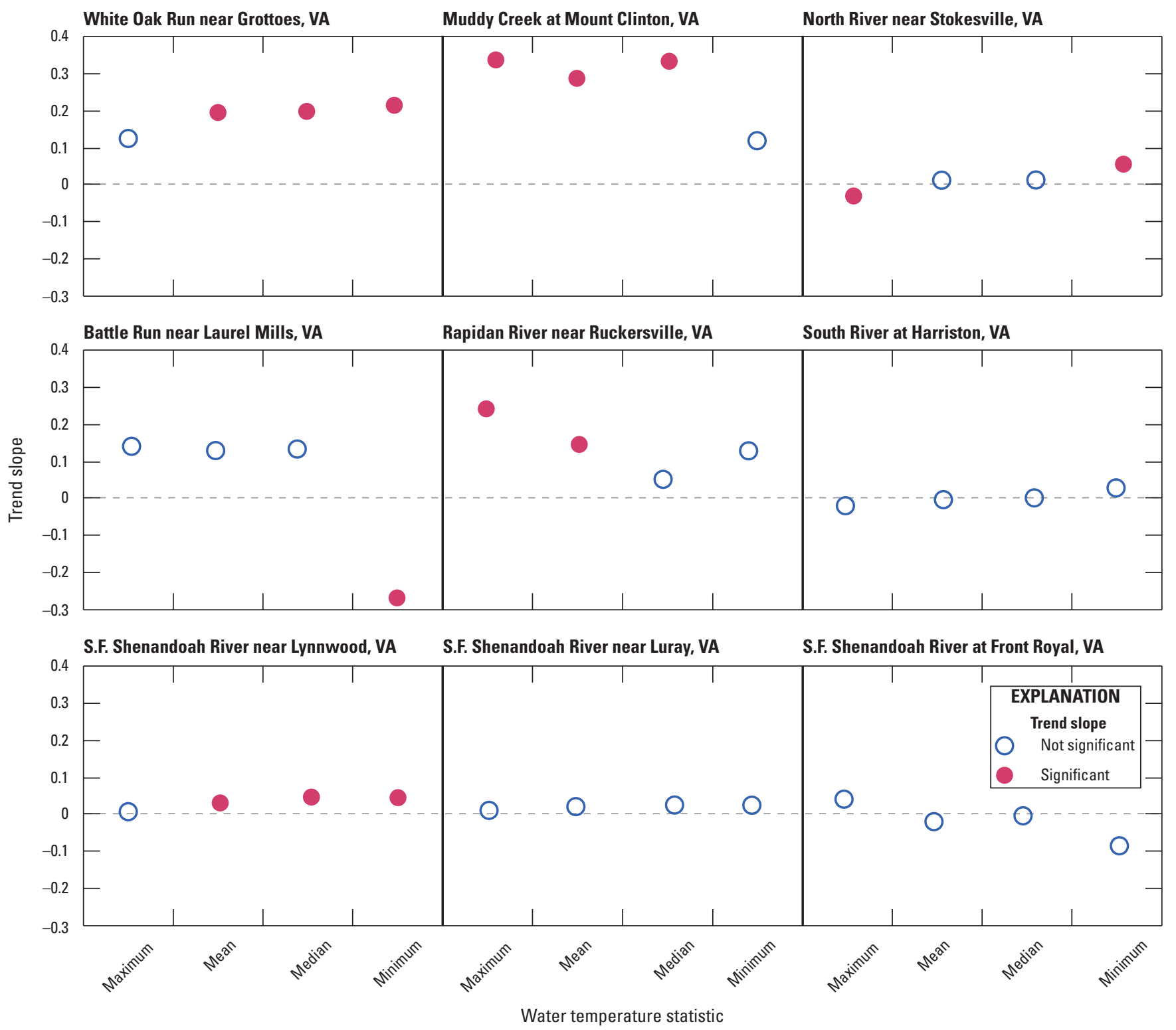

Figure 13. Annual water-temperature trend slopes and significance for nine U.S. Geological Survey (USGS) streamgages. 


\section{Comparison of Water-Temperature Trends and Air-Temperature Trends}

The trend analysis of air-temperature records indicates that air temperature has generally declined over the entire period of record (1935-2001; fig. 14). Air-temperature data from 1979 to 2001, the period for which water-temperature trends were evaluated in the park, however, show increasing trends comparable to water-temperature trends observed at sites throughout the park. These patterns suggest that increases in water temperature were associated with increases in air temperature.

The longer period of record for the air-temperature data provides an important perspective for the water-temperature trends observed in the park during recent decades. The period of warm air temperatures observed early in the air-temperature records (until about 1960; fig. 14) is comparable to the warm air temperatures observed in recent decades (1990s-2000s), and this pattern also is evident in the long-term water-temperature record at the South Fork Shenandoah River near Lynnwood, Va. streamgage. These patterns do not appear to be consistent with the climate-change hypothesis because increases of similar magnitude occurred much earlier, before climate change effects would be expected. It is possible that the increasing air temperature trends observed during the earlier decades (before the 1950s), however, were due to timber harvesting activities that were widespread during the early part of the century and usually involved complete removal of the forest (Clarkson, 1964; DeVivo, 1986); and that the subsequent cooling trends observed between 1960 and 1980 were associated with the forest re-growth that followed. In fact, as late as 1941 , more than 15 percent of the park remained deforested with nearly 50 percent of the remaining forest comprising younger trees (1- to 20-year age class) (Berg and Moore, 1941). Therefore, much of the park landscape was still recovering from timber harvest and agriculture well into the middle of the century. Thus, climate change remains a plausible hypothesis to explain more recent (1980-2010) increasing temperature trends.

Air-temperature patterns during the last 30 years, a period when forest growth has far exceeded forest removal throughout the eastern United States (Foster and others, 2004), showed increases as large as those observed during the early part of the century when much of the Appalachian forest was harvested. Other factors, such as the North Atlantic oscillation (Visbeck and others, 2001), and increasing urbanization (Kalnay and Cai, 2003), however, also may have contributed to the increases in air temperature observed in recent decades in and around the park. More research is needed, and it may not be possible to determine the precise effect of climate change on air temperatures in the park for any particular period of time. Temperature trends in air and surface waters observed in this study, and similar patterns observed by others (for example, Foster and others, 2004), however, are of significant interest to resource managers.

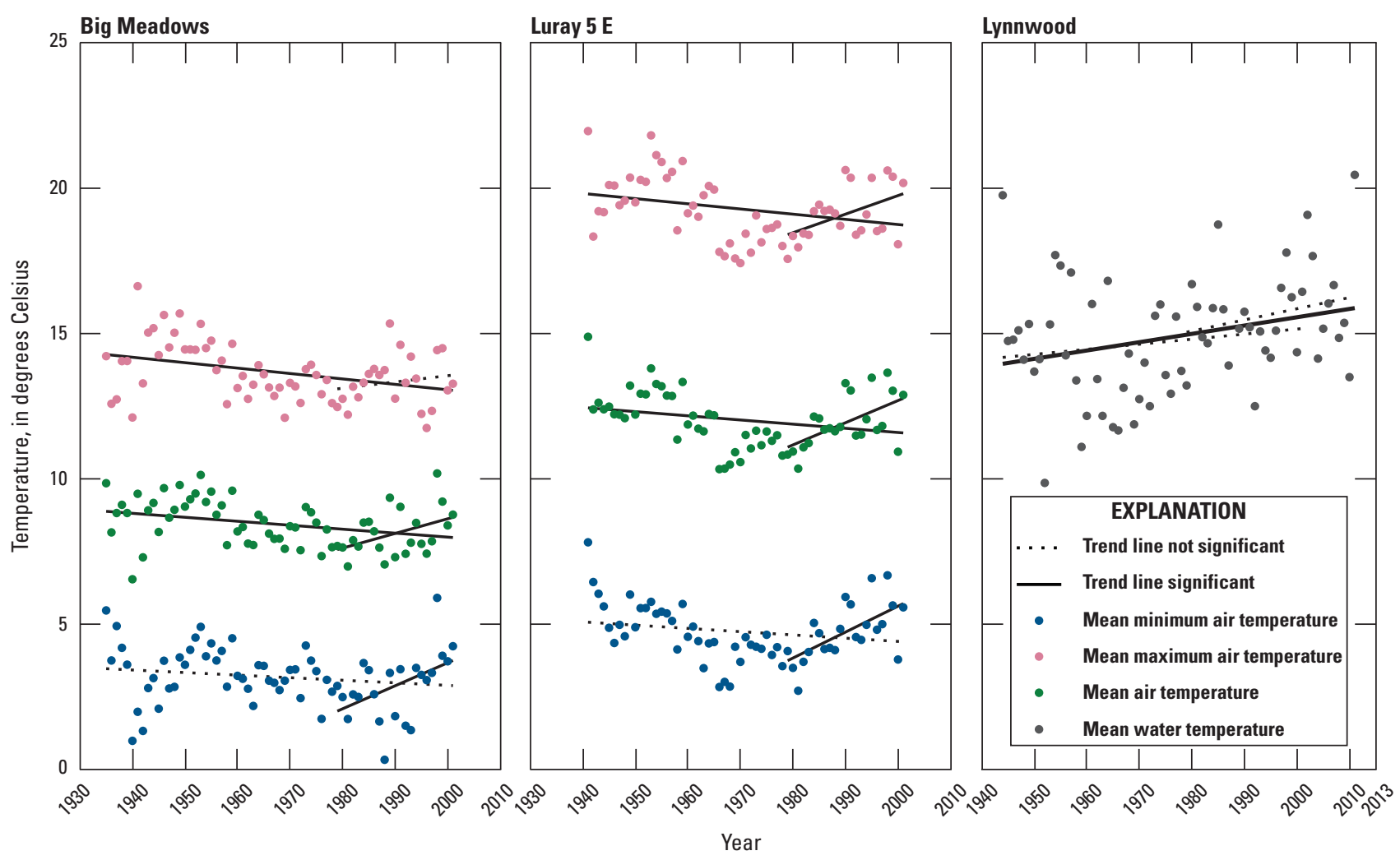

Figure 14. Annual air-temperature characteristics at the Big Meadows and Luray meteorological stations, and annual mean water temperature at the Shenandoah River at Lynnwood, Virginia, streamgage, with trend lines. 


\section{Spatial Patterns in Water Quality}

Spatial patterns in water quality throughout the park, particularly those associated with acidification, largely follow a north-south gradient coincident with geologic variation (fig. 15). Sites with $\mathrm{pH}$ data are well distributed throughout the park (fig. 15A), and the association of lower $\mathrm{pH}$ values in the areas underlain by siliciclastic geology (fig. 15) and higher $\mathrm{pH}$ in the areas underlain by granitic and basaltic geology is evident (fig. $15 A, E$ ). As would be expected, spatial patterns in ANC (fig. 15B) are similar to the patterns observed in $\mathrm{pH}$, although the distribution of sites with ANC data is less extensive (fig. $15 \mathrm{~B}$ ). $\mathrm{SO}_{4}{ }^{2-}$ data have been collected at fewer sites in the park than $\mathrm{pH}$ and $\mathrm{ANC}$, making spatial interpolation of $\mathrm{SO}_{4}{ }^{2-}$ patterns less informative (fig. $15 \mathrm{C}$ ). Although the graphical representation of $\mathrm{SO}_{4}{ }^{2-}$ is coarse, it reveals the same general patterns of acidity evident for $\mathrm{pH}$ and ANC, namely, a generally increasing gradient in $\mathrm{SO}_{4}^{2-}$ and decreasing gradients in $\mathrm{pH}$ and $\mathrm{ANC}$ from north to south, with the siliciclastic region having much higher stream $\mathrm{SO}_{4}{ }^{2-}$ concentrations and lower $\mathrm{pH}$ and ANC than streams in the remainder of the park. Specific conductance, a measure of electrical conductivity indicative of total ion concentration in water (Hem, 1985), has been measured extensively in the park (fig. 15D). Specific conductance of park streams is low, as would be expected for relatively undisturbed forested headwater streams. Variability within this low range of specific conductance values is associated with the relative solubility of the underlying geology, with the siliciclastic and granitic watersheds having lower conductivity than the watersheds draining basaltic areas.

Each of the median water-quality values (ANC, $\mathrm{pH}$, $\mathrm{SO}_{4}{ }^{2-}$ ) were significantly correlated with the first principal component, $\mathrm{ANC}$ and $\mathrm{pH}$ having positive correlations and $\mathrm{SO}_{4}^{2-}$ having negative correlation. Additionally, the 10- and 14-year trend slopes for $\mathrm{pH}$ and the 10- and 20-year trend slopes for ANC were positively correlated with the first principal component. Increases in the first principal component represent increases in elevation and decreases in the mean watershed slope and the proportion of siliciclastic geology in the watershed. Therefore, these results indicate that $\mathrm{pH}$ and ANC are greatest, and $\mathrm{SO}_{4}{ }^{2-}$ is lowest, in high-elevation watersheds having flat terrain and a small proportion of siliciclastic geology. Furthermore, these results indicate that $\mathrm{pH}$ and ANC have increased over time in such watersheds - one indication of recovery from acidification.

A significant negative correlation with principal component two was detected for median ANC, median $\mathrm{pH}$, ANC trends for the 10- and 20-year periods, and the $\mathrm{pH}$ trend for the 10-year period (fig. 16). Increases in principal component two are most strongly influenced by decreasing watershed area and increasing minimum watershed elevation (specifically, monitoring station elevation). The correlations indicate that $\mathrm{ANC}$ and $\mathrm{pH}$ values are lower, and trends in $\mathrm{pH}$ and $\mathrm{ANC}$ have lower slopes (some negative), in such watersheds.

The only significant correlations with the third principal component were for measures of $\mathrm{SO}_{4}{ }^{2-}$, specifically the median and 10- and 20-year trends. This component largely differentiates granitic geology from the other geologic types, with increasing component values reflecting greater proportions of granitic bedrock. The correlations between principal component 3 and $\mathrm{SO}_{4}^{2-}$ are positive, indicating a tendency for increased $\mathrm{SO}_{4}^{2-}$ concentrations in granitic watersheds.

Overall, this analysis demonstrates that water quality in watersheds with higher mean elevations, lower land-surface gradients, larger watershed areas, and lesser proportions of siliciclastic geology are least affected by acidification and tend to be improving over time. In contrast, watersheds with greater proportions of siliciclastic and granitic geology, with smaller watershed areas, and higher minimum watershed elevation tend to be more affected by acidification and are experiencing continued degradation. 

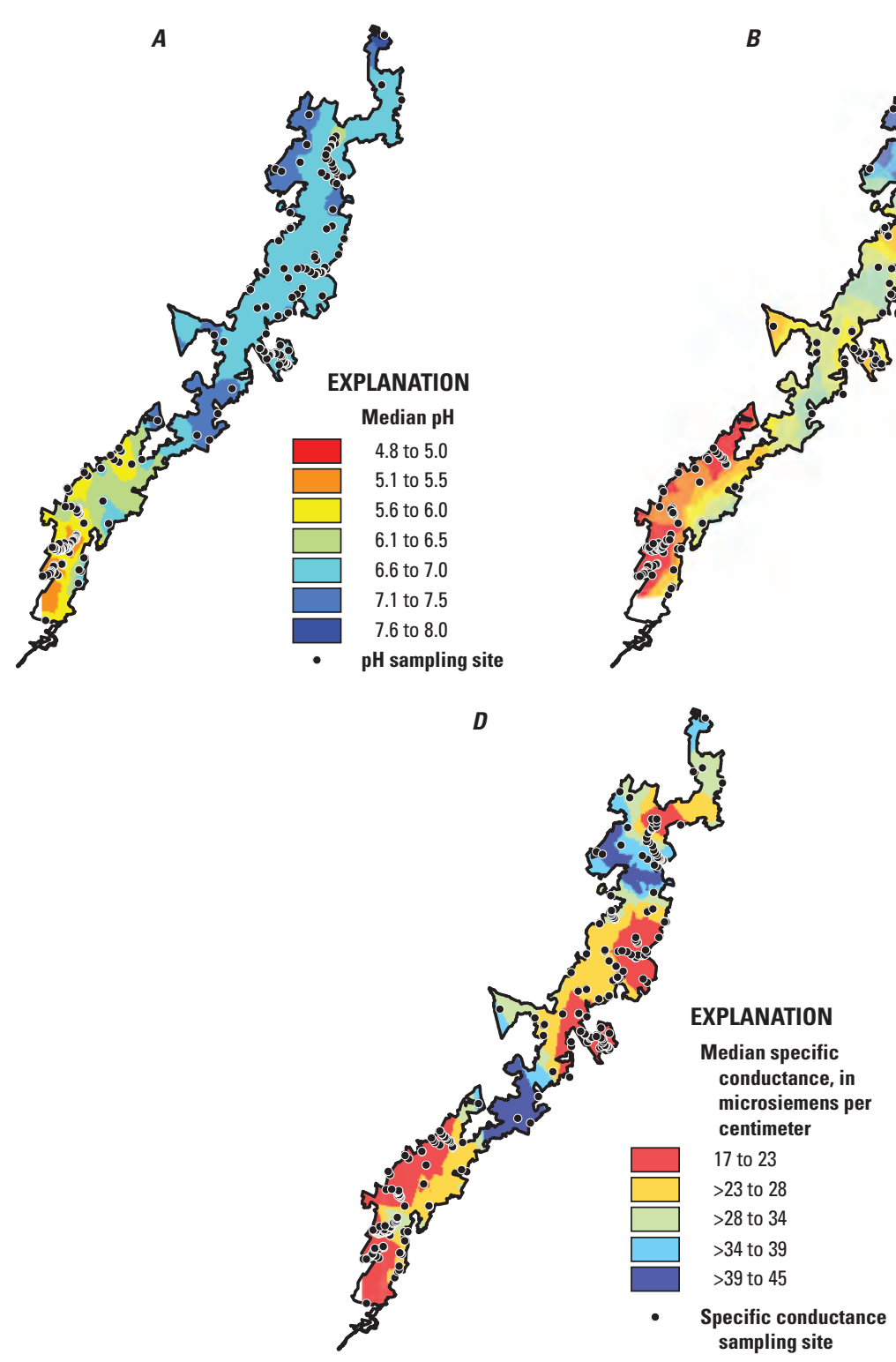
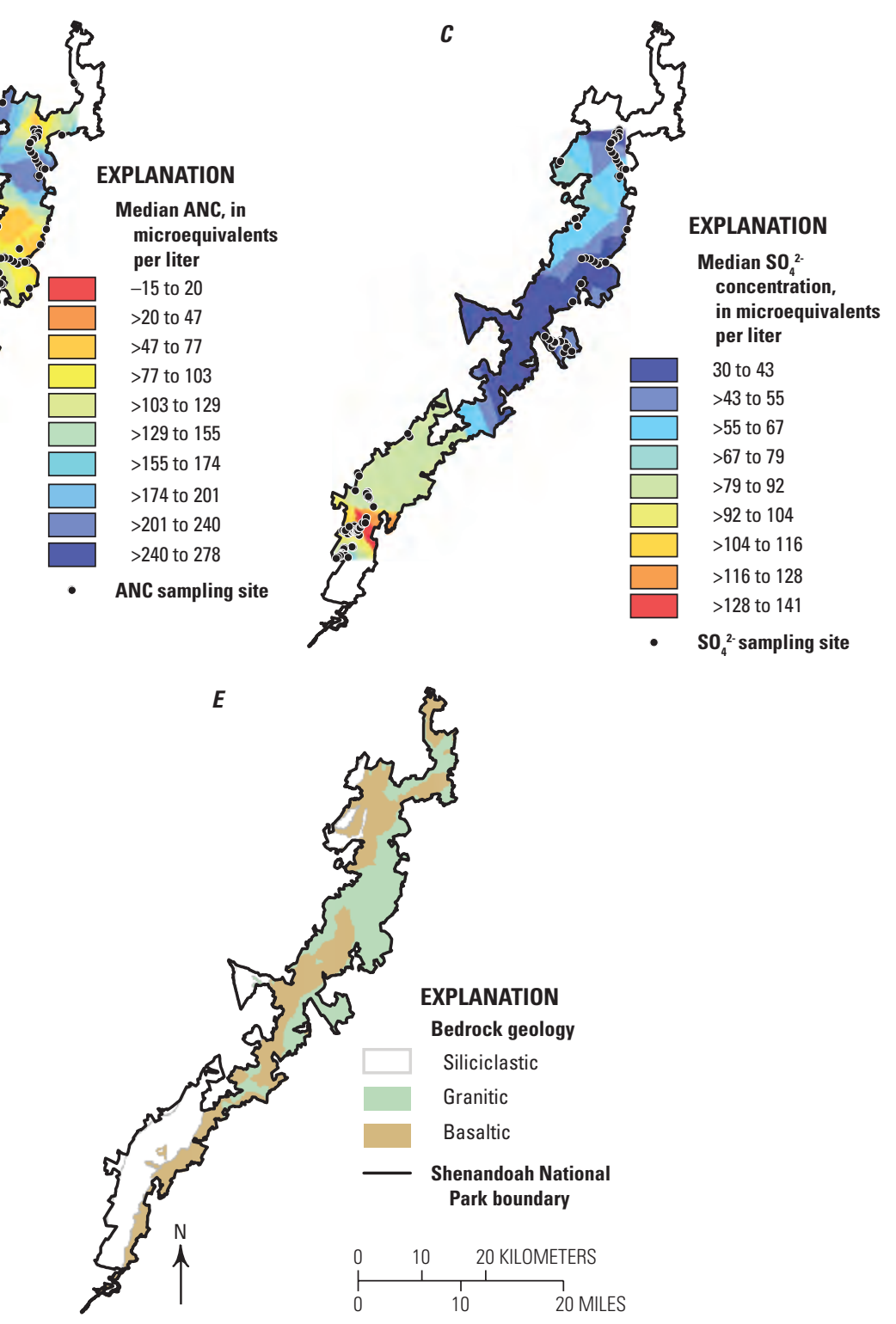

Figure 15. Spatial patterns in $A, \mathrm{pH}, B$, acid neutralizing capacity (ANC), $C$, sulfate $\left(\mathrm{SO}_{4}{ }^{2-}\right)$, and $D$, specific conductance, and $E$, underlying geology, in Shenandoah National Park. Location of study area provided in figure 1. 


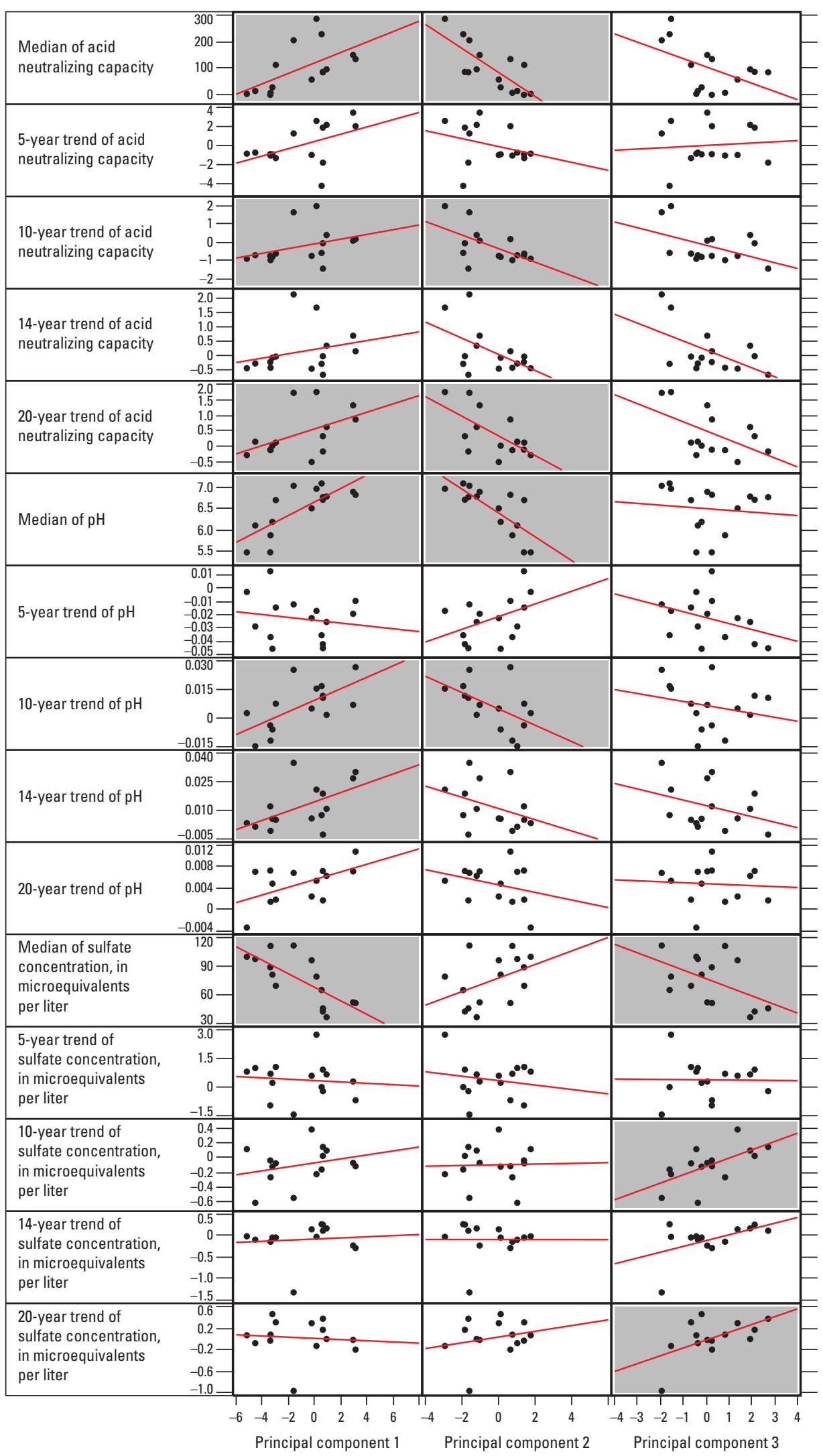

Figure 16. Principal component axes against water-quality variables, with significant correlations highlighted. 


\section{Analysis of Aquatic Macroinvertebrate Data}

Park staff began sampling AM in 1984 with the objective of using measures of community structure and composition as indicators of stream condition (J.E.B. Wofford, National Park Service, written commun., 2011). AM monitoring is utilized by the park because these organisms, which are numerous and directly affected by changes in water-quality, are relatively easy to sample and interpret (National Park Service, 2008). The AM dataset for the park was used to evaluate the status and trends of AM communities within the study area. Geology and watershed size were examined as potential environmental predictors of AM communities because of their demonstrated importance for acidic deposition, which was also demonstrated by Cosby and others (2006), and macroinvertebrate community composition (Snyder and others, 2013).

\section{Aquatic Macroinvertebrate Data Structure and Analysis}

Park personnel have collected AM data since 1984; however, the current analysis was limited to data collected after 1990 in order to facilitate integration of macroinvertebrate patterns with the physical and chemical assessments included herein. Furthermore, the analyses were limited to quantitative samples collected during the spring season (April-June) because summer sampling was discontinued in 1997, whereas spring sampling continued. Aquatic macroinvertebrate data derived from sampling that occurred in the spring of 1995 were used to assess spatial patterns because more sites were sampled that year $(\mathrm{N}=54)$ than any other, and because limiting the analysis to a single year would allow control of temporal trends in this spatial analysis. The additional sampling effort that occurred in 1995 was largely the result of an increased effort - in the Paine Run, Staunton River, and Piney River watersheds - made with the intent of incorporating intensive sampling within representative watersheds of the park. This approach biased the results somewhat toward those watersheds, but allowed a better representation of geology and the gradient in watershed area.

Temporal trends were assessed using data collected at 24 sites where approximately annual sampling occurred over the 20-year period between 1990 and 2009 (focal sites of LTEM program). Between 10 and 18 years of data were collected at focal sites over the 20-year period (table 8). Eleven of the 24 focal sites also were represented in the spatial dataset. Sites used in both spatial and temporal analyses are described in table 9 and are shown in figure 17. Because these sites are well distributed across gradients in watershed size and geology, inferences regarding landscape effects should be robust (fig. 18).
Stream sites were sampled using a portable invertebrate box sampler (PIBS) equipped with a 350-micrometer collecting net. At each site, three samples were collected at random locations within riffle areas, preserved in the field, and shipped to the laboratory of Dr. J. Reese Voshell at Virginia Polytechnic Institute and State University for taxonomic identification. Qualitative samples also were routinely collected, but not included in these analyses in order to ensure comparable levels of effort among samples, sites, and years for this assessment. Sampling protocols have remained consistent over the 20-year period of data collection, including personnel involved in taxonomic identification, allowing for robust assessment of spatial and temporal trends (J.E.B. Wofford, National Park Service, written commun., 2011).

In the laboratory, individual specimens were identified to the "lowest practical level," which was the species level of taxonomic resolution for some insect taxa, but the genus level for most insects, and higher levels (family or class) for most non-insect taxa, including worms and mollusks (J.E.B. Wofford, National Park Service, written commun., 2011). The variability in taxonomic resolution resulted in a large degree of taxonomic ambiguity in the raw database. That is, the same taxon often was identified at multiple levels of taxonomic resolution throughout the database, because of variation in the condition and maturity of individual specimens. This taxonomic ambiguity is common to large AM databases and can introduce additional uncertainty in computed summary measures (metrics) (Cuffney and others, 2007).

For the analyses presented here, taxonomic ambiguity was addressed using a sequential process. First, all specieslevel identifications were lumped up to the genus level, as there was extensive ambiguity at the species level. Second, the "distribute parents among children" (DPAC) method in the Invertebrate Data Analysis System software (IDAS; Cuffney and Brightbill, 2011) was used to resolve the remaining ambiguity within a sample. The DPAC method assigns "ambiguous parents" (for example, specimens of the family Baetidae) to "children" (for example, genera Baetis and Pseudocleon) based on the proportions of the "children" observed in the sample. Resolving ambiguity within a sample ensured that assumptions were not made about the identity of ambiguous taxa that could compromise assessment of spatial and temporal trends.

Spatial and temporal trends in 14 AM metrics (table 10) were assessed. These metrics commonly are used either individually or in combination to infer stream condition (Rosenberg and Resh, 1993; Barbour and others, 1999). Metrics are largely based on richness, relative abundance, and ecological characteristics of individual taxa or groups of taxa. Taxa collected from park samples, and their associated ecological characteristics required for metric computation, are shown in appendix 1. PCA was used to assess correlations among AM metrics and was conducted separately for spatial and temporal datasets to determine correlations among AM metrics between 


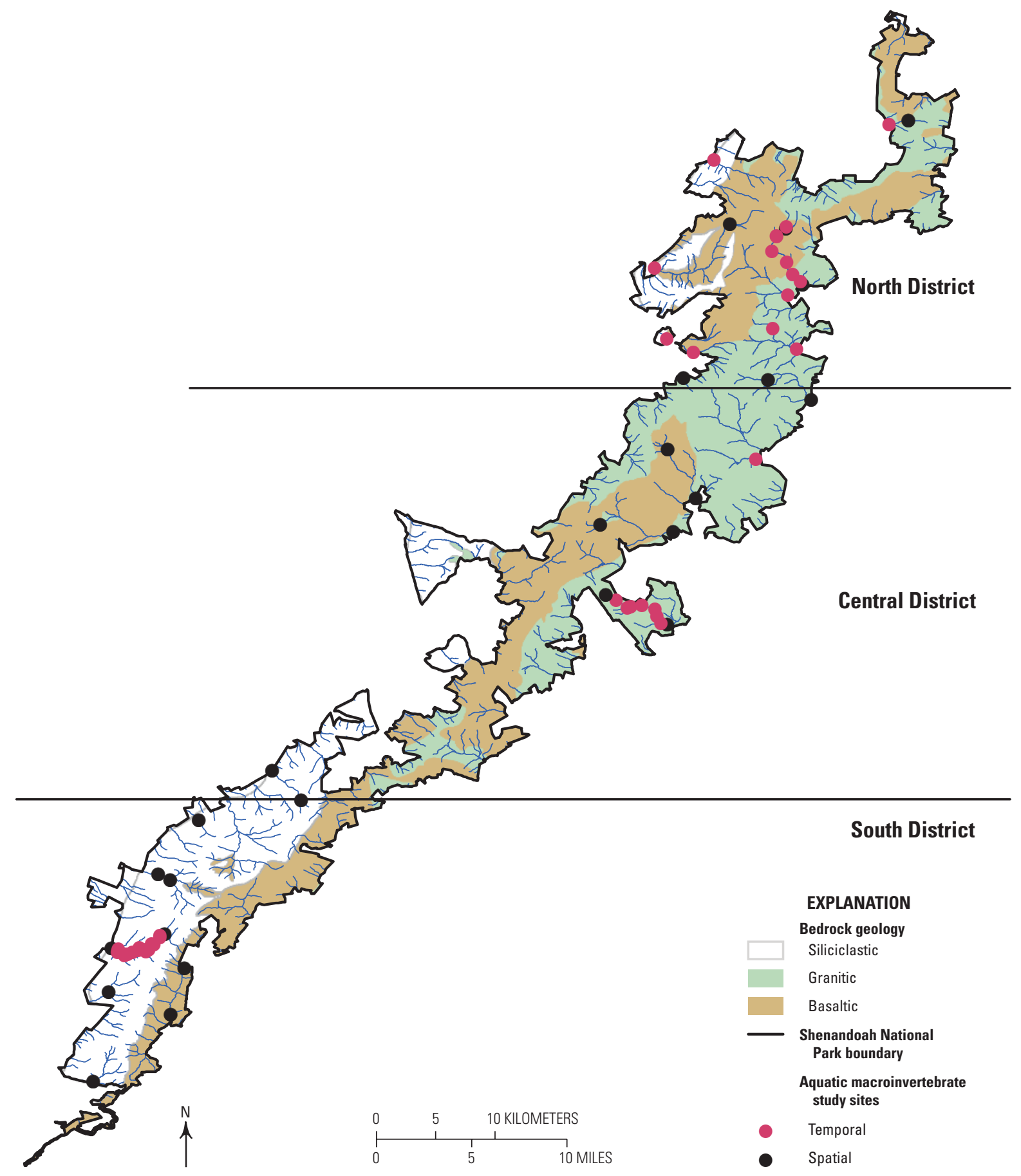

Figure 17. Macroinvertebrate sampling sites in Shenandoah National Park. Location of study area provided in figure 1. 


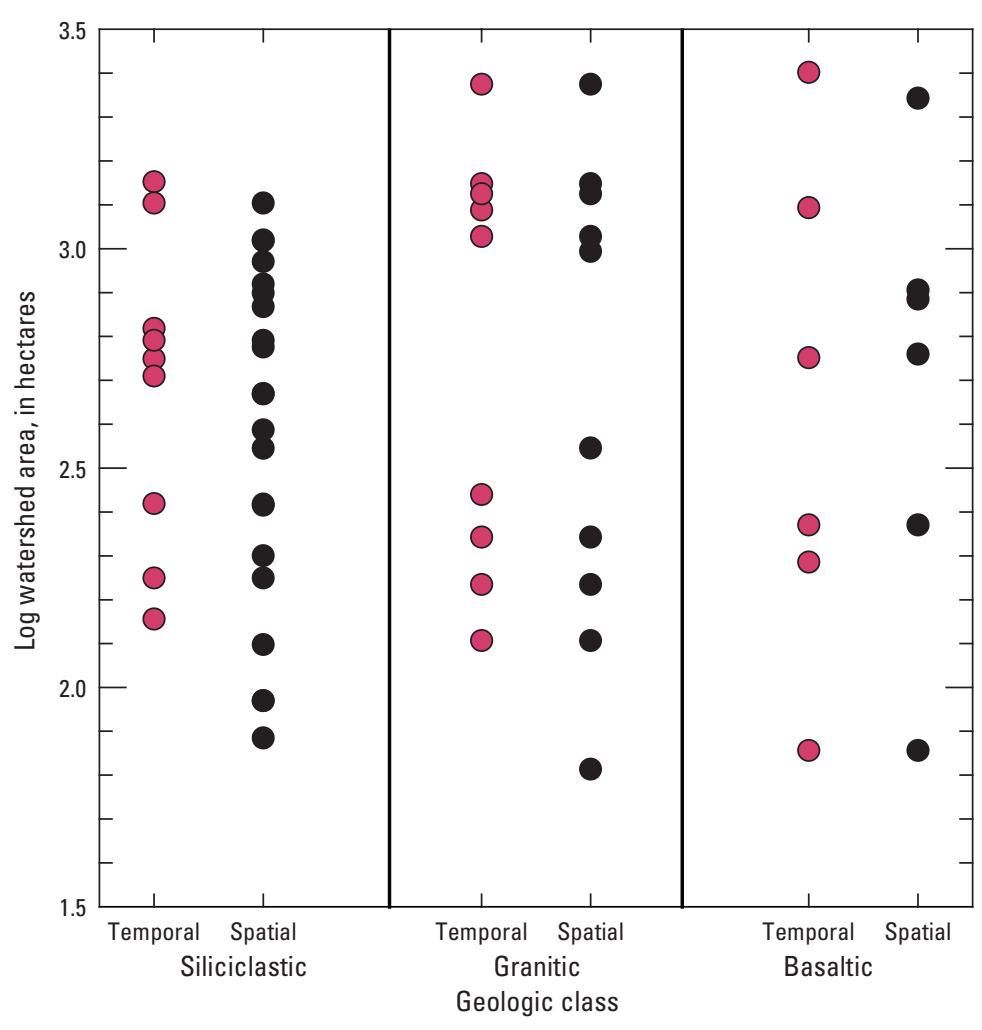

Figure 18. Watershed area of macroinvertebrate sampling sites used for temporal and spatial analyses, by geologic class.

sites within a year (spatial), as well as correlations among AM metric trend slopes (temporal). Prior to conducting PCA, the AM metrics were standardized using Z-scores so that differences in measurement scale among metrics would not skew PCA results (McCune and Grace, 2002).

For analysis of spatial patterns, general linear modeling (GLM) was used to assess the influence of landscape setting, determined by contributing watershed area and bedrock geology, on macroinvertebrate metric means. Geology (siliciclastic, granitic, and basaltic) was a class variable in the analyses, indicated by the dominant geology upstream of the sample site, and watershed area was a continuous variable; the interaction between geology and watershed area also was evaluated. An interactive backward selection process for model building was used, beginning with the full model, which considered geologic effects, watershed area and their interaction. Non-significant terms were then removed one at a time, beginning with the interaction term. For interaction terms that were found to be significant predictors of a metric $(p<0.10)$, the interaction was graphically evaluated to ensure the relation was not unduly influenced by outliers or points with high leverage. After the interaction term was evaluated, the same procedure was used to evaluate main effects. Finally, the relative importance of the predictor variables in the final model was evaluated using partial $\mathrm{R}^{2}$ statistics, which indicate the amount of variation in a metric explained by geology and watershed area.
Temporal trends were assessed for four distinct time periods consistent with those used for water-quality trend analysis. Analysis of temporal trends included three steps. First, linear regression was used to determine site-specific relations (regression slopes, $\beta$ ) between each of the 14 AM metrics and year for each of the four time periods. For metrics that were not normally distributed, the data were transformed prior to performing linear regressions. All AM metrics that were not normally distributed were proportion or percent metrics; therefore, the arcsine square-root transformation was used, because it often improves normality of proportion data (Sokal and Rohlf, 1995). No attempt was made to evaluate nonlinear or threshold models in these exploratory analyses.

Second, park-wide trends in each metric for each time period were evaluated using one-way $t$-tests. This analysis tested whether the mean trend slope was significantly different from zero (Sokal and Rohlf, 1995).

Third, the influence of geology and watershed area on temporal trends was assessed. This was accomplished using essentially the same interactive backward model selection procedure used to assess spatial patterns (described earlier), except that trend slopes were the response variables in the analysis. For metric-time period cases in which the best model included geology as a significant predictor of temporal trends, a one-sample $t$-test was conducted within each geology class to test whether the mean trend slope was significantly different than zero. For metric time-period cases where the best model included watershed area as a significant predictor, linear regressions of trend slopes on watershed area were conducted to determine the percentage of variation in trend slopes $\left(\mathrm{R}^{2}\right)$ explained by watershed area. Finally, for metric time-period cases in which the best model included the interaction between watershed area and geology as a significant predictor, linear regressions of trend slopes on watershed area were performed within each geology class.

\section{Aquatic Macroinvertebrate Community Characteristics}

The park's AM dataset used to assess spatial patterns among 54 sites in 1995 contained records of 53,665 individual AMs and 105 unique taxa. The park's AM dataset used to assess temporal trends among 24 sites between 1990 and 2009 contained records of 500,781 individual macroinvertebrates represented by 140 unique taxa. In terms of taxonomic composition, the abundance of individuals in the orders Ephemeroptera, Plecoptera, and Trichoptera, broadly considered the three most generally sensitive taxonomic orders, composed about half of the total abundance in the database, although relative abundance varied between about 40 and 65 percent over the years (fig. 19A). Relative abundance of individuals in the family Chironomidae, generally considered a group relatively tolerant to stress, represented, on average, about one-third of 
Table 8. Years in which samples were collected for 24 Long Term Ecological Monitoring sites used in temporal trend analysis. Site descriptions are provided in table 9.

[X, sample collected during year; - , sample not collected during year $]$

\begin{tabular}{|c|c|c|c|c|c|c|c|c|c|c|c|c|c|c|c|c|c|c|c|c|c|}
\hline \multirow[b]{2}{*}{$\begin{array}{c}\text { Site } \\
\text { identifier }\end{array}$} & \multirow{2}{*}{$\begin{array}{c}\text { Years } \\
\text { of } \\
\text { data }\end{array}$} & \multicolumn{20}{|c|}{ Year } \\
\hline & & 욤 & ळ్ & ซ్ & ஜூ & 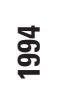 & 뇽 & ஜூ & ஓ् & ஓ̊ & 욤 & 유 & ర్రి & న్ న్ & గ్రి & 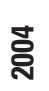 & 농 & 유 & 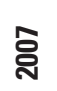 & 怘 & 응 \\
\hline $3 F 025$ & 11 & - & - & - & - & - & - & - & $\mathrm{X}$ & $\mathrm{X}$ & $X$ & $X$ & $\mathrm{X}$ & $X$ & $X$ & $X$ & - & $X$ & - & $X$ & X \\
\hline $3 F 103$ & 16 & $\mathrm{X}$ & $X$ & $\mathrm{X}$ & $\mathrm{X}$ & $\mathrm{X}$ & - & - & $\mathrm{X}$ & $X$ & $X$ & $X$ & $\mathrm{X}$ & $\mathrm{X}$ & $\mathrm{X}$ & $X$ & - & $X$ & - & $X$ & $\mathrm{X}$ \\
\hline $3 F 105$ & 10 & - & - & - & - & - & - & - & - & $X$ & $X$ & X & $\mathrm{X}$ & $X$ & $X$ & $X$ & - & X & - & $X$ & X \\
\hline $3 F 109$ & 10 & - & - & - & - & - & - & - & - & $\mathrm{X}$ & $X$ & $X$ & $\mathrm{X}$ & $X$ & $X$ & $\mathrm{X}$ & - & $X$ & - & $X$ & $X$ \\
\hline $3 F 123$ & 18 & $X$ & $\mathrm{X}$ & $X$ & $\mathrm{X}$ & $\mathrm{X}$ & $\mathrm{X}$ & $X$ & $\mathrm{X}$ & $\mathrm{X}$ & $X$ & $X$ & $X$ & $X$ & $X$ & $\mathrm{X}$ & - & $X$ & - & $X$ & X \\
\hline $3 F 143$ & 11 & - & - & - & - & - & - & - & - & $\mathrm{X}$ & $X$ & X & $\mathrm{X}$ & $X$ & $X$ & $X$ & - & $X$ & - & $X$ & X \\
\hline $3 F 271$ & 10 & - & - & - & - & - & - & - & - & $\mathrm{X}$ & X & $X$ & $\mathrm{X}$ & X & X & $X$ & - & $X$ & - & $X$ & X \\
\hline $3 F 300$ & 18 & $\mathrm{X}$ & $X$ & $X$ & $\mathrm{X}$ & $\mathrm{X}$ & X & $\mathrm{X}$ & $\mathrm{X}$ & $\mathrm{X}$ & X & X & $\mathrm{X}$ & $X$ & $X$ & $X$ & - & $X$ & - & $X$ & X \\
\hline $3 F 302$ & 16 & $\mathrm{X}$ & $X$ & $X$ & $\mathrm{X}$ & $X$ & - & - & $\mathrm{X}$ & $\mathrm{X}$ & X & $X$ & $\mathrm{X}$ & $X$ & X & $X$ & - & $X$ & - & $X$ & X \\
\hline 1F002 & 17 & $\mathrm{X}$ & $X$ & $\mathrm{X}$ & $\mathrm{X}$ & $\mathrm{X}$ & $X$ & - & $\mathrm{X}$ & $\mathrm{X}$ & $X$ & $X$ & $\mathrm{X}$ & $\mathrm{X}$ & $\mathrm{X}$ & $X$ & - & $X$ & - & $X$ & $\mathrm{X}$ \\
\hline 1F003 & 16 & $\mathrm{X}$ & $X$ & $X$ & $\mathrm{X}$ & - & - & X & $\mathrm{X}$ & $\mathrm{X}$ & X & $\mathrm{X}$ & $\mathrm{X}$ & $X$ & $X$ & $X$ & - & $X$ & - & $X$ & X \\
\hline $2 \mathrm{~F} 009$ & 16 & $\mathrm{X}$ & $X$ & $\mathrm{X}$ & $\mathrm{X}$ & $\mathrm{X}$ & $X$ & - & $\mathrm{X}$ & - & X & $X$ & $\mathrm{X}$ & $X$ & X & $\mathrm{X}$ & - & $X$ & - & $X$ & X \\
\hline $2 \mathrm{~F} 015$ & 16 & $\mathrm{X}$ & $X$ & $\mathrm{X}$ & $\mathrm{X}$ & $\mathrm{X}$ & $X$ & - & $\mathrm{X}$ & - & $X$ & $X$ & $\mathrm{X}$ & $\mathrm{X}$ & $\mathrm{X}$ & $X$ & - & $X$ & - & $X$ & $\mathrm{X}$ \\
\hline $2 \mathrm{~F} 072$ & 18 & $\mathrm{X}$ & $X$ & $\mathrm{X}$ & $\mathrm{X}$ & $\mathrm{X}$ & $X$ & $X$ & $X$ & $X$ & $X$ & $X$ & $\mathrm{X}$ & $X$ & $X$ & $X$ & - & $X$ & - & $X$ & $\mathrm{X}$ \\
\hline $2 \mathrm{~F} 090$ & 15 & $X$ & $\mathrm{X}$ & $\mathrm{X}$ & $\mathrm{X}$ & $X$ & - & - & $\mathrm{X}$ & - & $X$ & $X$ & $\mathrm{X}$ & $X$ & $X$ & $\mathrm{X}$ & - & $X$ & - & $X$ & X \\
\hline $2 \mathrm{~F} 131$ & 18 & $X$ & $\mathrm{X}$ & $X$ & $\mathrm{X}$ & $X$ & $X$ & $X$ & $\mathrm{X}$ & $\mathrm{X}$ & $X$ & $X$ & $\mathrm{X}$ & $X$ & $\mathrm{X}$ & $X$ & - & $X$ & - & $X$ & $\mathrm{X}$ \\
\hline $2 \mathrm{~F} 303$ & 12 & - & - & - & - & $\mathrm{X}$ & X & - & $\mathrm{X}$ & - & $X$ & X & $\mathrm{X}$ & $X$ & $X$ & $X$ & - & $X$ & - & $X$ & X \\
\hline 2F306 & 18 & $\mathrm{X}$ & $X$ & $\mathrm{X}$ & $\mathrm{X}$ & $\mathrm{X}$ & $X$ & $X$ & $\mathrm{X}$ & $\mathrm{X}$ & $X$ & $X$ & $\mathrm{X}$ & $\mathrm{X}$ & $\mathrm{X}$ & $X$ & - & $X$ & - & $X$ & $\mathrm{X}$ \\
\hline 1F118 & 15 & $\mathrm{X}$ & $X$ & $\mathrm{X}$ & $\mathrm{X}$ & $\mathrm{X}$ & - & - & $\mathrm{X}$ & - & $X$ & $X$ & $\mathrm{X}$ & $X$ & $\mathrm{X}$ & $X$ & - & $X$ & - & $X$ & $\mathrm{X}$ \\
\hline 1F308 & 18 & $\mathrm{X}$ & $X$ & $X$ & $\mathrm{X}$ & $\mathrm{X}$ & $X$ & $X$ & $\mathrm{X}$ & $\mathrm{X}$ & X & $X$ & $\mathrm{X}$ & $X$ & X & $\mathrm{X}$ & - & $X$ & - & $X$ & X \\
\hline 2F055 & 15 & $X$ & $X$ & $X$ & $\mathrm{X}$ & $X$ & - & - & $\mathrm{X}$ & - & $X$ & $X$ & $\mathrm{X}$ & $X$ & $\mathrm{X}$ & $X$ & - & $X$ & - & $X$ & X \\
\hline $2 \mathrm{~F} 253$ & 12 & - & - & - & - & - & X & X & - & $\mathrm{X}$ & X & $\mathrm{X}$ & $\mathrm{X}$ & $X$ & $X$ & $X$ & - & $X$ & - & $X$ & X \\
\hline $3 F 044$ & 11 & - & - & - & - & - & - & $X$ & - & $\mathrm{X}$ & X & $X$ & $\mathrm{X}$ & $X$ & X & $\mathrm{X}$ & - & $X$ & - & $X$ & X \\
\hline $3 F 084$ & 11 & - & - & - & - & - & - & $X$ & - & $\mathrm{X}$ & $X$ & $X$ & $X$ & $X$ & $X$ & $\mathrm{X}$ & - & $X$ & - & $X$ & X \\
\hline
\end{tabular}


Table 9. Site information, watershed area, predominant geology, and site elevation for sites used in analysis of temporal trends and spatial patterns in aquatic macroinvertebrates.

[ha, hectare; $\mathrm{m}$, meter]

\begin{tabular}{|c|c|c|c|c|c|}
\hline $\begin{array}{c}\text { Site } \\
\text { identifier }\end{array}$ & Site name & $\begin{array}{c}\text { Watershed } \\
\text { area (ha) }\end{array}$ & $\begin{array}{c}\text { Predominant } \\
\text { geology }\end{array}$ & $\begin{array}{l}\text { Elevation } \\
(\mathrm{m})\end{array}$ & $\begin{array}{c}\text { Analysis } \\
\text { performed }\end{array}$ \\
\hline $1 \mathrm{~F} 003$ & Piney River & 1,225 & Granitic & 366 & Temporal \\
\hline $1 \mathrm{~F} 118$ & Jeremy’s Run & 564 & Basaltic & 554 & Temporal \\
\hline $2 \mathrm{~F} 055$ & Rose River \& Hogcamp Branch & 193 & Basaltic & 800 & Temporal \\
\hline $2 \mathrm{~F} 090$ & Hazel River \& tributary & 275 & Granitic & 667 & Temporal \\
\hline $3 \mathrm{~F} 025$ & Madison Run & 1,420 & Siliciclastic & 430 & Temporal \\
\hline $3 \mathrm{~F} 044$ & Moormans River, North Fork & 1,240 & Basaltic & 498 & Temporal \\
\hline 3F084 & Moormans River, North Fork & 2,522 & Basaltic & 341 & Temporal \\
\hline $3 \mathrm{~F} 103$ & Twomile Run & 561 & Siliciclastic & 370 & Temporal \\
\hline $3 \mathrm{~F} 105$ & Lower Lewis Run & 262 & Siliciclastic & 444 & Temporal \\
\hline $3 \mathrm{~F} 109$ & Meadow Run & 657 & Siliciclastic & 511 & Temporal \\
\hline $3 \mathrm{~F} 271$ & White Oak Run & 512 & Siliciclastic & 447 & Temporal \\
\hline $3 \mathrm{~F} 302$ & Twomile Run & 143 & Siliciclastic & 506 & Temporal \\
\hline $2 \mathrm{~F} 072$ & Staunton River & 1,065 & Granitic & 316 & Temporal and spatial \\
\hline $1 \mathrm{~F} 002$ & Lands Run & 171 & Granitic & 517 & Temporal and spatial \\
\hline 1F308 & Piney River - Upper & 72 & Basaltic & 764 & Temporal and spatial \\
\hline $2 \mathrm{~F} 009$ & Whiteoak Canyon Run & 1,405 & Granitic & 343 & Temporal and spatial \\
\hline $2 \mathrm{~F} 015$ & Rose River \& Hogcamp Branch & 2,368 & Granitic & 341 & Temporal and spatial \\
\hline $2 \mathrm{~F} 131$ & Dry Run, N.F. & 220 & Granitic & 493 & Temporal and spatial \\
\hline $2 \mathrm{~F} 253$ & White Oak Canyon Run & 234 & Basaltic & 950 & Temporal and spatial \\
\hline $2 \mathrm{~F} 303$ & Hazel River & 1,333 & Granitic & 329 & Temporal and spatial \\
\hline $2 \mathrm{~F} 306$ & Staunton River & 128 & Granitic & 900 & Temporal and spatial \\
\hline $3 \mathrm{~F} 123$ & Paine Run & 1,270 & Siliciclastic & 425 & Temporal and spatial \\
\hline $3 F 143$ & Sawmill Run & 618 & Siliciclastic & 463 & Temporal and spatial \\
\hline $3 F 300$ & Paine Run & 177 & Siliciclastic & 557 & Temporal and spatial \\
\hline $1 \mathrm{~F} 001$ & Land's Run & 351 & Granitic & 360 & Spatial \\
\hline 1F005 & Piney River & 986 & Granitic & 409 & Spatial \\
\hline 1F006 & Jeremy’s Run & 2,202 & Basaltic & 285 & Spatial \\
\hline $1 \mathrm{~F} 030$ & Thornton River, North Fork & 1,832 & Granitic & 354 & Spatial \\
\hline $1 \mathrm{~F} 137$ & Piney River & 805 & Basaltic & 453 & Spatial \\
\hline $1 \mathrm{~F} 138$ & Piney River & 575 & Basaltic & 576 & Spatial \\
\hline $1 F 316$ & Thornton River, South Fork & 348 & Granitic & 436 & Spatial \\
\hline $1 \mathrm{~F} 317$ & Overall Run & 1,043 & Siliciclastic & 213 & Spatial \\
\hline $2 \mathrm{~F} 035$ & Thornton River, South Fork & 1,658 & Granitic & 292 & Spatial \\
\hline $2 \mathrm{~F} 073$ & Staunton River & 776 & Granitic & 412 & Spatial \\
\hline 2F074 & Staunton River & 732 & Granitic & 462 & Spatial \\
\hline $2 \mathrm{~F} 075$ & Staunton River & 511 & Granitic & 619 & Spatial \\
\hline 2F076 & Staunton River & 245 & Granitic & 753 & Spatial \\
\hline 2F096 & Pass Run & 768 & Basaltic & 408 & Spatial \\
\hline $2 \mathrm{~F} 252$ & Brokenback Run & 1,005 & Granitic & 338 & Spatial \\
\hline $2 F 315$ & Pass Run & 1,076 & Basaltic & 335 & Spatial \\
\hline $3 F 124$ & Paine Run & 933 & Siliciclastic & 447 & Spatial \\
\hline $3 \mathrm{~F} 125$ & Paine Run & 793 & Siliciclastic & 458 & Spatial \\
\hline NPI02 & Piney River & 390 & Basaltic & 673 & Spatial \\
\hline NPR1 & Paine Run & 830 & Siliciclastic & 458 & Spatial \\
\hline NPR3 & Paine Run & 467 & Siliciclastic & 483 & Spatial \\
\hline
\end{tabular}


Table 9. Site information, watershed area, predominant geology, and site elevation for sites used in analysis of temporal trends and spatial patterns in aquatic macroinvertebrates._- Continued

[ha, hectare; $\mathrm{m}$, meter]

\begin{tabular}{llrlrl}
\hline $\begin{array}{c}\text { Site } \\
\text { identifier }\end{array}$ & \multicolumn{1}{c}{ Site name } & $\begin{array}{c}\text { Watershed } \\
\text { area (ha) }\end{array}$ & $\begin{array}{c}\text { Predominant } \\
\text { geology }\end{array}$ & $\begin{array}{c}\text { Elevation } \\
\text { (m) }\end{array}$ & $\begin{array}{c}\text { Analysis } \\
\text { performed }\end{array}$ \\
\hline PI02 & Piney River & 93 & Granitic & 393 & Spatial \\
PI26 & Piney River & 145 & Basaltic & 779 & Spatial \\
PI29 & Piney River & 65 & Basaltic & 692 & Spatial \\
PR04 & Paine Run & 1,046 & Siliciclastic & 438 & Spatial \\
PR05 & Paine Run & 93 & Siliciclastic & 450 & Spatial \\
PR09 & Paine Run & 77 & Siliciclastic & 463 & Spatial \\
PR15 & Paine Run & 737 & Siliciclastic & 471 & Spatial \\
PR18 & Paine Run & 93 & Siliciclastic & 485 & Spatial \\
PR19 & Paine Run & 596 & Siliciclastic & 483 & Spatial \\
PR21 & Paine Run & 125 & Siliciclastic & 487 & Spatial \\
PR25 & Paine Run & 466 & Siliciclastic & 485 & Spatial \\
PR26 & Paine Run & 386 & Siliciclastic & 507 & Spatial \\
PR28 & Paine Run & 351 & Siliciclastic & 509 & Spatial \\
PR29 & Paine Run & 262 & Siliciclastic & 534 & Spatial \\
PR31 & Paine Run & 260 & Siliciclastic & 535 & Spatial \\
PR37 & Paine Run & 200 & Siliciclastic & 439 & Spatial \\
SR04 & Staunton River & 181 & Granitic & 355 & Spatial \\
SR09 & Staunton River & 624 & Granitic & 557 & Spatial \\
SR11 & Staunton River & 102 & Granitic & 652 & Spatial \\
SR13 & Staunton River & 49 & Granitic & 670 & Spatial \\
\hline
\end{tabular}

Table 10. Description of the 14 macroinvertebrate community metrics evaluated.

[\% , percent; <, less than; PTV, pollution tolerance value; SCI, stream condition index]

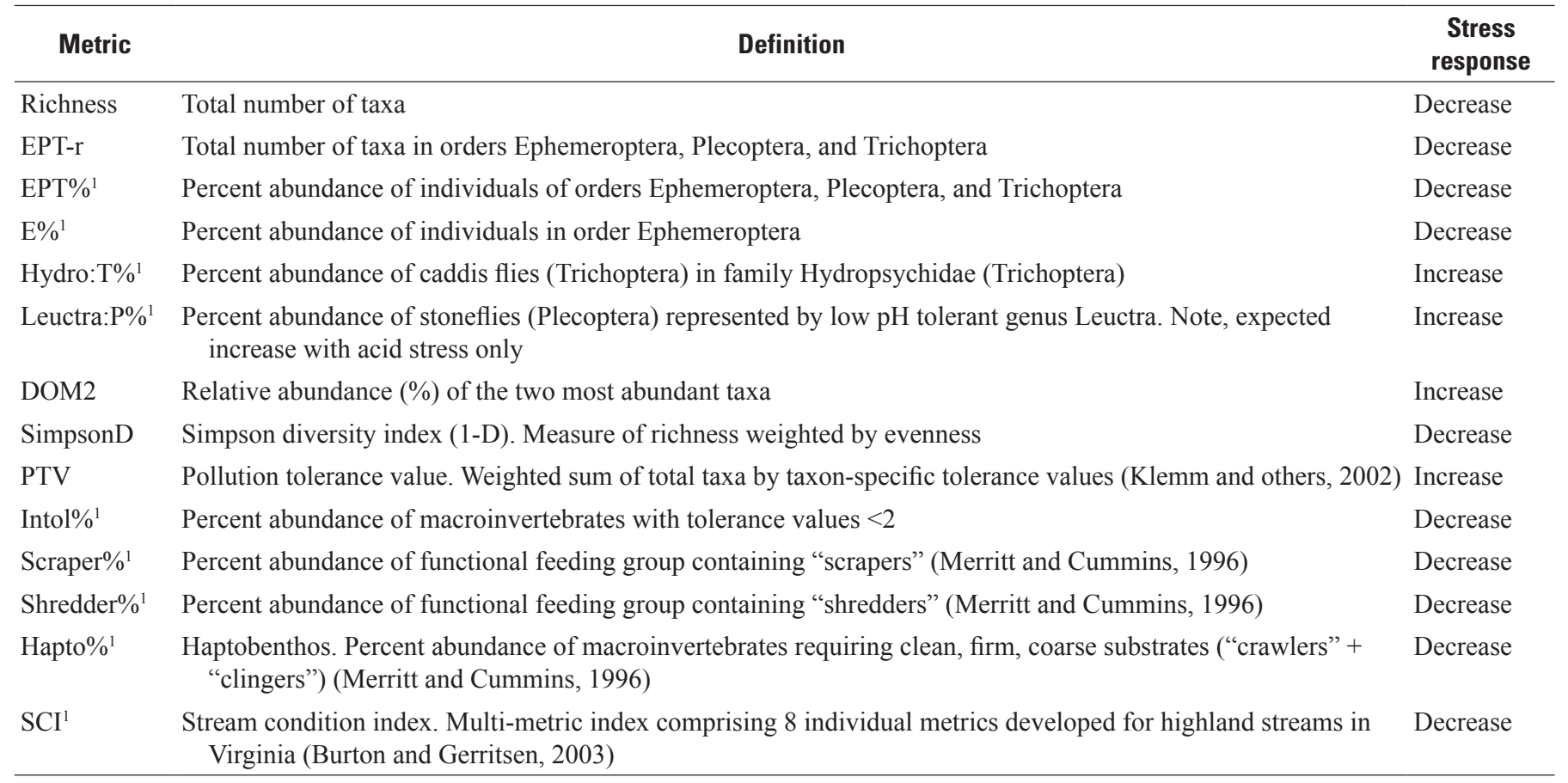

${ }^{1}$ Metric was arcsine square-root transformed prior to analyses. 


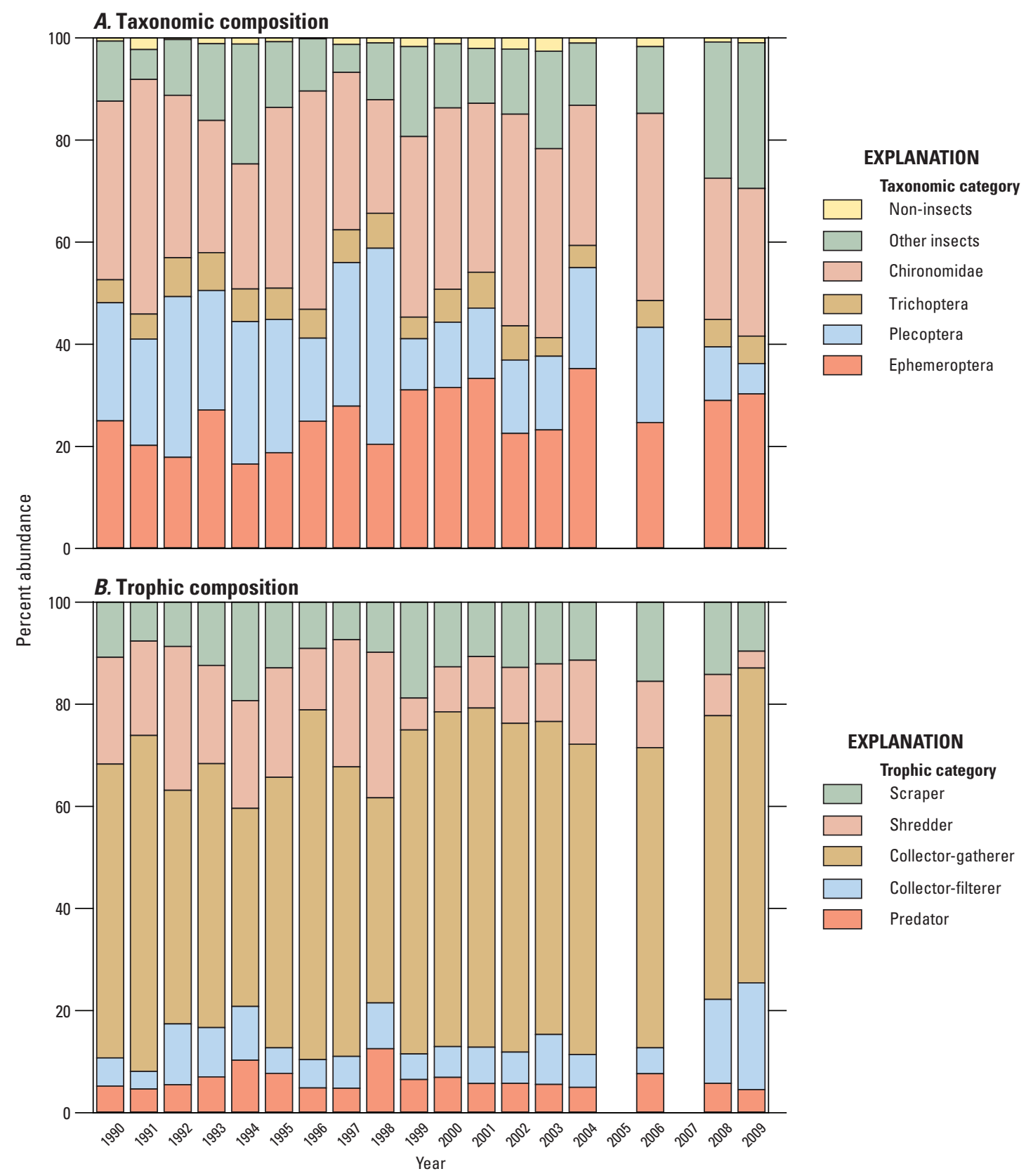

Figure 19. $A$, Taxonomic and $B$, trophic composition of aquatic macroinvertebrates by sample year computed from samples collected from 24 sites. 
the total AM abundance. Although it is difficult to make direct comparisons between patterns of taxonomic composition observed in the park and other datasets from around the region because of differences in sampling methods, the relative abundances of sensitive and tolerant taxonomic groups observed in the park suggest that, overall, streams in the park are representative of high-quality headwater streams in the region. Other insect taxa (orders Hemiptera, Megaloptera, Odonata, and non-midge Diptera) also represented a significant taxonomic component (mean $=15$ percent), whereas non-insect taxa were a relatively minor component of the AM fauna in terms of abundance (fig. 19A).

Stream communities are structured by the source and quality of food and nutrient inputs entering streams. These inputs are linked to characteristics of the stream and contributing watershed, such as stream width and riparian shading, that change in predictable ways as streams progress from headwaters to mouth (Vannote and others, 1980). Metrics that describe trophic composition are often included in stream condition assessments because they confer information regarding food web structure. That structure may be disrupted by natural and anthropogenic disturbances, including watershed deforestation, pest-induced changes in forest composition, and nutrient enrichment through land use or atmospheric deposition (Likens, 2010). In terms of trophic composition, collectors (comprising collector-filterer and collector-gatherer trophic groups) were the dominant trophic group, representing slightly more than half of the total number of individuals collected over the 20 years at the 24 sites (fig. 19B). Of the total annual AM abundance, (on average) shredders composed about 17 percent, scrapers 11 percent, and predators about 9 percent (fig. 19B). This distribution of trophic groups is fairly typical for larger (2nd and 3rd order) headwater streams (Haggerty and others, 2002; Heino 2005).

PCA results indicated that there were strong correlations among AM metric site scores among sites (spatial dataset; table 11), and among AM metric trend slopes (temporal dataset; table 11). Over 83 percent of the within-year spatial variation was explained by three PCA gradients, and nearly 77 percent of the temporal variation in AM metrics was explained by three PCA gradients (table 11). High correlations among the 14 metrics evaluated are not surprising, given that some groups of metrics are proportional and related (for example, Shredder\% and Scraper\%), and other metrics are simply subsets (for example, Richness and EPT-r). Distinct differences in the identity of correlated metrics between the spatial and temporal datasets, however, indicate that the factors that structure spatial variation are different than the factors that drive temporal trends. For example, spatial variation in the functional metrics Shredder\% and Scraper\% were highly correlated with the integrated stream condition index (SCI) and E\% (table 11), whereas temporal changes in those metrics were uncorrelated (table 11). For this reason, spatial and temporal trend analyses were conducted on the full complement of metrics.

Table 11. Factor loadings from principal components analysis of aquatic macroinvertebrate metrics for data used in the spatial and temporal analyses of aquatic macroinvertebrate communities.

[ns, correlation not significant for $\alpha=0.10$; SCI, stream condition index; PTV, pollution tolerance value]

\begin{tabular}{|c|c|c|c|c|c|c|c|}
\hline \multicolumn{4}{|c|}{ Spatial dataset } & \multicolumn{4}{|c|}{ Temporal dataset } \\
\hline Metric & $\begin{array}{c}\text { Principal } \\
\text { component } 1\end{array}$ & $\begin{array}{c}\text { Principal } \\
\text { component } 2\end{array}$ & $\begin{array}{c}\text { Principal } \\
\text { component } 3\end{array}$ & Metric & $\begin{array}{c}\text { Principal } \\
\text { component } 1\end{array}$ & $\begin{array}{c}\text { Principal } \\
\text { component } 2\end{array}$ & $\begin{array}{c}\text { Principal } \\
\text { component } 3\end{array}$ \\
\hline $\mathrm{SCI}$ & 0.936 & $\mathrm{~ns}$ & ns & PTV & -0.943 & ns & ns \\
\hline DOM2 & -0.924 & $\mathrm{~ns}$ & $\mathrm{~ns}$ & Intol $\%$ & 0.92 & ns & $\mathrm{ns}$ \\
\hline SimpsonD & 0.917 & $\mathrm{~ns}$ & ns & ЕРТ\% & 0.911 & ns & $\mathrm{ns}$ \\
\hline Leuctra:P\% & -0.847 & ns & ns & Hapto\% & 0.842 & ns & ns \\
\hline $\mathrm{E} \%$ & 0.834 & ns & ns & SCI & 0.825 & ns & $\mathrm{ns}$ \\
\hline Scraper $\%$ & 0.812 & ns & ns & SimpsonD & 0.791 & ns & ns \\
\hline Shredder $\%$ & -0.748 & $\mathrm{~ns}$ & ns & DOM2 & -0.707 & ns & ns \\
\hline Hapto $\%$ & ns & 0.778 & ns & $\mathrm{E} \%$ & 0.642 & ns & ns \\
\hline PTV & ns & -0.938 & ns & Shredder $\%$ & ns & -0.93 & ns \\
\hline Intol $\%$ & ns & 0.906 & ns & Leuctra:P\% & ns & -0.752 & ns \\
\hline ЕРТ\% & ns & 0.865 & ns & Scraper $\%$ & ns & 0.532 & ns \\
\hline Richness & ns & ns & 0.93 & Richness & ns & ns & 0.928 \\
\hline EPT-r & ns & $\mathrm{ns}$ & 0.915 & EPT-r & $\mathrm{ns}$ & ns & 0.884 \\
\hline Hydro:T\% & $\mathrm{ns}$ & $\mathrm{ns}$ & ns & Hydro:T\% & $\mathrm{ns}$ & $\mathrm{ns}$ & -0.533 \\
\hline Variance explained & 40.51 & 26.36 & 16.17 & Variance explained & 41.84 & 19.07 & 16.02 \\
\hline
\end{tabular}




\section{Spatial Patterns in Aquatic Macroinvertebrates}

A large fraction of spatial variation in AM metrics derived from samples collected in 1995 was explained by geology and watershed area (table 12). Of the 14 metrics assessed, 13 showed significant relations with one or both landscape predictors. Only the metric Hydro:T\% showed no relation with either watershed area or geology. The amount of variation explained by these two variables was substantial, ranging from weak relations such as EPT\%, for which less than 15 percent of total variation was explained, to very strong relations such as Shredder\%, for which nearly 80 percent of the total spatial variation was explained by geology and watershed area (table 12).

In general, geology was a stronger predictor than watershed area for most standard metrics (those not excluding Leuctra). Geology was a significant predictor of 13 metrics, with 6 metrics showing significant relations with geology alone, 6 metrics showing significant but independent (that is, no interaction between geology and watershed area) relations with geology and watershed area, and 1 metric significantly

Table 12. Partial coefficients of determination (partial $R^{2}$ ) for variables found to be statistically significant predictors $(p<0.05)$ for each metric, and overall model $R^{2}$, from interactive stepwise general linear modeling used to assess the effects of geology and watershed area on spatial variation in macroinvertebrate metrics.

[NI, not interpretable (main effects not interpretable when interactions are significant); ns, not significant; $\mathrm{R}^{2}$, coefficient of determination; PTV, pollution tolerance value; $\mathrm{SCI}$, stream condition index]

\begin{tabular}{lcccc}
\hline \multirow{2}{*}{ Metric } & \multicolumn{3}{c}{ Partial R } & Model \\
\cline { 2 - 4 } & Area & Geology & $\begin{array}{c}\text { Area } \times \\
\text { geology }\end{array}$ & R $^{2}$ \\
\hline Richness & 0.159 & 0.316 & ns & 0.475 \\
EPT-r & 0.179 & 0.316 & ns & 0.495 \\
EPT\% & ns & 0.145 & ns & 0.145 \\
EPT\% (without Leuctra) & ns & 0.402 & ns & 0.402 \\
E\% & ns & 0.445 & ns & 0.445 \\
Hydro:T\% & ns & ns & ns & 0 \\
Leuctra:P\% & ns & 0.318 & ns & 0.318 \\
DOM2 & ns & 0.636 & ns & 0.636 \\
SimpsonD & ns & 0.64 & ns & 0.64 \\
PTV & 0.115 & 0.207 & ns & 0.322 \\
PTV (without Leuctra) & 0.153 & 0.229 & ns & 0.382 \\
Intol\% & 0.196 & 0.136 & ns & 0.332 \\
Intol\% (without Leuctra) & 0.146 & 0.382 & ns & 0.528 \\
Scraper\% & ns & 0.579 & ns & 0.579 \\
Shredder\% & NI & NI & 0.138 & 0.783 \\
Shredder\% (without Leuctra) & 0.200 & ns & ns & 0.200 \\
Hapto\% & 0.121 & 0.172 & ns & 0.293 \\
SCI & 0.091 & 0.583 & ns & 0.674 \\
\hline
\end{tabular}

influenced by the interaction between geology and watershed area (table 12). The amount of variation in AM metrics explained by geology ranged from 14 percent for Intol $\%$ to 64 percent for SimpsonD (table 12). In contrast, watershed area was a significant predictor for only seven AM metrics, and in only one case (Intol\%) was it found to be more important than geology (table 12).

The observation that geology was a stronger predictor of AM community metrics is in contrast to what Snyder and others (2013) found when evaluating the importance of headwater streams in the park, where watershed area was found to be more important than geology for predicting the same set of metrics. In that assessment, however, small headwater streams $(<100$-hectare drainage areas) and perennial springs were included, whereas this analysis included long-term AM sampling in a small fraction of sites with watershed areas less than 100 hectares (ha). These differences between the two studies suggest a non-linear, bimodal relation between AM metrics and watershed area, wherein relatively large changes in AM communities occur as the contributing watershed area decreases to less than 100 ha. Snyder and others (2013) hypothesized that the reduced stream condition inferred from AM metrics in headwater areas was due to the increased likelihood of flow disturbance (especially droughts) in smaller watersheds.

The observed relations between geology and AM assemblage structure suggests a strong influence of water quality on $\mathrm{AM}$ assemblage structure, because $\mathrm{ANC}$ and $\mathrm{pH}$ have shown to be strongly tied to watershed geology in the park by this report and others (Herlihy and others, 1993; Cosby and others, 2006; Snyder and others, 2006). In general, the relations between most AM metrics and geology suggest that stream condition was poorer in siliciclastic watersheds where acidity was highest because of the low buffering capacity of rocks and soils in this geology type (Cosby and others, 2006). For example, most macroinvertebrate metrics expected to decline with stress (Richness, EPT-r, SimpsonD, E\%, Hapto, SCI, and Scraper\%) were lower in siliciclastic watersheds, and metrics expected to increase with stress (DOM2) were higher in siliciclastic watersheds (fig. 20). In addition, the Leuctra:P\% metric, which was adopted by the park's managers because of the known tolerance of the stonefly genus Leuctra to acidity (Kimmel and others, 1985; Fjellheim and Raddum, 1990), also showed a pattern that suggests acid stress was most pronounced in siliciclastic watersheds. Specifically, a greater proportion of Leuctra was present in siliciclastic watersheds than in others (fig. 20).

In contrast to the prevailing pattern, three AM metricsEPT\%, Intol\%, and pollution tolerance value (PTV)—showed the opposite pattern in metric scores, thereby suggesting that stream condition was better at sites in siliciclastic watersheds than in others. Both EPT\% and Intol\%, metrics generally expected to decline with stress, were highest in siliciclastic watersheds; moreover, PTV, a metric typically expected to increase with stress, was lowest in siliciclastic watersheds (fig. 20). These three metrics deviate from the prevailing pattern because of the overwhelming influence of a single taxon, the stonefly (Leuctra sp) and its relative sensitivity to different stressors. 

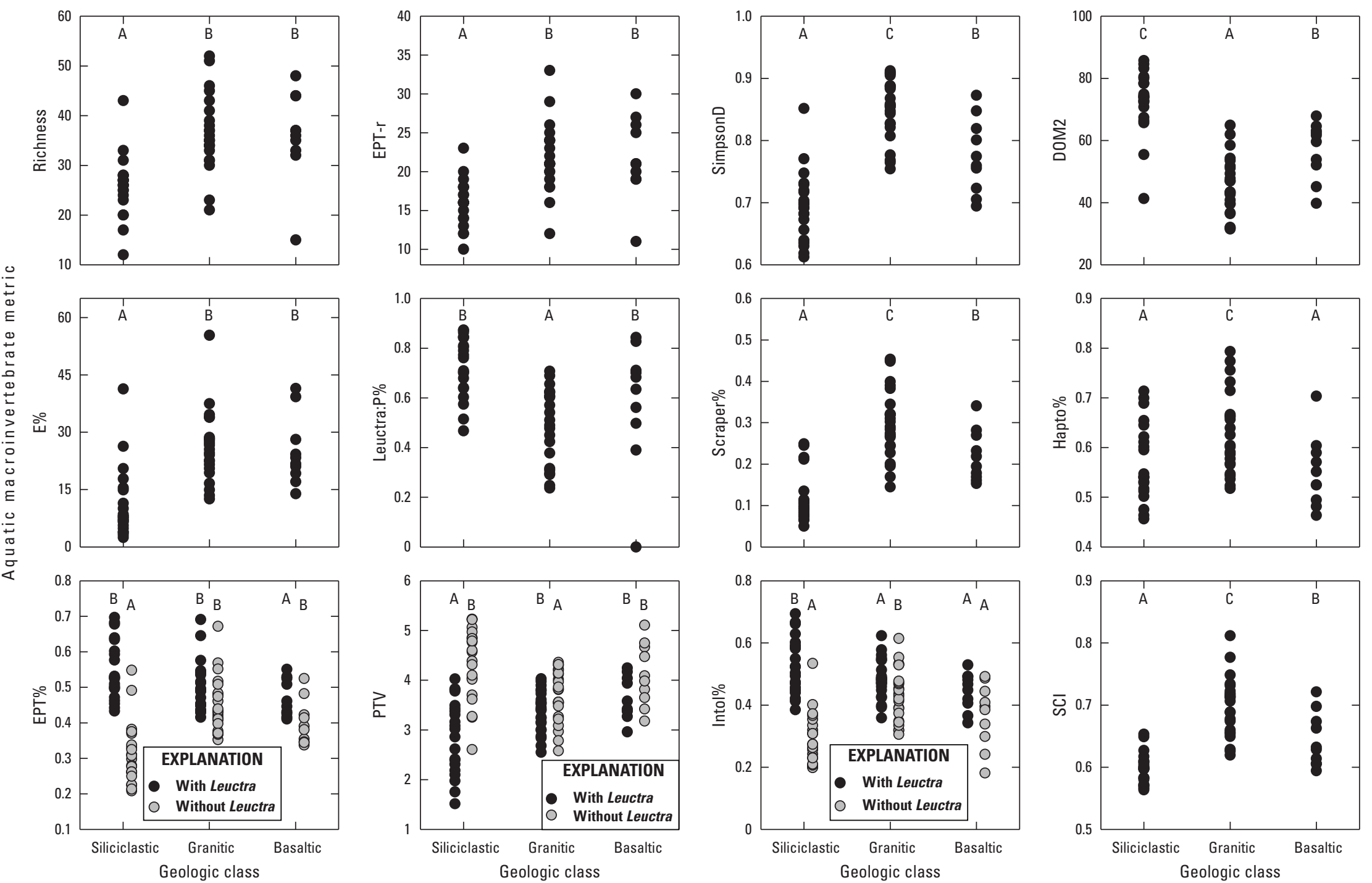

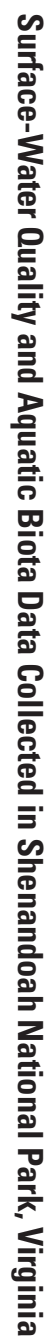

Figure 20. Aquatic macroinvertebrate metric values by geologic class for 12 metrics significantly influenced by geology. Letters at the top of each graph refer to the results of Tukey's multiple range tests for differences in group means (means for groups with the same letter are not significantly different from each other at $\alpha=0.05$ ). The raw (untransformed) data were plotted but statistical modeling was conducted on transformed data for metrics with non-normal distributions. 
Although Leuctra is tolerant to acidic conditions (Kimmel and others, 1985; Fjellheim and Raddum, 1990), it is widely considered to be highly sensitive to anthropogenic stress in general - the tolerance value for Leuctra is zero (appendix 1), which is the most sensitive assignment possible on the $0-10$ scale. Additionally, Leuctra is one of the most stenothermic genera of stonefly taxa, requiring a relatively narrow range of cool or cold water to complete their life cycle, and has been implicated as particularly vulnerable to warming water temperatures (Sweeney and others, 1992; Fochetti and Tierno De Figueroa, 2008; Tierno de Figueroa and others, 2010). Tolerance values were originally derived and modified from the seminal work by Lenat (1993) that based tolerance values on taxon-specific abundances across a water-quality gradient in North Carolina streams. These values, with regional modifications, are widely used in AM multimetric indices used to infer stream condition throughout North America (Barbour and others, 1999; Klemm and others, 2002; Burton and Gerritsen, 2003) and have been adopted by the park's management. Although Lenat (1993) does not describe the types of water-quality issues represented in the North Carolina state database, it is likely that the predominant stressors were sediments and chemical pollutants associated with
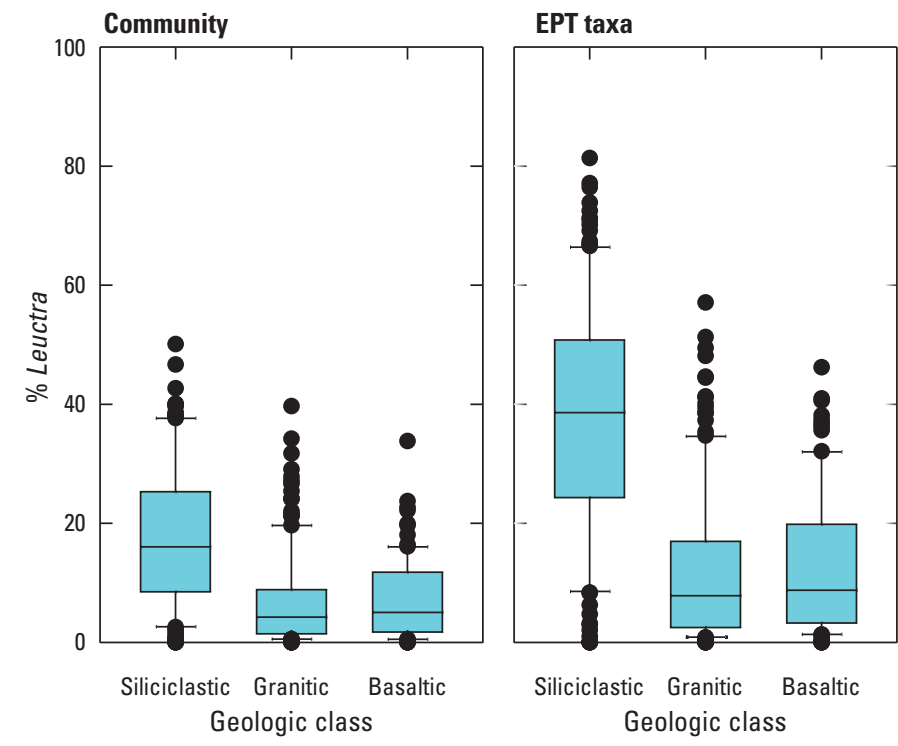

industrial and municipal wastewater as well as runoff from urban and agricultural development. High-elevation watersheds vulnerable to acidic deposition were probably not well represented, and consequently, it is unlikely that acidity was a major water-quality issue in the streams used to compute tolerance values. In this study, taxon-specific tolerance values were used to compute the metric PTV directly and identify intolerant taxa for computing the Intol\% metric (see table 10 ). Therefore, in regions where stream acidification is an important issue, it may be inappropriate and counterproductive to include the acid-tolerant taxa Leuctra in these AM metrics, which are designed to be indicative of general stream condition, especially if Leuctra is a numerically abundant taxon.

In the park, Leuctra was the second most abundant taxon collected. More than 55,000 Leuctra individuals out of a nearly 501,000 total specimens ( $>10$ percent) were collected at the 24 LTEM sites over the 20 -year monitoring period. Only individuals of the family Chironomidae were more abundant, and the family Chironomidae comprises more than a dozen individual genera in the park. Moreover, Leuctra composed a significant fraction of the EPT and intolerant taxa assemblages in the park, and the acid-tolerant genus was more abundant in siliciclastic watersheds than in others (fig. 21). Thus, given its

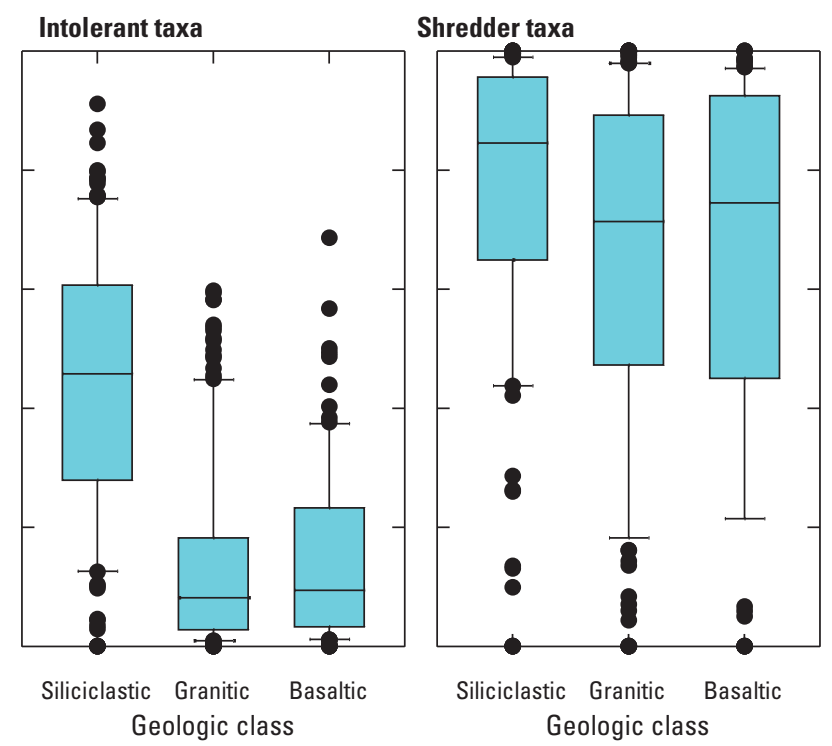

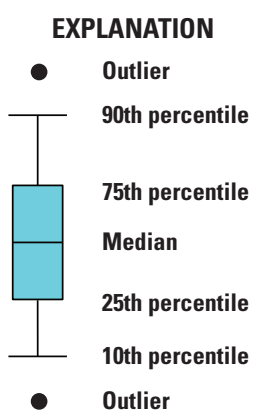

Figure 21. Percent abundance of Leuctra relative to the overall community, the Ephemeroptera, Plecoptera, and Trichoptera (EPT) assemblage, the intolerant taxa assemblage, and the shredder assemblage (right) by watershed type. Boxplots report the median (black line within boxes), the 25th and 75th percentiles (limits of box), the 10th and 90th percentiles (limits of error bars), and all outliers (points outside the 10th and 90th percentiles) as points. 
numerical abundance, it is clear that considering the acidtolerant genus Leuctra, a sensitive taxa based on its tolerance value, has the potential to greatly confound interpretations of trends in ecological condition.

Based on these findings, Leuctra was removed from the calculations of EPT\%, Intol\%, and PTV metrics and spatial patterns were reevaluated. In all three cases, the strength of the relations between geology and AM metrics increased (table 12), indicating that the Leuctra-adjusted metrics more closely reflected geologically-induced variation in water quality. Moreover, after removing Leuctra, these metrics were consistent with the prevailing pattern observed in the other metrics. That is, metric scores indicated that stream condition was poorest in siliciclastic watersheds (fig. 20). Taken together, the spatial patterns in AM metric scores correspond well to geologically-induced gradients in acidity, and to previously reported relations between acidity and aquatic macroinvertebrates (Kimmel and others, 1985; Griffith and others, 1995; Bowman and others, 2006).

Observed spatial relations between AM assemblage structure and geology were not entirely consistent with an acidity gradient. Specifically, although AM metric scores in siliciclastic watersheds, which have the lowest mean $\mathrm{pH}$ and ANC, were always poorest, AM metric scores in basaltic watersheds tended to be worse than scores in granitic watersheds (fig. 20), even though mean $\mathrm{pH}$ and $\mathrm{ANC}$ are typically higher in basaltic than in granitic watersheds, as demonstrated in this study and by Cosby and others (2006). Spatial patterns in AM metrics correlate better with total $\mathrm{SO}_{4}^{2-}$ concentrations than with $\mathrm{pH}$ and $\mathrm{ANC}$. Mean $\mathrm{SO}_{4}^{2-}$ concentrations were highest in siliciclastic watersheds, followed by basaltic and then granitic watersheds, an effect also documented by Cosby and others (2006) and Snyder and others (2013). Although high levels of sulfate salts are known to cause osmoregulation problems and toxicity in freshwater macroinvertebrates (Soucek, 2007), streams in the park are low-ionic strength waters having specific conductance values typically ranging between 18 and 50 microsiemens per centimeter $(\mu \mathrm{S} / \mathrm{cm})$; consequently, $\mathrm{SO}_{4}{ }^{2-}$ concentrations are not toxic at observed levels.

Sulfate is the primary anion responsible for acidification in mid-Atlantic region streams (Herlihy and others, 1993). The observation that $\mathrm{pH}$ and $\mathrm{ANC}$ are higher in basaltic watersheds than granitic watersheds, despite greater $\mathrm{SO}_{4}^{2-}$ concentrations, suggests that the concentrations of base cations (calcium, magnesium, sodium, and potassium) in basaltic watersheds are sufficient to neutralize the effect of the increased $\mathrm{SO}_{4}{ }^{2-}$, at least on average. Based on these observations, it is hypothesized that, although average $\mathrm{pH}$ and $\mathrm{ANC}$ values are higher in basaltic watersheds, the higher $\mathrm{SO}_{4}{ }^{2-}$ concentrations in basaltic watersheds lead to acidification levels greater than in granitic watersheds during some biologically important times such as storm events. In this case, although mean $\mathrm{ANC}$ and $\mathrm{pH}$ might be lower in granitic watersheds, minimum $\mathrm{pH}$ and $\mathrm{ANC}$ would be expected to be lower in basaltic watersheds, and these most extreme conditions may be more important than average conditions to AM populations. A more detailed analysis of storm-event water-quality patterns would be required to test this hypothesis. Although data for such an analysis are available, the analysis was beyond the scope of the current effort.

In addition to geology, watershed area was found to be a significant predictor of spatial variation in six AM metrics, although the relation was relatively weak in all cases (partial $\mathrm{R}^{2}<0.20$, table 12). The two richness metrics (Richness and EPT-r) both increased with watershed area (fig. 22). This pattern is not surprising and generally conforms to patterns observed by others, whereby macroinvertebrate richness generally increases from headwaters to mid-reach sized streams (Clarke and others, 2008, and references therein).

Spatial patterns in PTV, Intol\%, Hapto\%, and SCI suggest stream condition was better in smaller watersheds than larger watersheds. Specifically, PTV, a metric generally expected to increase with stream-condition degradation, increased with watershed area; in contrast, Intol\%, Hapto\%, and SCI, metrics expected to decline with stream-condition degradation, all decreased with watershed area (fig. 22). Unlike the case for watershed geology, the relation between the Intol\% metric and watershed area remained essentially unchanged after removing Leuctra (table 12). Once again, this is the opposite of what Snyder and others (2013) found for these four metrics in their comparison of small headwater streams to larger streams. In that study, the authors found that patterns for these same four AM metrics suggested that stream condition improved as watershed area increased. This discrepancy suggests a non-linear and possibly bimodal relation between watershed area and many AM community metrics, whereby the relation changes as contributing watershed area declines to less than 100 ha. In addition, although all six of these metrics showed significant relations with geology (fig. 20), the fact that the interaction between watershed area and geology was not a significant predictor for any of them suggests that changes in AM metrics with watershed area were probably not associated with corresponding changes in water quality. Based on these factors, it is hypothesized that the weak relations between the four non-richness metrics of stream condition and watershed area observed from this analysis are probably coincidental, relating more to natural changes in component taxa habitat preferences with changing watershed area than to some form of degradation of habitat in larger watersheds. These results emphasize the need to account for natural variation in physical factors such as watershed area when interpreting bioassessment results.

Spatial variation in one metric, Shredder\%, was related to the interaction between watershed area and geology (table 12). Shredder $\%$ showed a highly significant decline with watershed area in siliciclastic watersheds, a weak but significant increase with watershed area in granitic watersheds, and no relation with watershed area in basaltic watersheds (fig. 23A). The relation observed in siliciclastic watersheds is consistent with what is typically expected in unperturbed watersheds, in that shredders are typically most abundant in headwater areas where streams are narrow, leaf inputs are high, and light levels are low, and gradually decline as streams widen (Vannote and others, 1980; Wohl and others, 1995). 

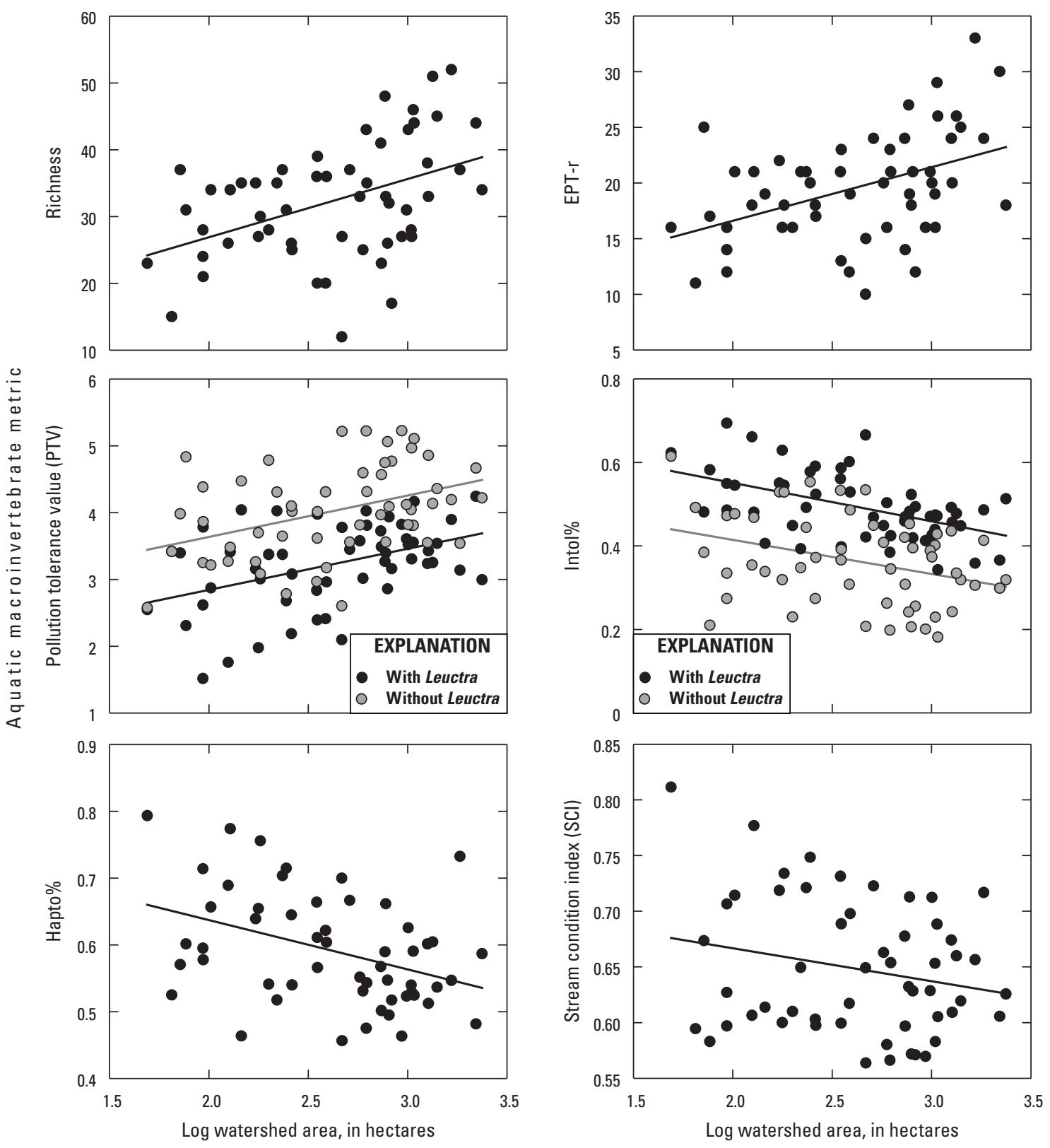

Figure 22. Relations between aquatic macroinvertebrate (AM) metrics and watershed area for the six metrics significantly influenced by watershed area.

The Shredder $\%$ metric was unduly influenced by the acidtolerant stonefly, Leuctra, as with PTV, Intol\% and EPT\% metrics discussed above. Leuctra was the dominant shredder taxon in the park, composing as much as 100 percent of the shredder assemblage in some samples. As with the other three metrics, the relative abundance of Leuctra in the shredder assemblage was greatest in siliciclastic watersheds (fig. 21). When Leuctra was removed and the Shredder\% metric recomputed, geology was no longer a significant predictor of Shredder\% (table 12), and the relation between Shredder $\%$ and watershed area reflected the expected pattern of gradual decline in Shredder\% with watershed area for all geology types (fig. 23B).

\section{Temporal Trends in Aquatic Macroinvertebrates}

Temporal trends for all 14 AM metrics were observed, although trends were park-wide for some metrics, whereas they depended on underlying geology or watershed area for others (table 13). In addition, trends seemed to be relatively consistent among time periods for the seven metrics that exhibited park-wide trends (E\%, Leuctra:P\%, Hapto\%, Richness, EPT-r, SimpsonD, and DOM2), although the magnitude and statistical significance of trends varied. In contrast, for those metrics whose trends depended on landscape factors, the relations often differed between time periods. For example, the 

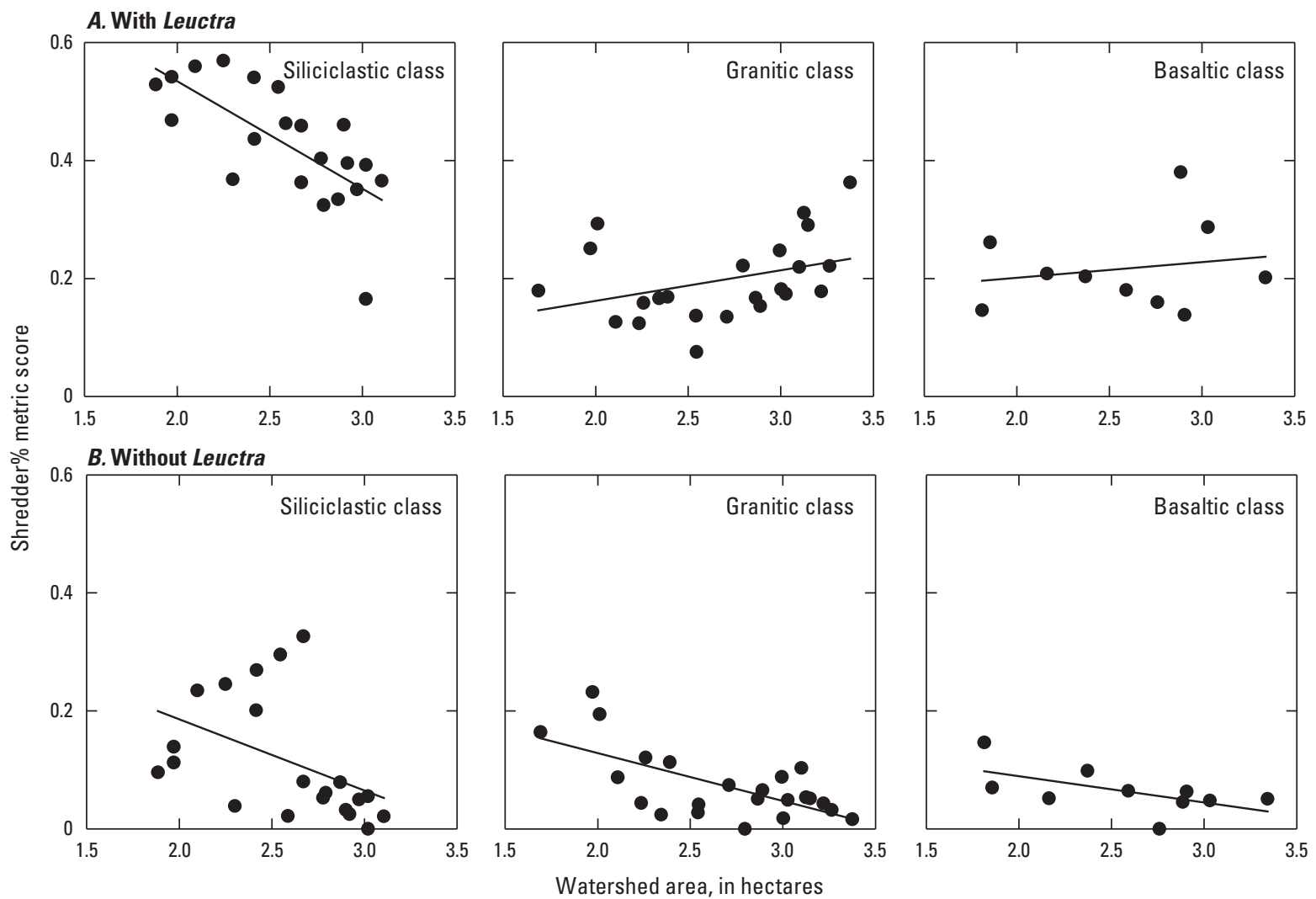

Figure 23. Shredder\% computed A, with Leuctra, and B, without Leuctra, against watershed area, by geologic class.

Table 13. Description of temporal trends of 14 aquatic macroinvertebrate metrics.

[Statistically significant $(\mathrm{p}<0.10)$ temporal trends are identified as park-wide or dependent upon underlying geology or watershed area for each time period evaluated. ns, not significant; PTV, pollution tolerance value; SCI, stream condition index]

\begin{tabular}{lllll}
\hline \multicolumn{1}{c}{ Metric } & \multicolumn{1}{c}{$\begin{array}{c}\text { 20-year } \\
\text { trend }\end{array}$} & $\begin{array}{c}\text { 14-year } \\
\text { trend }\end{array}$ & $\begin{array}{c}\text { 10-year } \\
\text { trend }\end{array}$ & $\begin{array}{c}\text { 5-year } \\
\text { trend }\end{array}$ \\
\hline Richness & ns & Park-wide & Park-wide & Park-wide \\
Ept-r & ns & Park-wide & Park-wide & Park-wide \\
EPT\% $^{1}$ & Geology & ns & ns & Watershed area \\
E\% & Park-wide & ns & ns & Park-wide \\
Hydro:T\% & Geology & ns & ns & ns \\
Leuctra:P & Park-wide & Park-wide & Park-wide & Park-wide \\
DOM2 & ns & ns & Park-wide & ns \\
SimpsonD & ns & ns & Park-wide & ns \\
PTV $^{1}$ & Geology & ns & ns & Watershed area \\
Intol\% ${ }^{1}$ & Geology & Geology & ns & Watershed area \\
Scraper\% $\%$ & Geology & ns & ns & Park-wide \\
Shredder\% ${ }^{1}$ & ns & Geology & ns & Watershed area \\
Hapto\% ${ }^{1}$ & Park-wide & Park-wide & Park-wide & Park-wide \\
SCI & Geology & ns & ns & ns \\
\hline
\end{tabular}

${ }^{1}$ The genus Leuctra was not included in calculating these metrics. 
20-year trends for six AM metrics (EPT\%, Hydro:T\%, PTV, Intol $\%$, Scraper $\%$, SCI) were significantly influenced by geology (table 13), suggesting a relation to water-quality trends. In contrast, the more recent 5-year trends for three of those same six metrics (EPT\%, PTV, Intol\%) depended on watershed area and were not influenced by geology (table 13). These patterns suggest that the environmental factors driving long-term trends (20-year) differed from those responsible for short-term (5-year) trends for these metrics.

Preliminary review of the AM metrics exhibiting parkwide trends indicated no clear temporal trends in terms of overall stream condition, with some metrics seeming to indicate improving stream condition and others suggesting declines. For example, AM diversity, as indicated by the Richness and EPT-r metrics, declined significantly over the 5-, 10-, and 14-year time periods, and the SimpD and DOM2 metrics (also measures of diversity or evenness) showed significant declines in stream condition, but only for the 10 -year time period (fig. 24). Likewise, the Leuctra:P\% metric showed highly significant declines for all four time periods evaluated (fig. 24). This metric could be indicative of either improving (declining) stream acidity, because Leuctra is relatively tolerant to acidic conditions, or declining stream conditions, because Leuctra is also known to be highly sensitive to other chemical pollutants and habitat degradation.

In contrast to the metrics indicating declining conditions, Hapto\% and E\%, two AM metrics expected to decline with stress, showed significant increasing trends over time, suggesting improvement in stream condition. The Hapto\% metric showed increasing trends for all four time periods evaluated, and the $\mathrm{E} \%$ metric showed significant increases for both longterm (20-year) and short-term (5-year) time periods (fig. 24). After excluding the genus Leuctra, however, the Hapto\% metric was mainly composed of mayflies (E\%), thus the strong similarity in temporal patterns of the two metrics (fig. 24). In addition to the proportion of mayflies (E\%), temporal trends in the actual abundance of mayflies were evaluated (not shown) and no significant trends were detected. Consequently, the increasing trends observed for both of these metrics were largely due to the decreasing abundance of other taxa (particularly the genus Leuctra); therefore, these metrics are probably not indicative of improving stream condition.

For other AM metrics, temporal trends were related to geology and watershed area. Geology was found to have a significant effect on temporal trends for seven AM metrics, although the influence was limited to long-term trends (fig. 25). Variation in long-term trends explained by geology ranged from about 20 percent for the Hydro:T\% metric to over 50 percent for Intol\% (fig. 25). In general, where geology was an important predictor of trends, metric scores at sites in siliciclastic watersheds indicated declining stream condition over time relative to sites in granitic and basaltic watersheds (EPT\%, Hydro:T\%, PTV, Intol\%, Scraper\%) or, as in the case of SCI, sites in granitic and basaltic watersheds indicated improving stream condition relative to sites in siliciclastic watersheds (fig. 25). The effect of geology was also evident at the 14-year timeframe for Intol\%, although substantially less variation was explained than at the 20 -year timeframe (fig. 25). Geologic effects on Shredder\% at the 14-year timeframe were comparable to those for Intol\% (fig. 25). Again, in both of these cases, sites in siliciclastic watersheds showed evidence of declining stream condition relative to sites in granitic and basaltic watersheds.

Watershed area also affected trends for four AM metrics (fig. 26) although, in contrast to underlying geology, the influence of watershed area was limited to short-term (5-year) trends (not shown). Patterns for three of the four AM metrics (Shredder\%, PTV, and Intol\%) suggest that stream condition degraded between 2005 and 2009 in smaller watersheds (less than 1,000 ha) and either improved or did not change in larger watersheds (fig. 26). Similarly, the 5-year trend for the EPT\% metric suggests that stream condition did not change significantly in smaller watersheds but improved in larger watersheds (fig. 26).

In summary, the prevailing evidence derived from AM metric trends suggests an overall decline in stream condition over the last 20 years in the park, although a few metrics showed some evidence of improvement in stream condition in selected landscape settings. Specifically, the PTV, Intol\%, and SCI metrics showed evidence of improving trends in streams underlain by granitic and (or) basaltic bedrock but declining trends in streams underlain by siliciclastic bedrock. Declining trends in macroinvertebrate community conditions were evident at both short-term and long-term time scales and, although some metrics showed declines park-wide, declines in other metrics depended on landscape factors (geology type, watershed area, or correlates).

Additional information can be derived from the trend data to inform those designing new or additional AM trend monitoring efforts in the park's streams about the period of data collection required to detect changes in the AM community. For a given metric, the trend slope alone (even if statistically significant) does not provide meaningful information regarding the relative sensitivity or statistical power of the metric to detect change over time. Conventional power analysis equations (Zar, 1999), therefore, were used to compute the minimum detectable change (MDC), which is defined as the absolute change in the mean metric value that can be detected between two samples (in this case, time periods), given observed variances. MDC cannot be directly compared among metrics, however, because metrics vary with respect to scale. The number of years required to detect a significant change (YTDC) was computed by dividing MDC by the mean trend slope. YTDC provides a sense of the magnitude of the observed trends and how they compare among metrics.

For the aforementioned analyses, YTDC was computed for two sets of metrics. For the five metrics that exhibited park-wide trends, data from the 10-year timeframe were used because trend slopes, which indicate change in metric value per year, were greatest for the 2000-2009 time period. The Hapto\% metric is not shown because the long-term trend for this metric was suspected to be spurious, as discussed earlier. 

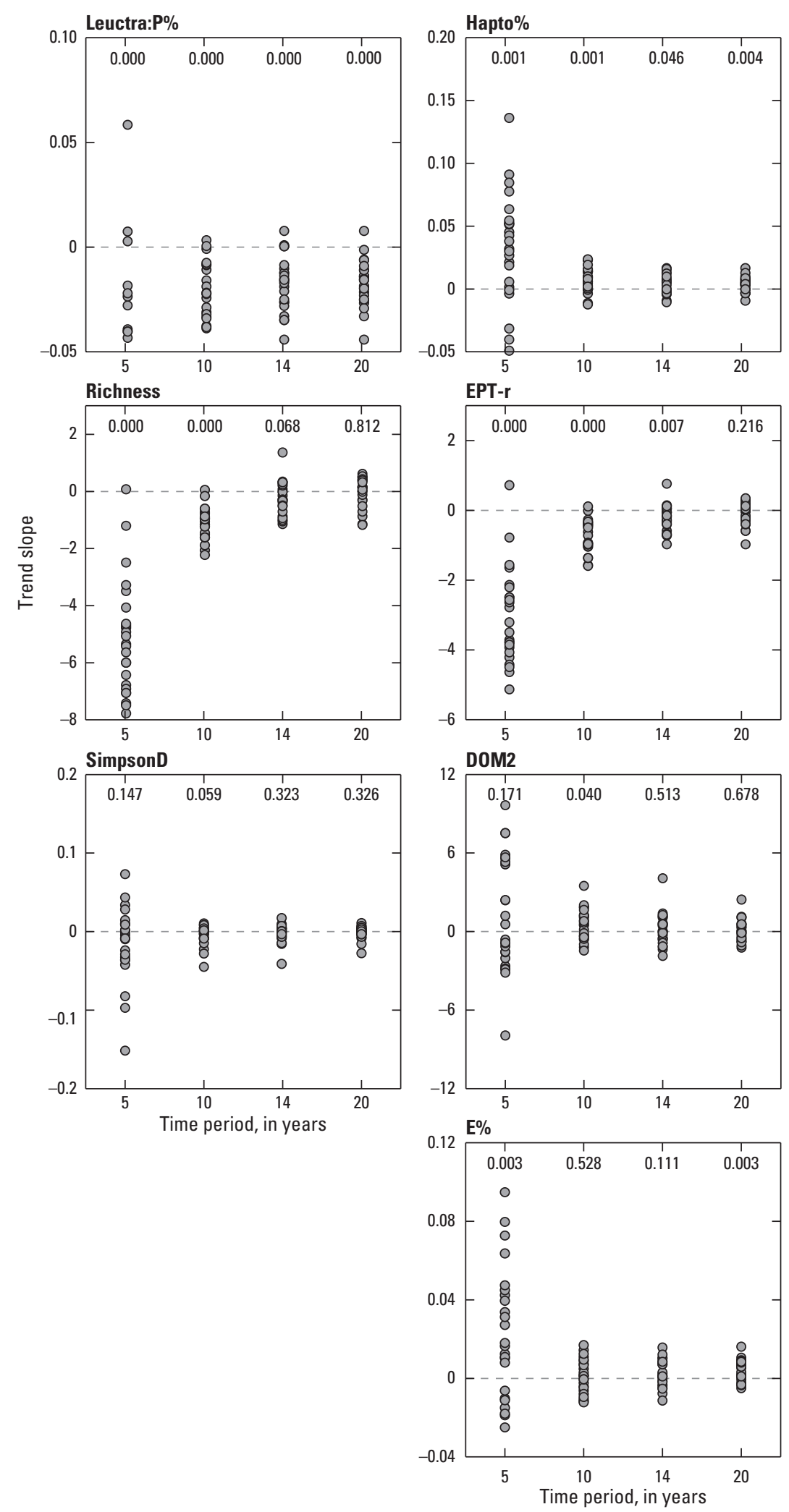

Figure 24. Trend slopes for the seven aquatic macroinvertebrate (AM) metrics with trends independent of geology and watershed area (park-wide) by time period. $p$-values from one-sample $t$-tests to determine significance $(\alpha=0.10)$ are shown above the plotted points. Data used to compute trend slopes were arc sine transformed for the Leuctra:P\%, Hapto\%, and $\mathrm{E} \%$ metrics; therefore, plotted slope values cannot be used to infer percent change per year directly. The trend slopes for the Richness, EPT-r, SimpsonD, and DOM2 metrics were computed from regressions of untransformed data and therefore can be interpreted directly. 

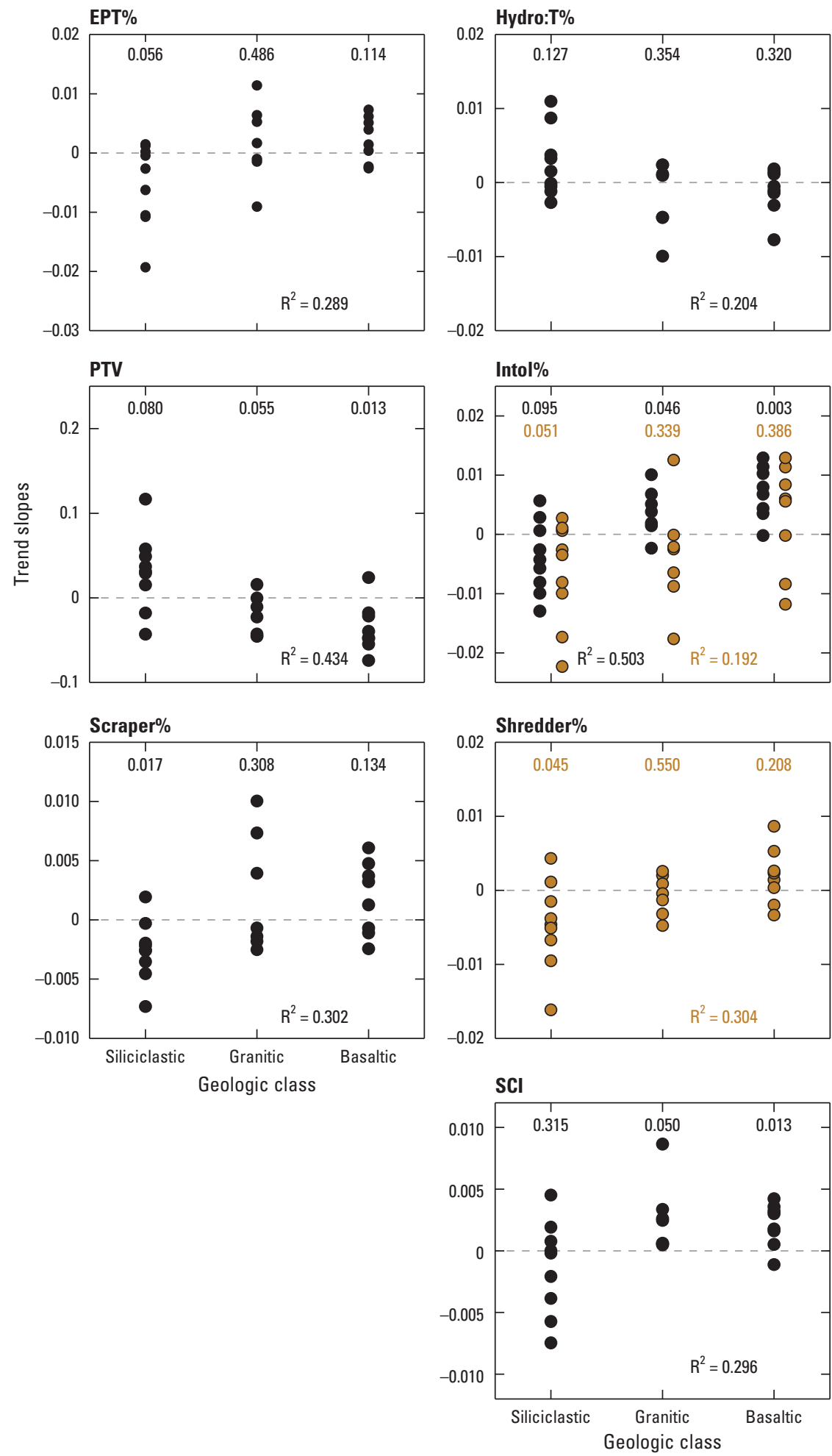

Figure 25. Trend slopes by geologic class for the seven metrics with longterm trend slopes indicating significant geologic effects. The $p$-values from one-sample $t$-tests to determine significance $(\alpha=0.10)$ are shown above the plotted points. Information in brown applies to the 14-year trends and black applies to 20-year trends. 

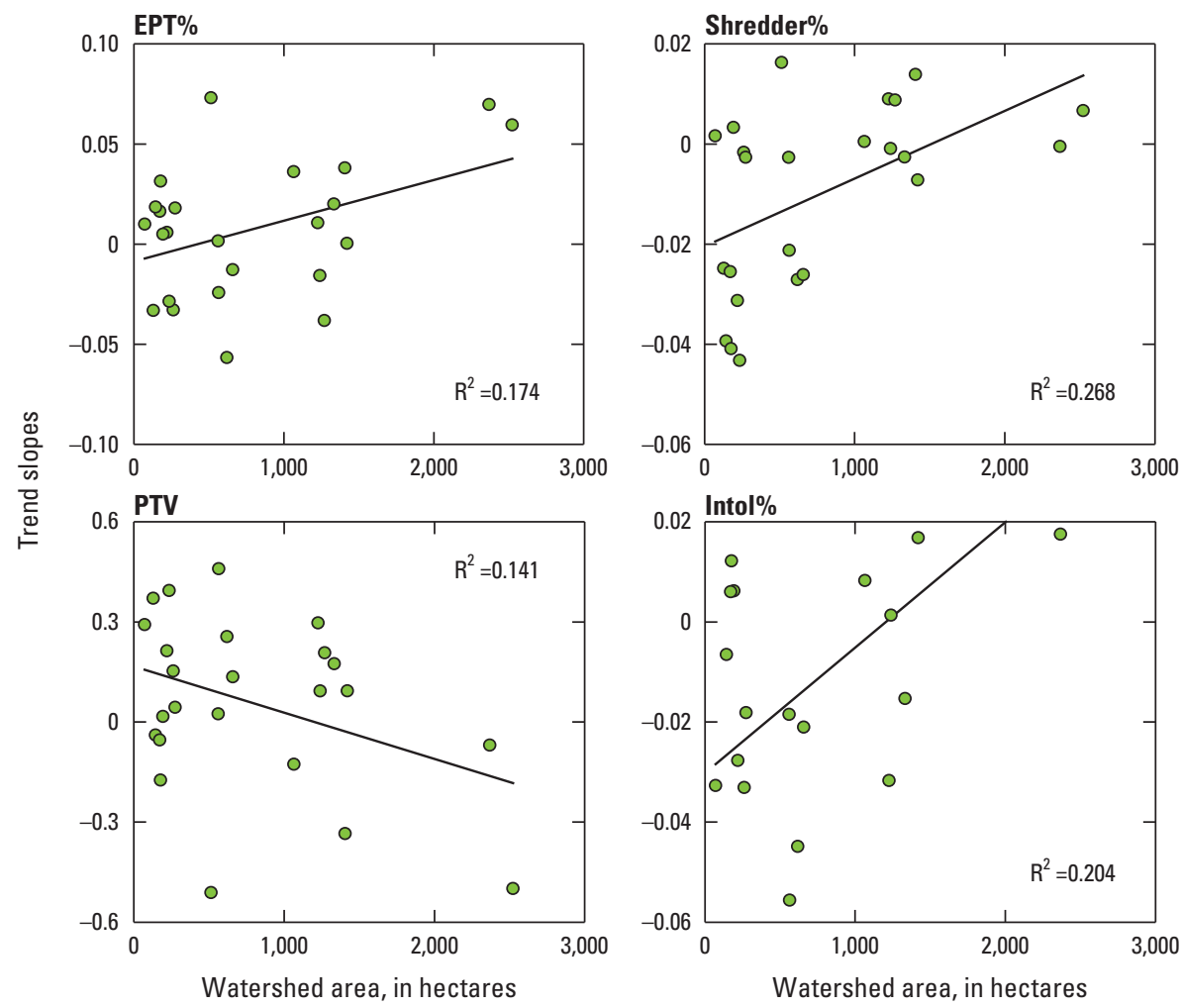

Figure 26. Trend slope as a function watershed area for selected aquatic macroinvertebrate metrics.

Likewise, for the seven AM metrics whose trend slopes depended on geology, the 20-year timeframe was used for the same reason; that is, maximum observed trend slopes among sites tended to be highest for the 20 -year timeframe. Thus, these results report the "maximum potential" power to detect change rather than the average. A type I effort rate of 0.10 and a power of 0.20 were used for all calculations. As with trend analyses, power calculations were made on transformed data where appropriate (table 10). Direct comparisons between the two groups should be made with caution because variances used in MDC calculations were computed using different sample sizes. Specifically, sample sizes for the metrics whose trends depended on geology were smaller than those used for park-wide metrics because $\mathrm{N}$ equaled the number of sites within a geologic type rather than total number of sites. Thus, one would expect lower power (and therefore greater YTDC) for those metrics. In addition, calculations were made for a given metric only for geologic types that showed statistically significant trend slopes (table 13).
In terms of metrics having park-wide trends, those for total richness and EPT-r were strongest. Given the average 10 -year trend slope, park-wide changes in these metrics could be detected in as few as three years (fig. 27). The Leuctra:P\% metric trend also was strong, with significant differences detectable in as few as six years. The DOM2 and SimpD metric trends were weaker and required between 15 and 18 years of data to detect a significant change.

For those metrics whose trend varied with geology, at least 20 years of data were typically required to detect a significant change (fig. 27), indicating the weakness of observed trends and highlighting the importance of long-term monitoring data. Additionally, those metrics whose trends were indicative of declining stream condition, which always occurred in the siliciclastic watersheds, could be detected in fewer years than corresponding metrics indicative of improving stream condition, which always occurred in granitic and basaltic watersheds (fig. 27). 


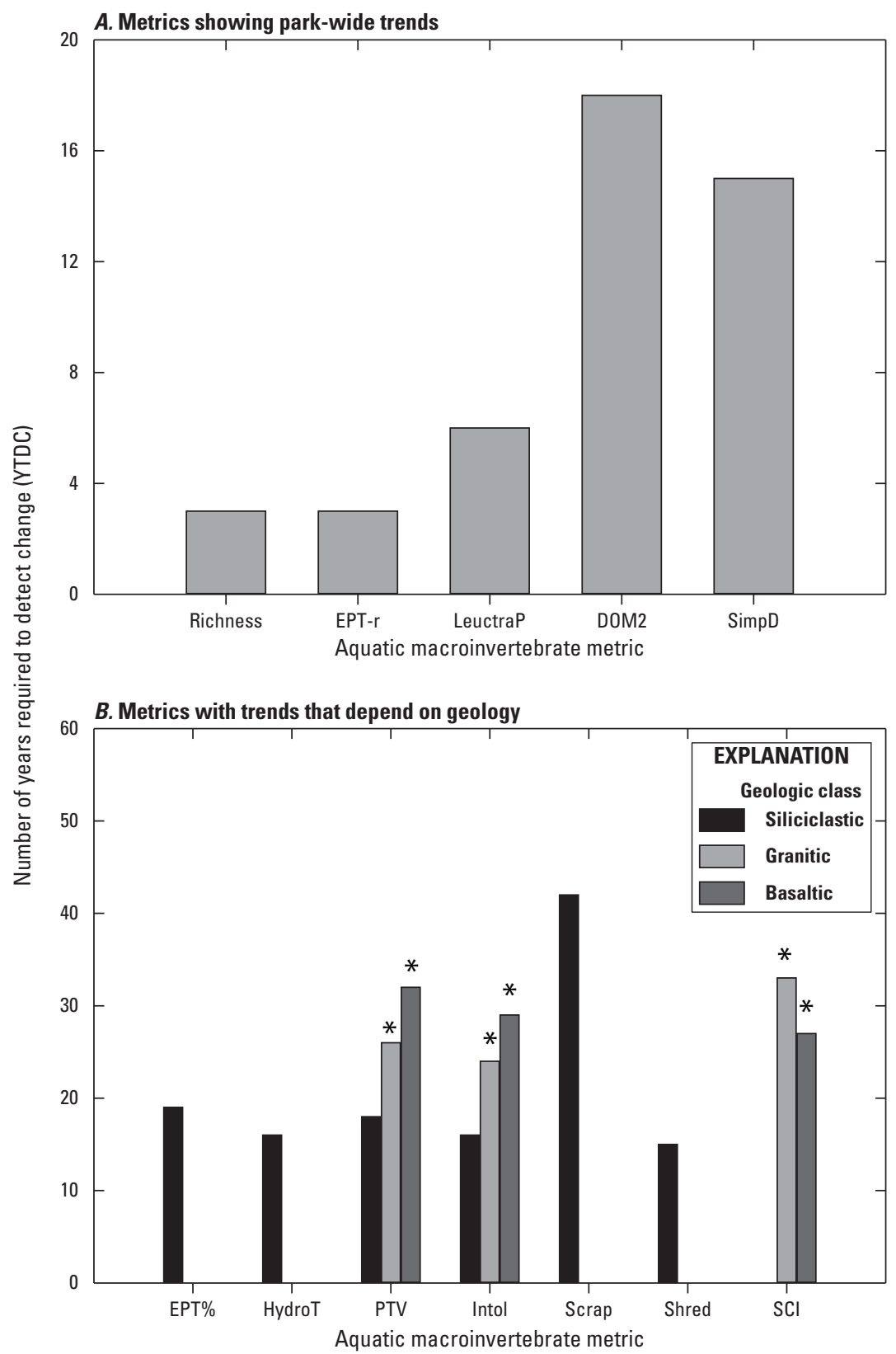

Figure 27. The number of years required to detect a statistically significant change in metric means for $A$, metrics that showed significant trends parkwide, and $B$, metrics with trends dependent on geology. Asterisks above the bar indicates that trends were positive (improvement in stream condition). All other trends were negative (declining stream condition). 


\section{Analysis of Fish Data}

Stream fishes are a valued biological resource within the park, and a robust fish-community dataset has been collected by NPS personnel over several years. This dataset was used to evaluate the status and trends of stream fish communities within the study area. Analyses focused on geology and watershed size as environmental predictors of stream fish communities because of their demonstrated importance in relation to acidic deposition (Bulger and others, 1995) and fish community composition (Roberts and Hitt, 2010).

\section{Fish Data Structure and Analysis}

Park personnel have collected stream fish data since 1982, with an emphasis on understanding brook-trout population dynamics (Atkinson, 2002). The 1996-2009 fish dataset includes 107 sample sites and 512 individual survey events (fig. 28; table 14). This dataset provides an unparalleled resolution for spatial and temporal analysis of Appalachian stream fish communities.

Stream sites were sampled using 3-pass backpack electrofishing techniques within standardized 100-m reaches. Captured fishes were identified to species, counted by pass number, and released. The majority of sampling events occurred during June and July, but some samples were collected during May, August, and September (table 14). The number of sampling sites per year has generally increased over time, as has the variation in sample size (table 14). Because the proportion of samples per month remained nearly constant over time (table 14), however, temporal changes are unlikely to be confounded by sampling effort.

Counts of brook trout young-of-year (YOY) were distinguished from adults (age greater than 1 year; age 1+) (Atkinson, 2002). Although it is possible that some juvenile fishes were erroneously considered "adults" in this analysis, brook trout spawning may occur in either the first or second full year in the study area (Jenkins and Burkhead, 1994), so it was appropriate to distinguish YOY from adult (age 1+) fish in this analysis. The total abundances were estimated for each species as the sum of abundances within each pass.

Subsets of the fish dataset were evaluated to accomplish different objectives. First, all sites were evaluated to describe the approximate relative abundance of all fish species in the study area $(n=107)$. Second, sites that supported at least three species and over 9 years of annual survey data $(n=25)$ were selected for community trend analyses. Third, all sites that supported more than 9 years of annual survey data $(n=32)$ were selected for brook-trout trend analyses; no required species richness threshold was necessary in the selection of these sites. Of the 32 brook-trout focal sites, 22 (69 percent) also were included as fish community sites. Community and brook trout focal sites included locations throughout the study area (fig. 28).

Fish-community and brook-trout population analyses followed similar methods for water quality and AM communities. Specifically, simple-linear-regression slope coefficients were calculated for biotic metrics (fish richness, brook trout YOY, and adult brook-trout abundances) as a function of year. In addition, the per-capita intrinsic rate of increase $(r)$ was calculated as

$$
r=\ln \left(\mathrm{N}_{t} / \mathrm{N}_{t-1}\right)
$$

where

$$
\begin{aligned}
\mathrm{N} & \text { is the adult abundance, and } \\
t & \text { is the sampling year. }
\end{aligned}
$$

This approach provided estimates of increasing and decreasing trends for fish metrics over time. Linear models for temporal trend analysis were evaluated using the same time periods, significance criteria, and geologic classes used for the water-quality and AM trend analyses. GLM was used to evaluate the importance of geologic class, upstream watershed area, and interactive effects on fish metrics (species richness, YOY, and adult brook-trout abundance) among time periods.

Table 14. Number of fish community sampling events per month from 1996 to 2009.

\begin{tabular}{ccrrccc}
\hline \multirow{2}{*}{ Year } & \multicolumn{6}{c}{ Month } \\
\cline { 2 - 7 } & May & June & July & August & September & Total \\
\hline 1996 & 0 & 10 & 13 & 6 & 0 & 29 \\
1997 & 0 & 14 & 14 & 4 & 0 & 32 \\
1998 & 0 & 16 & 18 & 0 & 0 & 34 \\
1999 & 0 & 17 & 19 & 0 & 0 & 36 \\
2000 & 0 & 18 & 17 & 2 & 0 & 37 \\
2001 & 0 & 17 & 19 & 4 & 0 & 40 \\
2002 & 0 & 20 & 20 & 1 & 0 & 41 \\
2003 & 0 & 16 & 20 & 0 & 0 & 36 \\
2004 & 0 & 21 & 18 & 10 & 0 & 49 \\
2005 & 0 & 8 & 7 & 0 & 0 & 15 \\
2006 & 3 & 17 & 25 & 16 & 0 & 61 \\
2007 & 0 & 2 & 4 & 0 & 0 & 6 \\
2008 & 1 & 26 & 29 & 7 & 0 & 63 \\
2009 & 0 & 12 & 14 & 5 & 2 & 33 \\
\hline Total & 4 & 214 & 237 & 55 & 2 & 512 \\
\hline
\end{tabular}




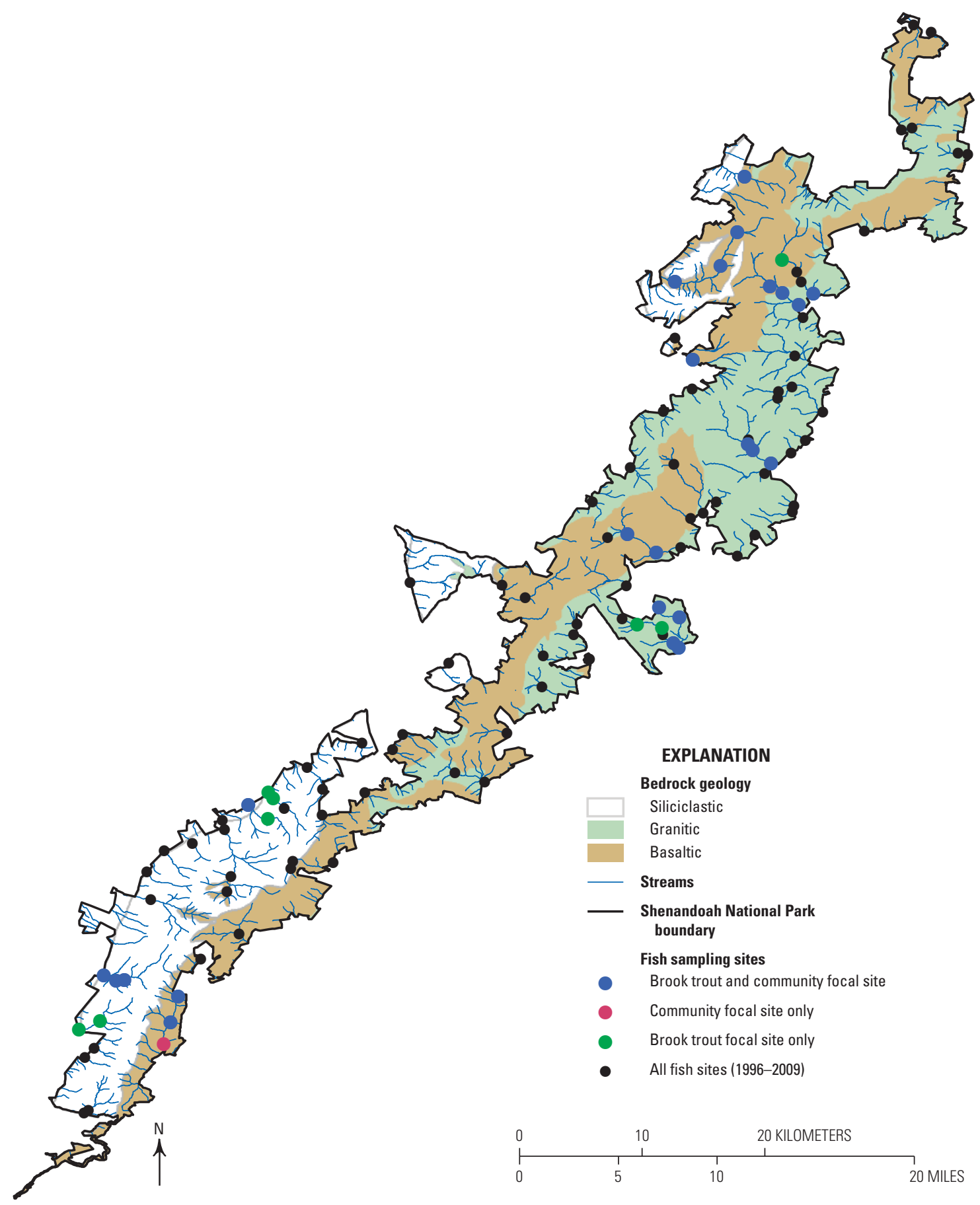

Figure 28. All fish sampling site locations, and those selected for brook trout analyses and community analyses, within Shenandoah National Park. Location of study area provided in figure 1. 


\section{Fish Community Characteristics}

The park's fish dataset contained records of 261,028 individual fish and 33 species $(n=107)$. Members of the family cyprinidae were numerically dominant (table 15), primarily because of the large number of blacknose dace (Rhinichthys atratulus) in the dataset (37 percent, table 15). Salmonid fishes were second-most abundant in the dataset, primarily because of brook trout abundances ( 25 percent), rather than introduced rainbow trout (Oncorhynchus mykiss) and (or) brown trout
(Salmo trutta) (table 15). Cottid and catostomid fishes collectively contributed approximately one-fifth of the total individuals in the dataset because of relatively high abundances of mottled sculpin (Cottus bairdi) and torrent sucker (Thoburnia rhothoeca) (table 15). Most of the taxonomic diversity was represented by relatively low abundances. For example, 22 species (67 percent) were represented by fewer than 1,000 individuals, and 12 species (36 percent) contained fewer than 100 individuals in the dataset. In contrast, the most abundant species (blacknose dace) consisted of nearly 100,000 individuals (table 15).

Table 15. Fish species and abundances reported from 1996 to 2009 from 3-pass backpack electrofishing surveys at 107 sites.

[Species codes correspond to those shown in figure 29. \%, percentage; $<$, less than]

\begin{tabular}{|c|c|c|c|c|c|}
\hline Family (\% of total) & Scientific name & Common name & Code & $\begin{array}{l}\text { Number of } \\
\text { individuals }\end{array}$ & $\%$ of tota \\
\hline Anguillidae (0.2) & Anguilla rostrata & American eel & AME & 428 & 0.16 \\
\hline \multirow{3}{*}{ Catostomidae (9.4) } & Catastomus commersoni & White sucker & WHS & 496 & 0.19 \\
\hline & Hypentelium nigricans & Northern hog sucker & NHS & 85 & 0.03 \\
\hline & Thoburnia rhothoeca & Torrent sucker & TOS & 24,033 & 9.21 \\
\hline \multirow{6}{*}{ Centrarchidae (0.1) } & Ambloplites rupestris & Rock bass & ROB & 30 & 0.01 \\
\hline & Lepomis auritus & Redbreast sunfish & $\mathrm{RDB}$ & 8 & $<0.01$ \\
\hline & Lepomis macrochirus & Bluegill & BLG & 2 & $<0.01$ \\
\hline & Lepomis gibbosus & Pumpkinseed & PKS & 3 & $<0.01$ \\
\hline & Micropterus dolomieu & Smallmouth bass & SMB & 322 & 0.12 \\
\hline & Micropterus salmoides & Largemouth bass & LMB & 2 & $<0.01$ \\
\hline \multirow{2}{*}{ Cottidae (11.3) } & Cottus bairdi & Mottled sculpin & MTS & 28,705 & 11.00 \\
\hline & Cottus girardi & Potomac sculpin & POS & 653 & 0.25 \\
\hline \multirow{12}{*}{ Cyprinidae (49.0) } & Campostoma anomalum & Central stoneroller & CES & 3,591 & 1.38 \\
\hline & Clinostomus funduloides & Rosyside dace & RYD & 8,740 & 3.35 \\
\hline & Cyprinella analostana & Satinfin shiner & SNS & 3 & $<0.01$ \\
\hline & Exoglossum maxillingua & Cutlips minnow & CUM & 133 & 0.05 \\
\hline & Luxilus cornutus & Common shiner & $\cos$ & 1,226 & 0.47 \\
\hline & Nocomis leptocephalus ${ }^{1}$ & Bluehead chub & BLC & 4,904 & 1.88 \\
\hline & Phoxinus oreas & Mountain redbelly dace & MRD & 2,335 & 0.89 \\
\hline & Pimephales notatus & Bluntnose minnow & BLM & 36 & 0.01 \\
\hline & Rhinichthys atratulus & Blacknose dace & $\mathrm{BKD}$ & 95,624 & 36.63 \\
\hline & Rhinichthys cataractae & Longnose dace & LGD & 10,829 & 4.15 \\
\hline & Semotilus atromaculatus & Creek chub & CRC & 255 & 0.10 \\
\hline & Semotilus corporalis & Fallfish & FAF & 254 & 0.10 \\
\hline \multirow{3}{*}{ Ictaluridae $(0.1)$} & Ameiurus natalis & Yellow bullhead & YEB & 6 & $<0.01$ \\
\hline & Ameiurus nebulosus & Brown bullhead & $\mathrm{BRB}$ & 1 & $<0.01$ \\
\hline & Noturus insignis & Margined madtom & MAM & 296 & 0.11 \\
\hline \multirow{3}{*}{ Percidae (4.7) } & Etheostoma blennioides & Greenside darter & GRD & 3 & $<0.01$ \\
\hline & Etheostoma flabellare & Fantail darter & FAD & 11,945 & 4.58 \\
\hline & Etheostoma olmstedi & Tessellated darter & TED & 414 & 0.16 \\
\hline \multirow{3}{*}{ Salmonidae (25.2) } & Oncorhynchus mykiss & Rainbow trout & RBT & 56 & 0.02 \\
\hline & Salmo trutta & Brown trout & BRT & 367 & 0.14 \\
\hline & Salvelinus fontinalis & Brook trout & BKT & 65,240 & 24.99 \\
\hline
\end{tabular}

${ }^{1}$ Combined with records of river chub (Nocomis micropogon) due to taxonomic uncertainty for juvenile specimens. 


\section{Temporal Trends and Spatial Patterns in Fish Communities}

Most species did not exhibit dramatic changes in average abundance during 1996-2009, such as park-wide colonization or extirpation (fig. 29). Some patterns, however, merit further investigation: potential increases in average abundance of American eel (Anguilla rostrata; AME), margined madtom (Noturus insignis; MAM), mountain redbelly dace (Phoxinus oreas; MRD), and decreases in average abundances of creek chub (Semotilus atromaculatus; CRC) and the common shiner (Luxilus cornutus; COS) (fig. 29), although variation in average abundance may have been influenced by the number of sampling events per year (table 14). For example, low abundances during 2007 were probably a reflection of the relatively small number of samples that year, and increases in American eel abundance may be attributed to the removal of Embrey Dam on the Rappahannock River in 2004 (Hitt and others, 2012).

Fish species richness in focal sites tended to increase or remain constant over time; no sites exhibited an obvious loss of richness (fig. 30). Temporal increases in richness were most pronounced in the North Fork of Thornton River (1F030) and in Hughes River (2F038), where richness appeared to increase from approximately 9 to 13 species and from 11 to 15 species, respectively (fig. 30). Richness at sites supporting three species in 1996 (typically brook trout, blacknose dace, and sculpin) remained relatively constant over time. In contrast, sites with four or more species in 1996 showed more variation in richness over time (sites 2F039, 2F040, 2FVA4). Collectively, these results suggest that fish dispersal and recolonization dynamics may be operating across larger spatial scales than the 100-meter sampling reach (Brown and others, 2011).

Mean species richness was greater in granitic and basaltic watersheds than in siliciclastic watersheds and increased with watershed area (fig. 31). Granitic watersheds supported sites having the greatest fish richness, with the opposite being true for siliciclastic watersheds (fig. 31). GLM results indicated watershed area and geologic class affected mean species richness within all time periods $(5,10$, and 14 years) (table 16). No interactive effects of geology and watershed area on mean species richness were observed (table 16).

Species richness tended to increase over time, but these changes were evident only for the 14-year analysis period (fig. 32). In the 14-year analysis, geologic classes exhibited important differences: sites draining granitic and basaltic watersheds showed increasing species richness, whereas sites draining siliciclastic watersheds showed no such trends (fig. 32). In addition, larger streams tended to accumulate more species over time than smaller streams. Although the effect of watershed area on fish richness trends was largely insignificant in the GLMs (table 16), this was primarily because of decreasing species richness observed at one site

Table 16. Stepwise general linear model results for effects of geology and watershed area on stream fish community richness, brook trout young-of-year abundance, and brook trout adult (age greater than 1 year: age 1+) abundance among time periods of 5 , 10, and 14 years. Non-significant terms were sequentially removed from models.

[ns, not significant for $\alpha=0.10$; YOY, young-of-year]

\begin{tabular}{|c|c|c|c|c|c|c|c|c|}
\hline \multirow{2}{*}{ Response } & \multirow{2}{*}{ Metric } & \multirow{2}{*}{ Years } & \multicolumn{2}{|c|}{ Geologic class } & \multicolumn{2}{|c|}{ Watershed area } & \multicolumn{2}{|c|}{ Interaction } \\
\hline & & & F-statistic & $p$-value & F-statistic & $p$-value & F-statistic & $p$-value \\
\hline \multirow{9}{*}{ Mean } & Richness & 5 & 3.72 & 0.043 & 14.50 & $<0.001$ & $\mathrm{~ns}$ & ns \\
\hline & & 10 & 3.60 & 0.047 & 16.99 & $<0.001$ & ns & ns \\
\hline & & 14 & 3.83 & 0.040 & 18.39 & $<0.001$ & ns & ns \\
\hline & YOY & 5 & 5.76 & 0.009 & ns & ns & ns & ns \\
\hline & & 10 & 7.77 & 0.003 & 4.90 & 0.036 & ns & ns \\
\hline & & 14 & 8.49 & 0.001 & 4.86 & 0.037 & ns & ns \\
\hline & Adult & 5 & $\mathrm{~ns}$ & ns & 7.47 & 0.011 & ns & ns \\
\hline & & 10 & 2.94 & 0.071 & 5.94 & 0.022 & ns & ns \\
\hline & & 14 & 4.55 & 0.020 & 7.622 & 0.010 & ns & ns \\
\hline \multirow{9}{*}{ Slope } & Richness & 5 & ns & $\mathrm{ns}$ & ns & ns & 3.09 & 0.069 \\
\hline & & 10 & ns & ns & ns & ns & ns & ns \\
\hline & & 14 & ns & ns & ns & ns & ns & ns \\
\hline & YOY & 5 & 4.27 & 0.022 & ns & ns & ns & ns \\
\hline & & 10 & $\mathrm{~ns}$ & $\mathrm{~ns}$ & ns & ns & ns & ns \\
\hline & & 14 & $\mathrm{~ns}$ & ns & ns & ns & ns & ns \\
\hline & Adult & 5 & 6.47 & 0.005 & ns & ns & ns & ns \\
\hline & & 10 & $\mathrm{~ns}$ & ns & ns & ns & $\mathrm{ns}$ & ns \\
\hline & & 14 & 3.93 & 0.032 & ns & ns & ns & ns \\
\hline
\end{tabular}



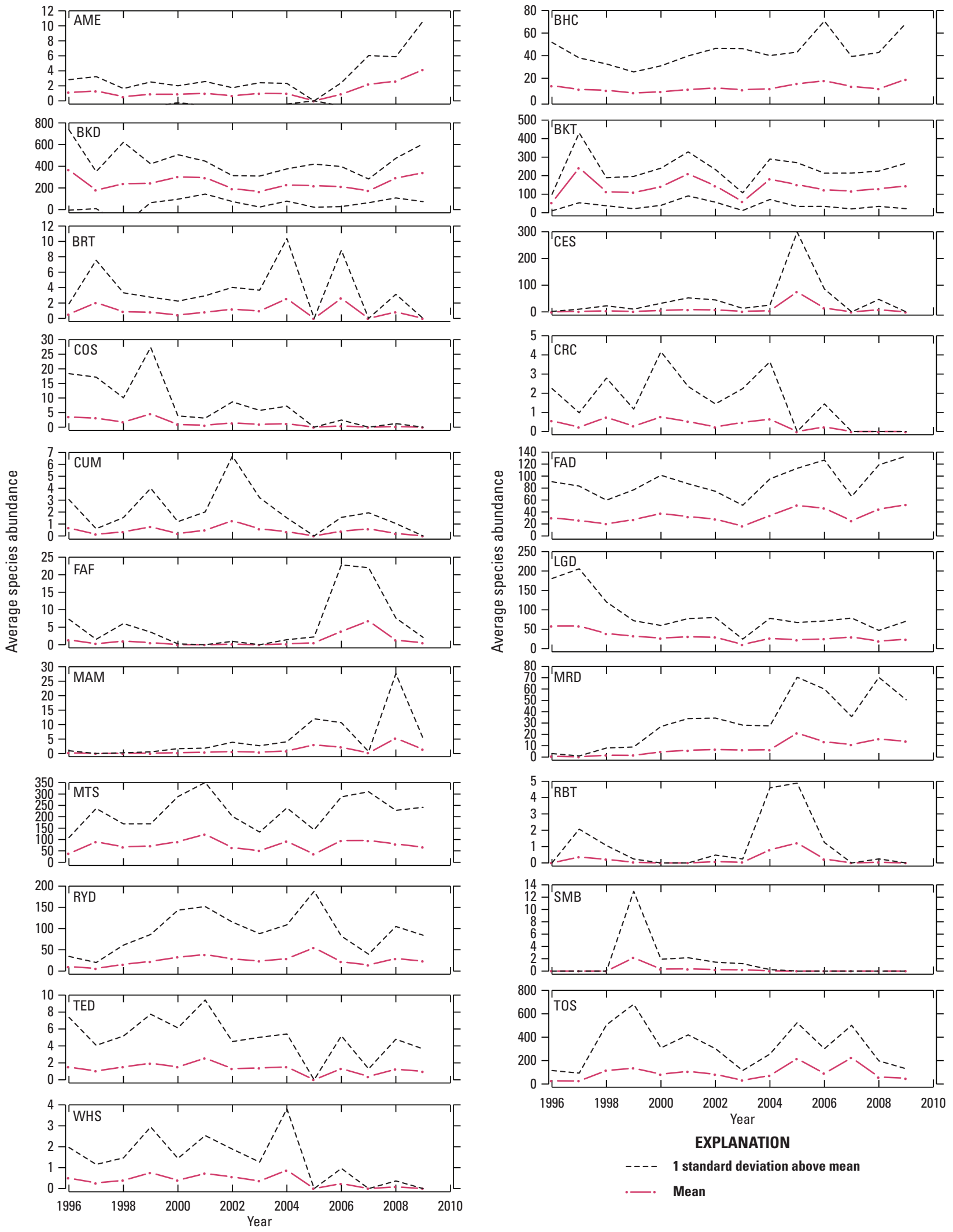

EXPLANATION

- - - 1 standard deviation above mean

- _. Mean

Figure 29. The temporal variation in average abundance of species within Shenandoah National Park community focal sites $(n=25)$. 

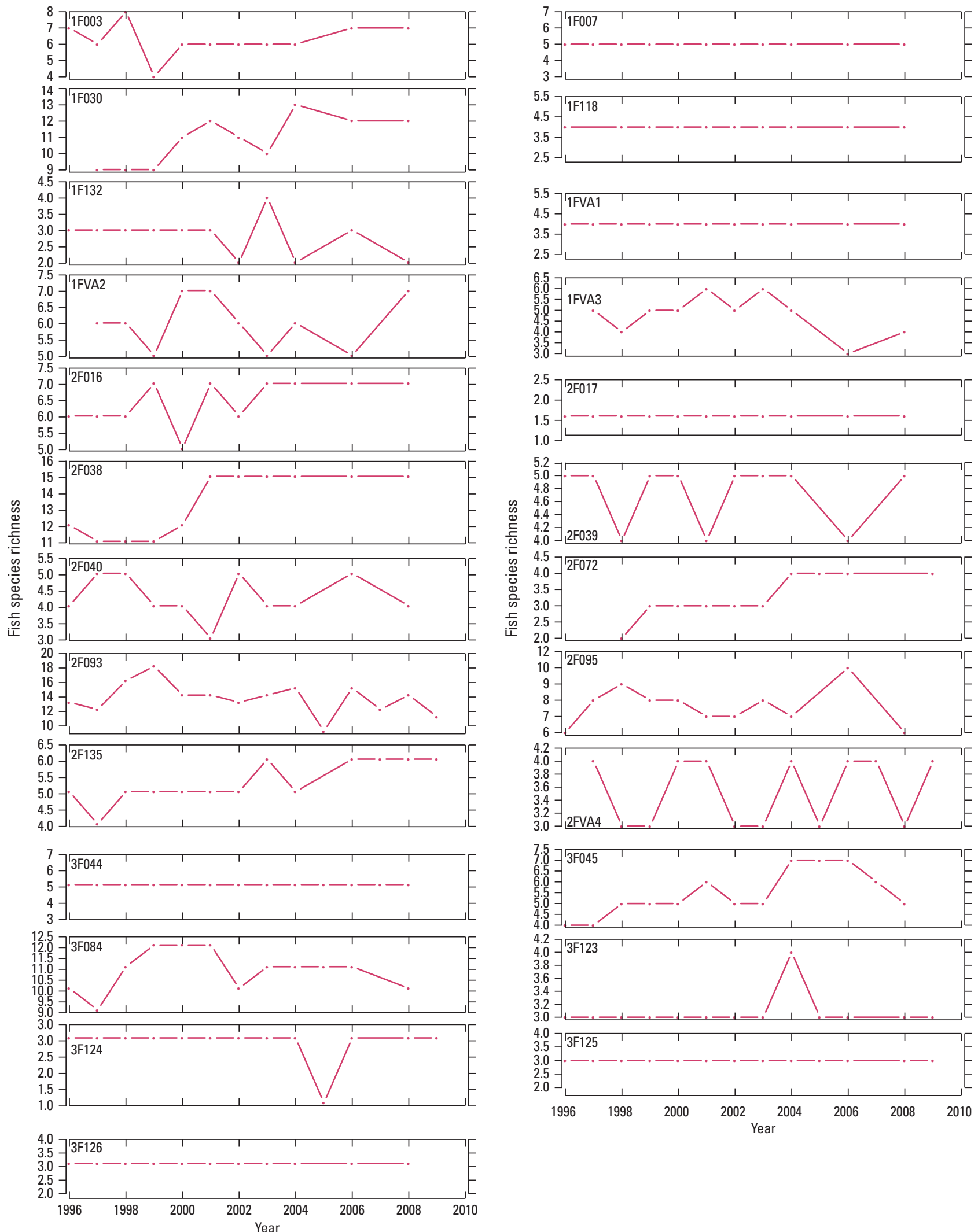

Figure 30. The temporal variation in fish species richness for community focal sites by National Park Service (NPS) site code. Site locations and attributes are provided in table 9. 

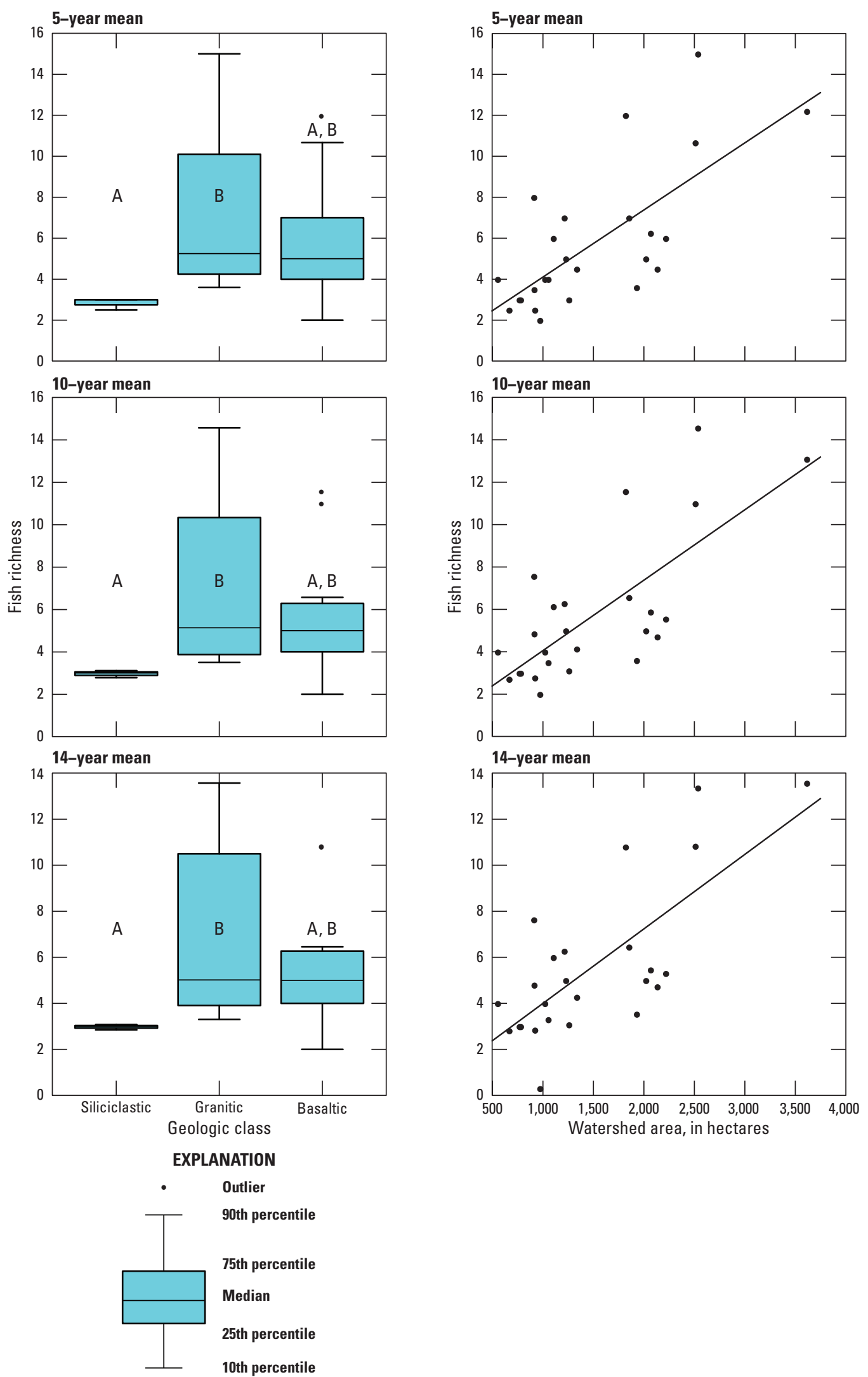

Figure 31. Distributions of mean fish richness by geologic class and against watershed area for three time periods analyzed. Letters on boxplots indicate significant differences between classes (alpha $=0.10)$. A least-squares regression line is shown for watershed-area graphs. 

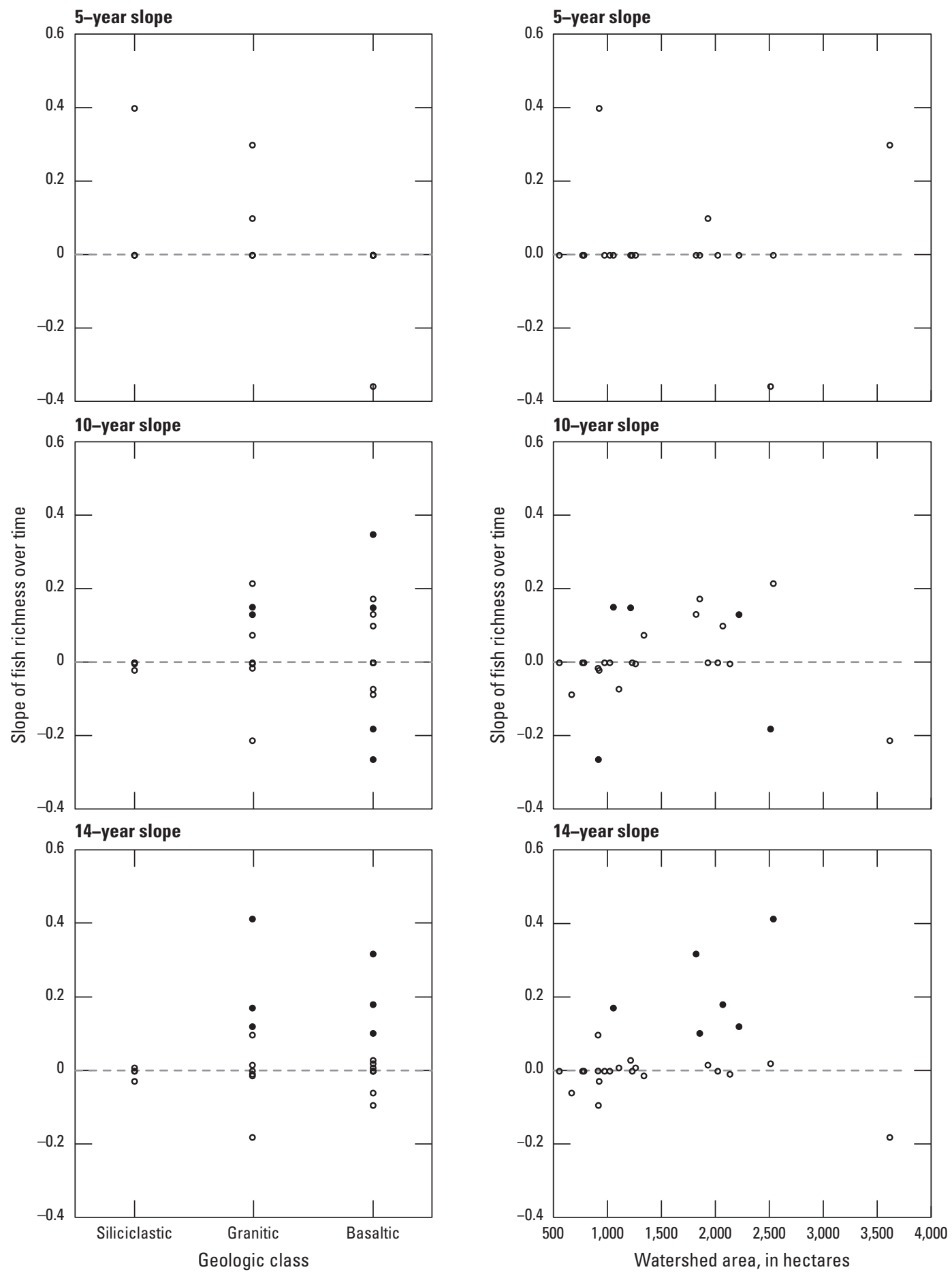

\section{EXPLANATION}

Trend slope

- Not significant $(\alpha=0.10)$

- Significant $(\alpha=0.10)$

Figure 32. Fish richness trend slope as functions of geologic class and watershed area for the three time periods analyzed. 
(2F093). Removal of this site from the analysis yielded a significant relation between watershed area and species richness slopes $(p<0.01)$. The outlier site $2 \mathrm{~F} 093$ is notable for its history: it was established in 1996 after a major flood in 1995, which reworked the substrate and removed riparian canopy cover. The decline in species richness for this site suggests that floods may have long-term effects on fish community composition, despite the recovery of brook trout (Roghair and Dolloff, 2005) and AMs (Snyder and Johnson, 2006). Another fish community focal site, however, was scoured by the 1995 flood (2F072; Staunton River), and this site showed increasing species richness ( 14 -year slope coefficient $=0.172$; watershed area $=1,065 \mathrm{ha}$ ). Some increases in richness were associated with the appearance of native American eel at a site, whereas other increases were associated with the occurrence of nonnative rainbow trout or potentially non-native torrent sucker.

Detection of temporal trends in fish richness required more than 5 years of data. No significant $(\mathrm{p}<0.10)$ trend slopes were detected for the 5-year period, whereas 6 significant trends were detected for the14-year period (fig. 32). Statistical significance in this regard generally was detected only for positive or negative changes in slope greater than 0.10 , suggesting the sensitivity of linear regression models to detect a net gain or loss of 1 species every 10 years, on average. This finding indicates the necessity of long-term monitoring data for detecting changes in stream-fish richness.

\section{Temporal Trends and Spatial Patterns in Brook Trout Population}

Mean brook-trout YOY abundances were substantially greater in granitic and basaltic watersheds than in siliciclastic watersheds, but were invariant with respect to watershed size (table 16; fig. 33). The effect of geologic class on mean YOY abundance was observed in the 5-year analysis, as well as the 10- and 14-year analyses (table 16; fig. 33). Siliciclastic watersheds supported approximately half of the mean YOY abundance observed in other geologic classes (fig. 33).

Temporal trends in YOY abundance varied substantially among time periods and geologic classes (fig. 34). The 5-year time periods generally showed more variation in YOY abundance trends than longer time intervals. For the 10- and 14-year analyses, more sites were characterized by decreasing trends in YOY abundance than increasing trends (fig. 34). Basaltic sites generally showed the fastest rate of decrease (largest negative slope coefficients), but these declines mostly were not significant (fig. 34). Stream volume was probably not important for YOY abundance trends, because decreasing YOY abundances were observed across sites having small and large upstream watershed areas (fig. 34). The apparent increases in YOY abundance within granitic sites for the 5-year analysis were not observed in analyses of longer timespans (fig. 34).

As with YOYs, the mean abundance of adult (age 1+) brook trout was greater in granitic and basaltic watersheds than in siliciclastic watersheds (table 16; fig. 35). Larger watersheds tended to support lower average abundances of adult brook trout (fig. 35), and these differences were statistically significant (table 16). Five-year temporal trends in adult abundances were more variable than trends for longer time spans (fig. 36). Unlike YOY trends, however, trends in adult abundances at some sites increased over time in the 14-year analysis. These increasing trends were more prevalent for siliciclastic and granitic sites than basaltic sites, where both increasing and decreasing trends were observed in relatively equal amounts (fig. 36). Watershed size was not associated exclusively with increasing or decreasing trends in adult abundance over time (fig. 36). Model sensitivity in detecting significant temporal change in adult brook-trout abundances increased with the length of the period analyzed, underscoring the importance of long-term monitoring data.

Per capita intrinsic rates of increase (r) for adult brook trout populations generally centered around zero, indicating population stability over the period of record (fig. 37). Preliminary analyses revealed insignificant differences among geologic classes or watershed size, but other patterns merit additional consideration. Several sites exhibited decreasing variation in $\mathrm{r}$ over time. For example, intrinsic rates of increase in Jeremy's Run (1F007) and Hughes River (2F038) showed more variability in the first half of the time series than the second (1997-2003 versus 2003-09) (fig. 37). This result suggests possible differences in the natural disturbance regime among park locations. In addition, all focal sites showed consistent patterns of change during selected periods. For example, of the 22 sites with data, 19 ( 86 percent) showed r increasing from 1997 to 1998 and decreasing the following year. This result suggests an important role of densityindependent environmental factors, such as flow regime, apart from the density-dependent effects of predation and competition. Further research is needed to understand whether or not the temporal synchrony observed here is also observed across larger regions of the southern Appalachians.

This analysis provided several inferences regarding fish community and brook-trout population dynamics within the park. Fish species richness was found to be depressed in acidsensitive (siliciclastic) watersheds, as reported by Bulger and others (1995), and fish species richness has increased over time in granitic and basaltic watersheds not sensitive to acidification. Likewise, abundances of YOY and adult brook trout were depressed in siliciclastic watersheds, but in contrast to fish species richness, increasing trends in adult brook trout abundance were detected in acid-sensitive sites over the 14-year analysis timeframe. The observed long-term increases in adult brook trout abundance in acid-sensitive streams do not reflect improvements in fish community composition (species richness). Analysis of brook-trout population growth rates revealed stable populations $(r \sim 0)$ and highly synchronous patterns of annual variation park-wide. Further analysis of spatially structured environmental factors, such as streamflow and water temperature, could therefore enable predictions of brook trout responses to climate change within the park and throughout the Appalachian Mountains. Conservation of fish biodiversity and brook trout populations in acid-sensitive watersheds remains an important challenge for research and management. 

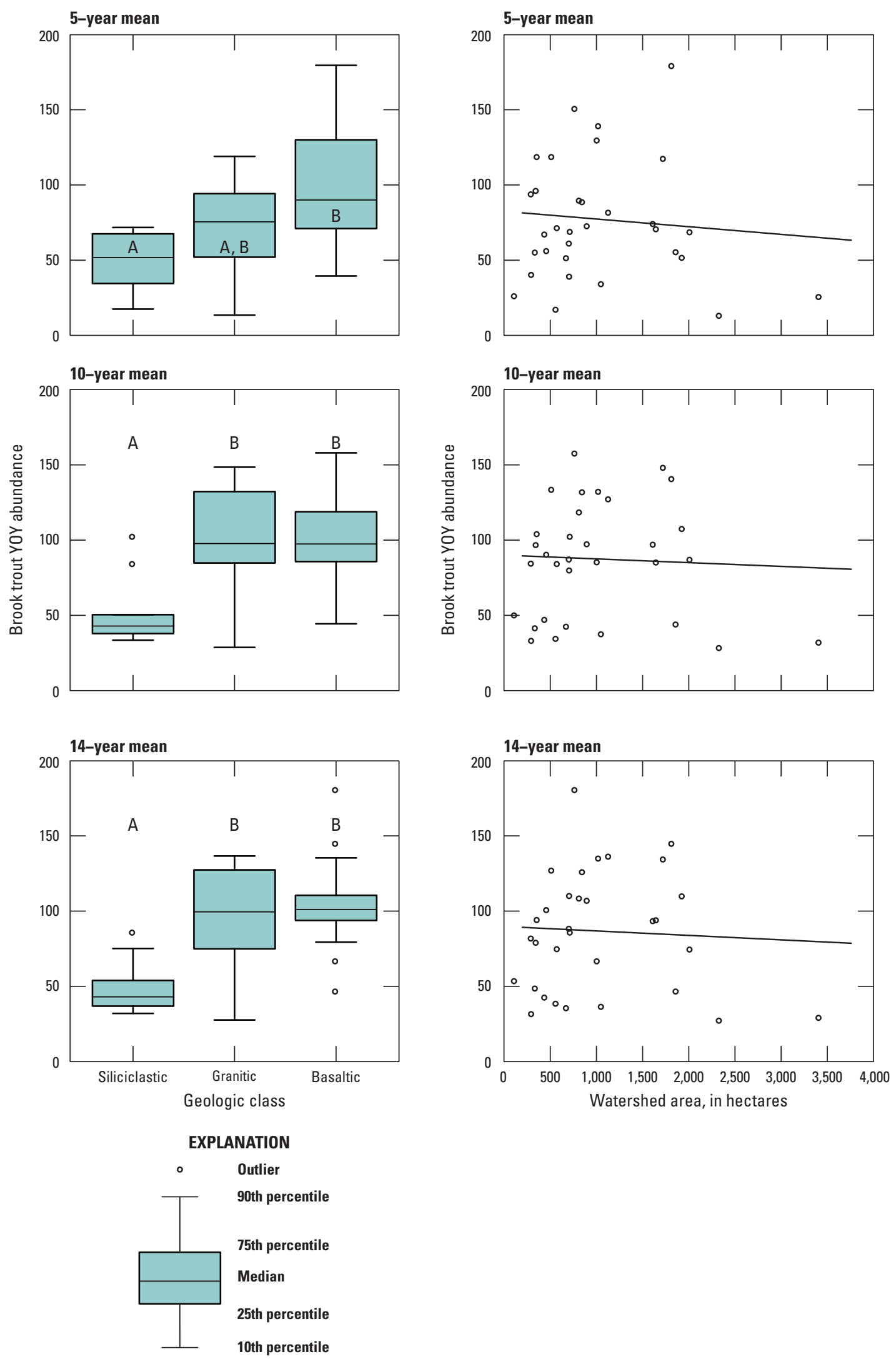

Figure 33. Distributions of brook trout young-of-year (YOY) mean abundance by geologic class and against watershed area for three time periods analyzed. Letters on boxplots indicate significant differences between classes (alpha $=0.10$ ). Watershed area plots show a least-squares regression line. 

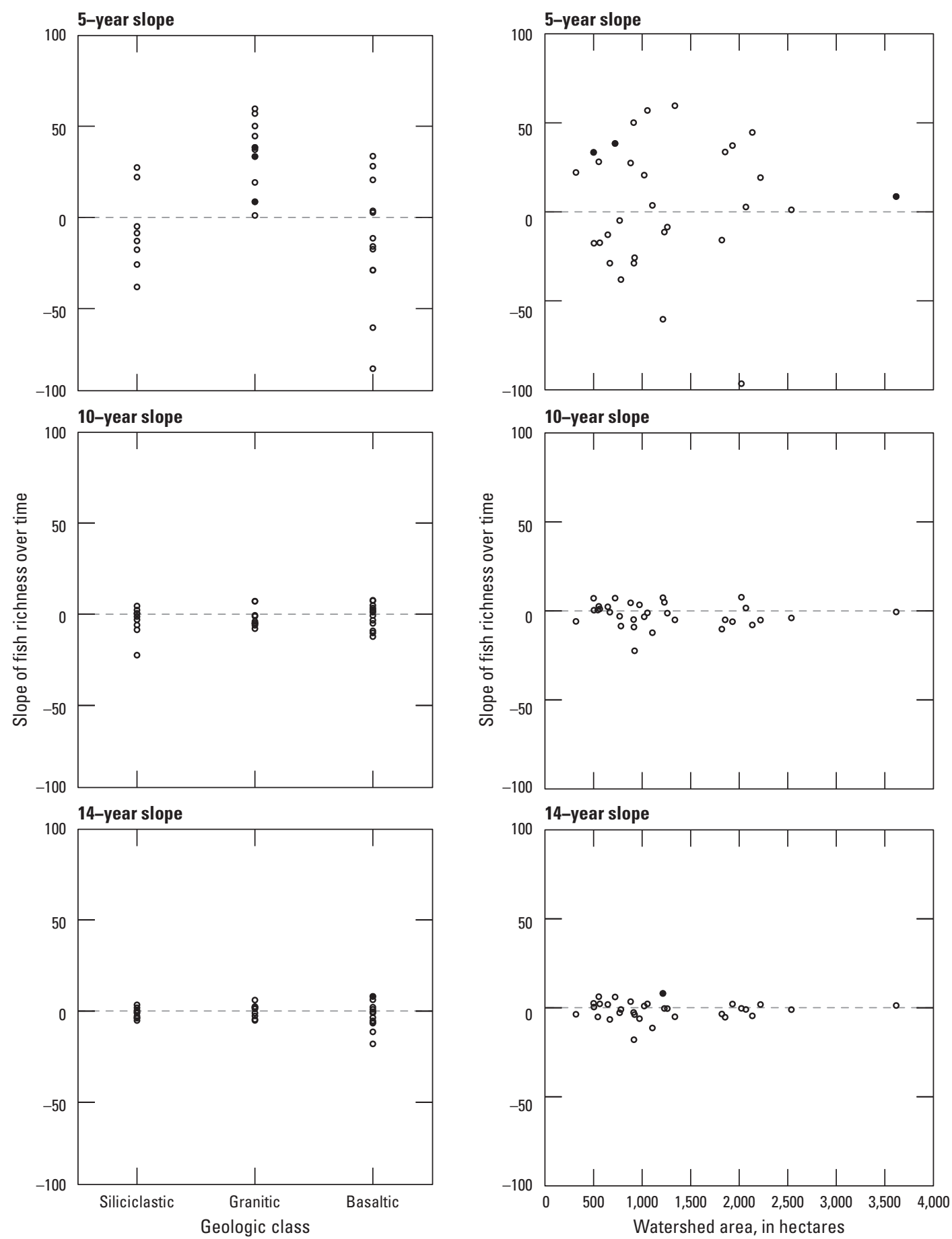

EXPLANATION

Trend slope

- Not significant $(\alpha=0.10)$

- Significant $(\alpha=0.10)$

Figure 34. Brook trout young-of-year (YOY) abundance trend slopes by geologic class and against watershed area for three time periods analyzed. 

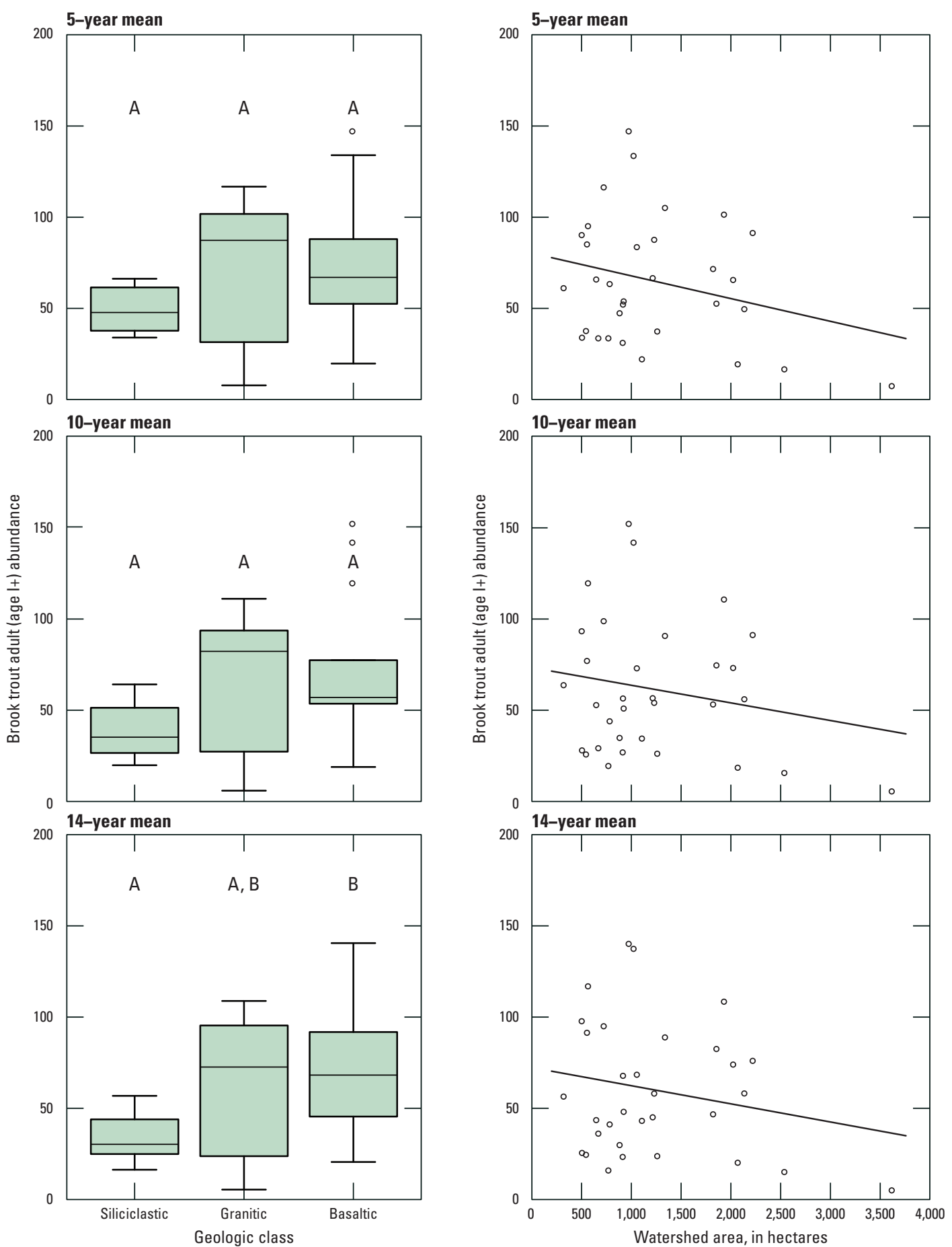

EXPLANATION

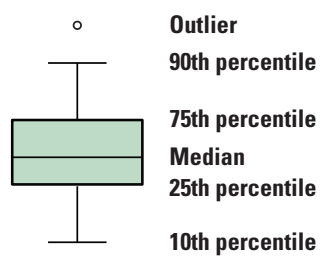

Figure 35. Distributions of brook trout adult (age greater than 1 year; age 1+) mean abundance by geologic class and against watershed area for three time periods analyzed. Letters on boxplots indicate significant differences between classes (alpha $=0.10$ ). Watershed area plots show a least-squares regression line. 

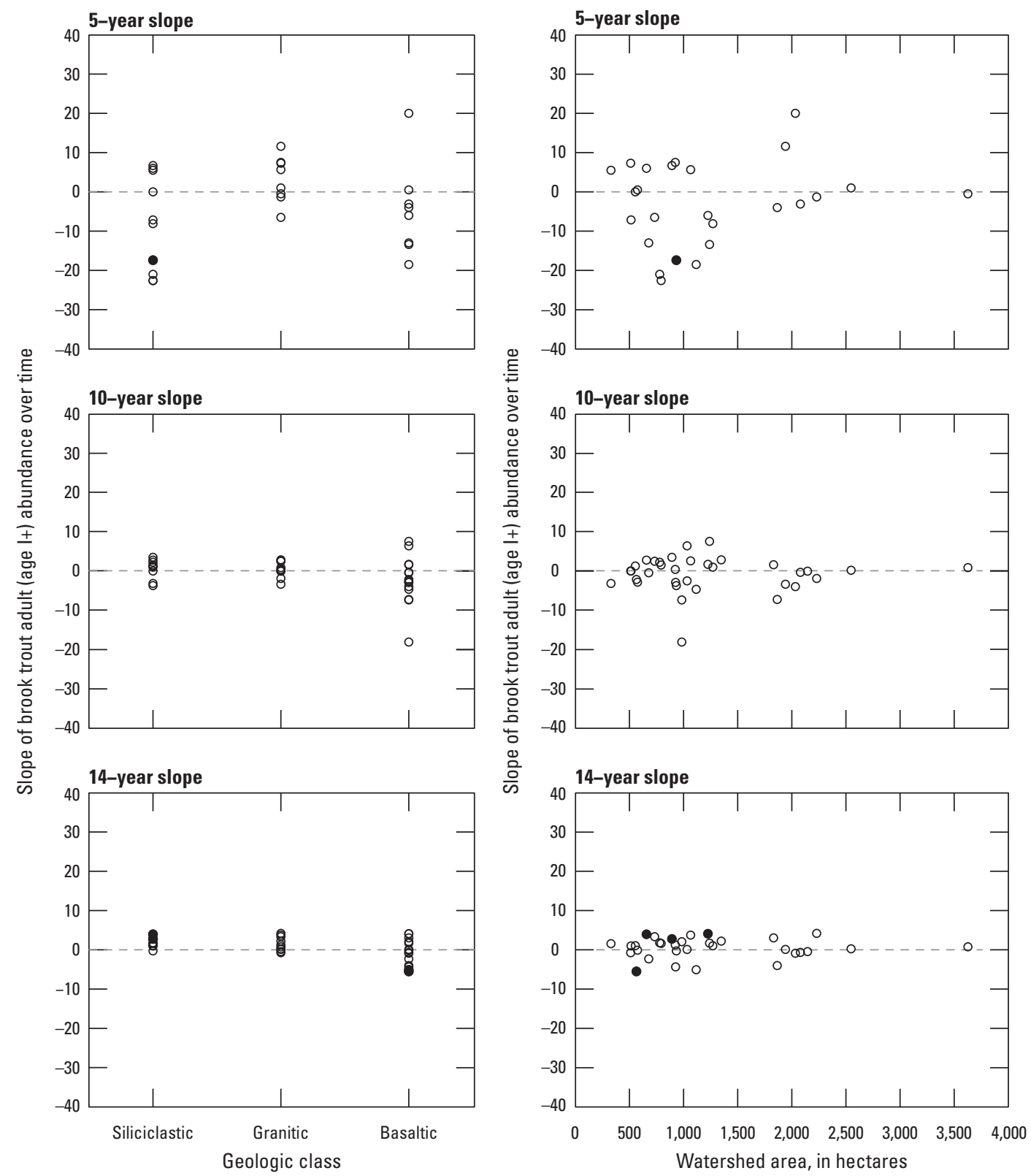

EXPLANATION

Trend slope

- Not significant $(\alpha=0.10)$

- Significant $(\alpha=0.10)$

Figure 36. Brook trout adult (age greater than 1 year; age 1+) abundance trend slopes by geologic class and against watershed area for three time periods analyzed. 

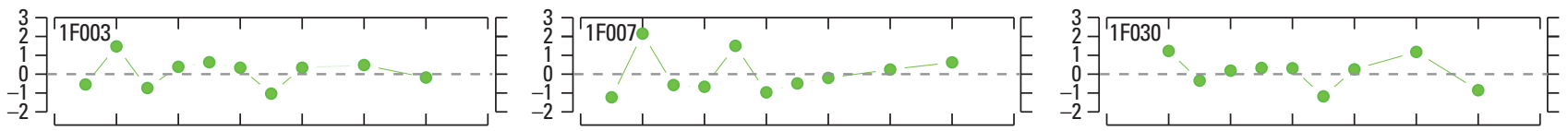

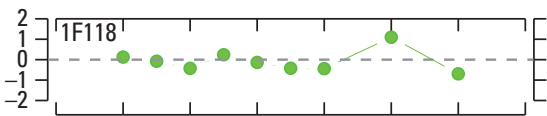
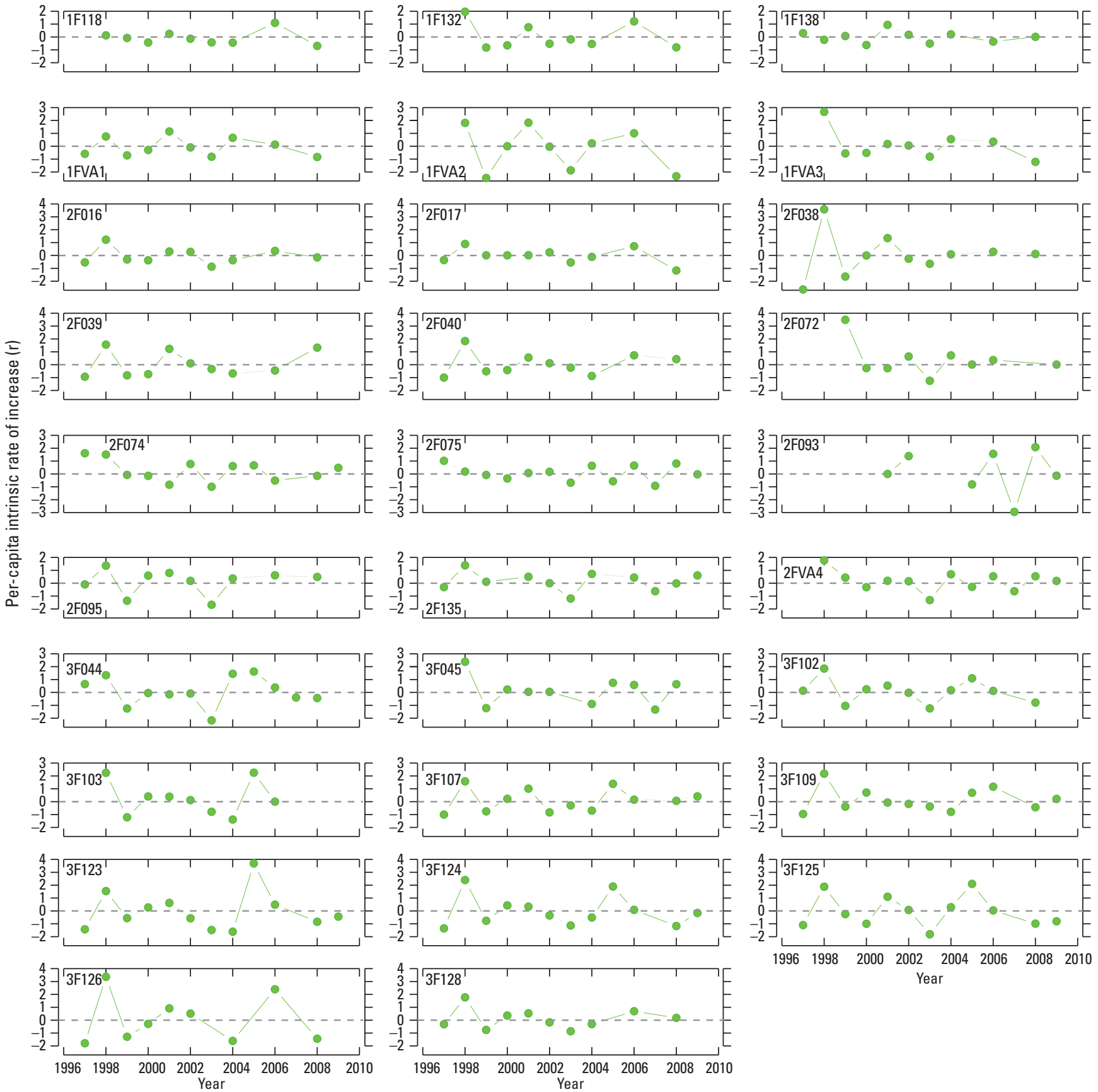

Figure 37. Per capita rate of increase $(r)$ for adult brook trout at 32 focal sites. 


\section{Relations Among Environmental Factors, Water Quality, Aquatic Macroinvertebrates, and Fish}

Similar temporal trends among water-quality, AM, and fish metrics were evaluated in order to derive hypotheses about causal explanations for temporal trends. Unfortunately, the relations cannot be modeled directly because data were not collected consistently from common sites. Three anthropogenic stressors are most likely to affect stream condition in the park: acidic deposition, pest-induced declines in forest health (primarily caused by the gypsy moth), and climate change. Local factors such as human development are less important in the park because of the protection afforded by its status as a national park unit.

\section{Stream Acidification}

Federal mandates associated with Title IV amendments of the Clean Air Act established in 1990 have significantly improved air quality nationally, including substantial reductions in sulfur dioxide $\left(\mathrm{SO}_{2}\right)$ and nitrous oxide $\left(\mathrm{NO}_{\mathrm{x}}\right)$ emissions, the primary gasses that contribute to acidic deposition. In a recent national acidic deposition assessment, Burns and others (2011) found that in addition to substantial improvements in air quality, there is evidence that the chemistry of some lakes and streams are recovering, although these improvements have been modest and sparse. In particular, streams in the mid-Atlantic have shown minimal evidence of improvement, with only 12 percent of monitored streams showing increasing trends in ANC and decreasing trends in $\mathrm{SO}_{4}{ }^{2-}$ concentrations between 1990 and 2008 (Burns and others, 2011).

The assessment of stream-water quality in the park presented herein shows a conflicting pattern of acidity trends. Long-term trends in ANC and $\mathrm{pH}$ suggest some improvement in terms of decreasing acidity, but short-term trends suggest increasing acidity. Long-term increases in $\mathrm{pH}$ occurred across all geology classes park-wide. In contrast, the long-term increases in ANC were largely limited to sites in watersheds underlain by basaltic geology (figs. 7 and 8 ). Decreasing trends in $\mathrm{SO}_{4}^{2-}$ concentrations indicated long-term improvements in basaltic watersheds, but increasing trends in siliciclastic and granitic watersheds indicate deteriorating conditions in those watersheds (fig. 9). These patterns conform to the general conclusion of Burns and others (2011) that recovery of midAtlantic streams to acidic deposition is weak at best.

There is some evidence that the AM community may have responded favorably to the long-term improvements in stream $\mathrm{pH}$ observed park-wide. Specifically, the proportion of the acid tolerant stonefly Leuctra (Leuctra:P\% metric) declined park-wide, a result consistent with park-wide declines in stream acidity. The Leuctra: $\mathrm{P} \%$ metric was selected for use in the long-term biological monitoring program in the hope that it would be a stress-specific indicator of acidity in streams; however, Leuctra abundance is also strongly related to water temperature. In contrast to the Leuctra: $\mathrm{P} \%$ metric, however, the majority of AM and water-quality data suggest water quality is not improving, at least not enough to positively affect AMs. First, the trend slopes for long-term increases in $\mathrm{pH}$ were modest (mean=approximately 0.005 per year, fig. 8). Thus, on the average, $\mathrm{pH}$ increased about $0.1 \mathrm{pH}$ unit over 20 years, an improvement not likely to be biologically significant. Second, short-term trends in $\mathrm{pH}$ actually showed the opposite trend (decreasing $\mathrm{pH}$; fig. 8), whereas the Leuctra:P\% metric declined within both long-term and short-term timeframes (fig. 24). Finally, other AM metrics that would also be expected to improve in response to decreasing acidity or increased water quality in general (EPT\%, PTV, Intol\%, Scraper\%, and Hydro:T\%), instead, were indicative of long-term stream degradation (fig. 25), and in many cases (EPT\%, PTV, Scraper\%, Hydro:T\%, and Intol\%; fig. 25) the evidence for degradation was most pronounced in those streams draining siliciclastic bedrock. Thus, in contrast to long-term trends in the Leuctra: $\mathrm{P} \%$ metric, these results suggest AM communities are continuing to be affected by acidic deposition despite the modest long-term improvements observed in $\mathrm{pH}$. This conclusion is consistent with results of acid-base chemistry modeling studies in the park (Cosby and others, 2006; Sullivan and others, 2008) that predict that recovery of park streams to acidic deposition will lag behind improvements in air quality, in part, because of concomitant declines in the base cations (calcium, magnesium, sodium, and potassium) that neutralize acidity.

Bulger and others (1995) reported a positive relation in the park between fish richness and minimum ANC values, and attributed this to the loss of fish species in siliciclastic watersheds. Although air quality has improved over the study period (Fioletov and others, 2011), species richness was lower in siliciclastic watersheds (fig. 31) and did not increase over time at these sites (fig. 32). Furthermore, abundances of YOY and adult (age 1+) brook trout were substantially lower in siliciclastic watersheds than in others (figs. 33 and 35). These results, therefore, are consistent with Bulger and others (1995) and further indicate that improvements in air quality have not substantially influenced species richness or brook trout populations in acid-sensitive watersheds. The observed increases in species richness in granitic and basaltic watersheds could indicate that these sites (1) are recovering from earlier losses of species richness, (2) support more suitable habitat for potentially immigrating fish species, and (or) (3) are connected to source populations that promote colonization dynamics within stream networks. 


\section{Water Temperature}

Park-wide increases in mean, median, and maximum water temperatures were detected for multiple time periods over the last 30 years (fig. 10), and the magnitude of these trends was substantial and probably biologically meaningful. The average annual park-wide increase in mean water temperature was $0.04{ }^{\circ} \mathrm{C}$, which equates to about $1.2{ }^{\circ} \mathrm{C}$ over the last 30 years. Short-term trends generally coincided with long-term trends, but were more variable. Increases in water temperature generally reflected increases in air temperature over the same time period, suggesting that water temperatures are responding to warmer air temperatures. The cause for warming air temperature over the last 30 years, however, is not clear, although observed patterns suggest that global (climate change) or regional (North Atlantic oscillation, land-use change) factors seem more likely than local (gypsy moth defoliation) factors as possible explanations. Irrespective of the cause, there is evidence that warming water temperatures have affected biological communities in the park.

The Leuctra:P\% metric seemed to track park-wide increases in water temperature, as the Leuctra:P\% showed declines across all four time-frames evaluated and, as with observed increases in water temperature, these declines were independent of geology (fig. 24). Observed decreases in the Leuctra:P\% metric are more consistent with park-wide increases in water temperatures than decreases in acidity. As a group, the stoneflies (order Plecoptera) are the most stenothermic of aquatic insect orders, requiring a relatively narrow range of cool or cold water to complete their life cycle (Sweeney and others, 1992; Fochetti and Tierno De Figueroa, 2008). Moreover, the genus Leuctra is one of the most stenothermic genera of stonefly taxa and has been implicated as particularly vulnerable to warming water temperatures (Tierno de Figueroa and others, 2010).

In order to examine the relation between water temperature and AM communities more fully, both mean annual water temperature and mean abundance of Leuctra were plotted by study year (fig. 38), showing that temporal patterns in water temperature and Leuctra abundance are essentially mirror images of each other. For example, during the most recent 5 -yr period between 2005 and 2009, water temperatures were substantially higher than average (1-3 standard deviations above the long-term average) while Leuctra abundance was substantially lower than average (1-3 standard deviations below the long-term average). In contrast, between 1999 and 2004, water temperatures were generally cooler than average, while Leuctra abundance was higher than average. During the early part of the monitoring period (1991-99), water temperatures exhibited considerably more annual variation than during the later part, fluctuating between warmer than average and cooler than average every 1-2 years. Even during this more variable period, however, the abundance of Leuctra mirrored water temperatures closely (fig. 38). The relation between water temperature and the
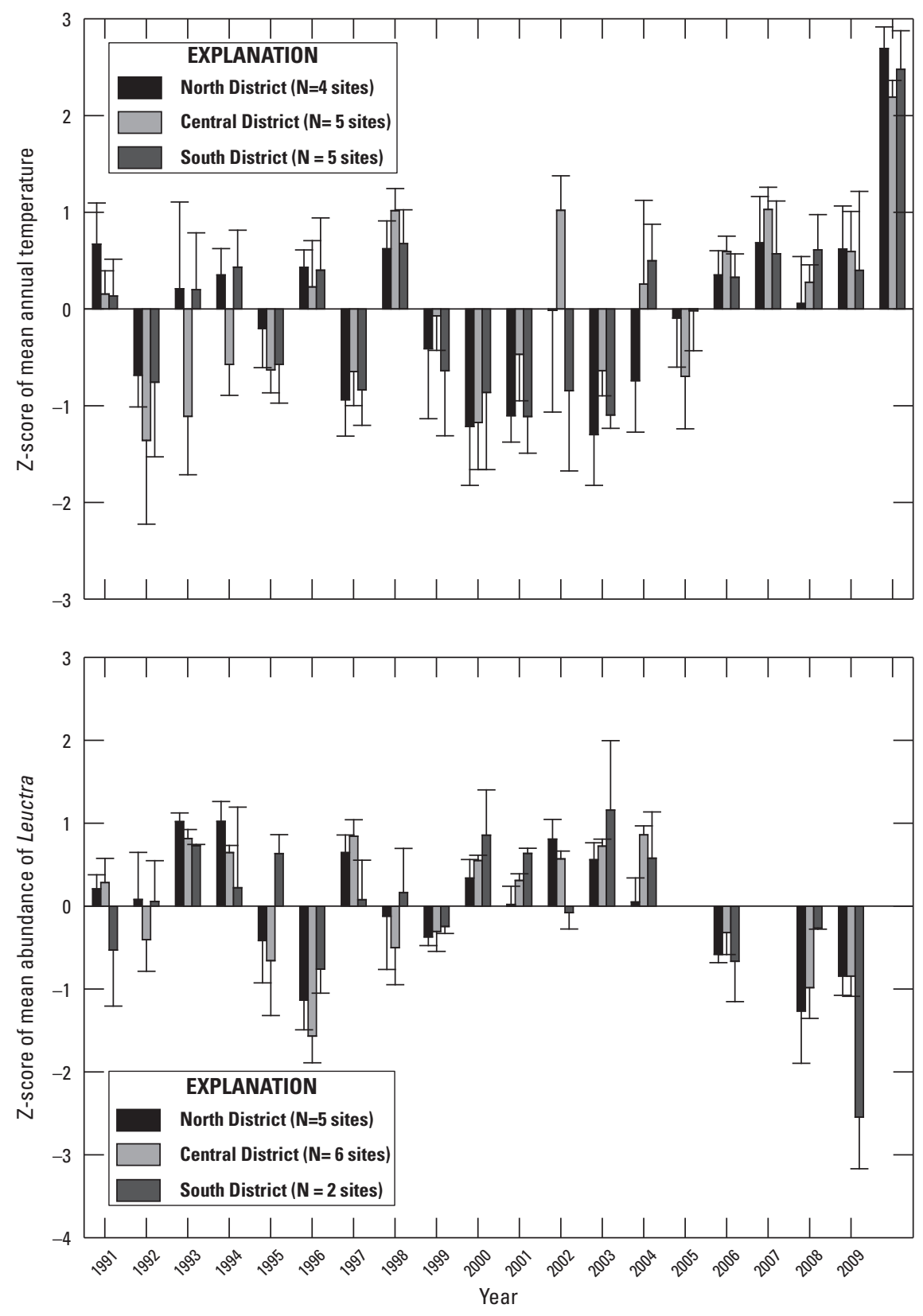

Figure 38. Z-scores of mean annual temperature $\left({ }^{\circ} \mathrm{C}\right)$ and abundance of the genus Leuctra (Log abundance +1 ) for sites with records spanning the entire monitoring period, grouped by Shenandoah National Park district. Graphs show means \pm 1 standard deviation. 
percentage of the total community composed of the genus Leuctra also was evaluated (data not shown). The analysis demonstrated that the percentage of Leuctra in the community also tracked water temperatures, but not as closely as the total abundance of Leuctra, suggesting that variation in total AM abundance was influenced by factors other than water temperature.

The data just presented provide strong support for the hypothesis that park-wide declines in Leuctra:P\% metric resulted from the effect of increasing water temperatures on the thermally sensitive and numerically abundant stonefly, Leuctra. Although these analyses cannot indicate whether recent regional increases in temperature are the result of climate change, the absolute or relative abundance of the genus Leuctra probably is responding to increasing water temperature. Therefore, the genus Leuctra may serve as a sensitive indicator of climate change.

The fact that the genus Leuctra possesses traits that make it a useful indicator of both acidity and water temperature changes in streams poses a dilemma. Leuctra is relatively acid tolerant and the decline in its relative abundance may be indicative of improving water quality (decreasing acidity); however, it is thermally sensitive and thus its decline may be indicative of increasing water temperature. The majority of evidence presented herein supports the latter explanation. This dilemma also raises the question of whether a broader perspective on species traits might serve to improve trend assessment in the park. For example, there may be other taxa that, like Leuctra, are sensitive to increasing water temperatures but, unlike Leuctra, are also sensitive to acidity. An examination of trends in these other indicator taxa would help distinguish between the effects of multiple stressors, although such examination is beyond the scope of this study. Additional details on the concept of a species-trait approach to bioassessment are presented later herein.

Changing water temperatures may affect stream fish communities through several direct and indirect pathways. Direct effects involve physiological tolerance limits (such as upper lethal water temperatures), growth rates, disease incidence rates, and biotic interactions, such as predation and competition rates. Indirect effects primarily involve the availability and quality of prey sources, such as aquatic macroinvertebrates and juvenile fish for adult brook trout and American eel, and the secondary consequences of changing fish densities and richness. It would be expected that the observed increases in water temperature would increase fish richness, and evidence in support of this prediction was found within granitic and basaltic watersheds (14-year trends; fig. 32). Water temperature increases also were observed in siliciclastic watersheds, however, where fish richness did not increase. It is suspected that colonization by fishes from outside the park boundaries is facilitated by increasing water temperatures, and such upstream colonization has been reported elsewhere (Roberts and Hitt, 2010; Hitt and Roberts, 2012). For example, observed increases in maximum water temperature (fig. 10) did not reach thermal maxima for most cool-water fishes commonly found in Virginia (Cherry and others, 1977). Further increases in fish richness would be expected if water temperatures continue to rise, reflecting the shift from a cold- to cool-water stream ecosystem and the colonization of streams in the park by source populations outside park boundaries. Further research is needed to predict asymptotic species richness given alternative water-temperature scenarios.

Increasing water temperatures also are expected to affect brook trout distributions and abundance through influences on growth rates, prey quality, competition/predation, and physiological tolerance limits. There currently is no evidence that increasing water temperatures are affecting population growth rates for brook trout in the park, because the observed mean water temperatures are generally less than $17^{\circ} \mathrm{C}$, the preferred limits for brook trout, (Cherry and others, 1977). Moreover, marginal increases in water temperature will increase individual growth rates and may increase survival, especially for YOY fishes. The observed increase in water temperature (approximately $1.2^{\circ} \mathrm{C}$ over 30 years) was estimated using linear modeling techniques, and future changes in water temperature may or may not exhibit linearity; therefore, continued monitoring of brook trout populations is critical for Shenandoah National Park to manage this resource effectively, should environmental factors alter the rate of water temperature change over time.

\section{Forest Defoliation}

Forest defoliation by insect pests, in particular the gypsy moth (Lymantria dispar), could have affected stream condition and associated biological structure and composition over the monitoring period. The gypsy moth was first reported in the park in 1984, more than 60 percent defoliation was observed by 1987 in the northern section of the park, and defoliation had spread throughout the park by 1992, including the southern section. For example, 85.2 percent of the Paine Run watershed was defoliated by 1992 (Eshleman and others, 1998). Thus, gypsy moth effects were prevalent throughout the monitoring period and, although periodic defoliation from gypsy moth continues, much of the park shows marked recovery.

Effects of forest defoliation by gypsy moth might be expected to cascade to streams in several ways. First, nutrient concentrations, especially that of dissolved nitrogen, might be expected to increase in streams, either from direct inputs through gypsy moth frass, or through reduced uptake of soil nutrients by the affected forest. The amount of light reaching streams also would be expected to increase as forests are defoliated. Because nutrients and light are naturally limited resources in headwater streams, increases might be expected to fuel autochthonous (instream) primary production by benthic algae. At the same time, allochthonous inputs from leaf material of the surrounding forest, the primary carbon source of headwater streams, probably would be reduced in defoliated watersheds. All of these factors would be expected to force a shift in trophic composition of AM consumers from shredders, 
which capitalize on large leaf material that fall into the stream, to scrapers, which feed primarily on benthic algae (Vannote and others, 1980). Lastly, the increase in sunlight associated with insect defoliation could increase water temperatures. Therefore, it is possible that forest defoliation might explain the observed increases in water temperature and associated AM community responses described earlier.

Previous research conducted in selected watersheds in the park indicated that gypsy moth defoliation results in sharp increases in $\mathrm{NO}_{3}{ }^{-}$concentrations in streams, but these increases occur primarily during storm events (Eshleman and others, 1998; Scanlon and others, 2010). As previously described, it was not possible to use the available $\mathrm{NO}_{3}{ }^{-}$data to conduct any meaningful analysis of $\mathrm{NO}_{3}{ }^{-}$trends because of the preponderance of non-detects in the dataset and limitations of the modeling approach. Based on these earlier intensive studies, it is reasonable to assume that storm-event $\mathrm{NO}_{3}{ }^{-}$concentrations have increased substantially in park streams relative to pre-infestation periods, but one would expect some level of recovery during the more recent part of the monitoring period. Although light levels have not been systematically monitored in the park, it is possible that light levels have increased relative to pre-infestation periods as well.

Aquatic macroinvertebrate trophic metrics (Shredder\% and Scraper\%) showed significant temporal trends in park streams, although temporal patterns do not appear to be related to gypsy moth induced changes in stream nutrient concentrations. Specifically, although the Shredder\% metric declines throughout the monitoring period, the Scraper $\%$ metric also shows long-term declines (fig. 25). The declines in both metrics were limited to sites in siliciclastic watersheds because no significant changes were observed in granitic or basaltic watersheds (fig. 25). Unless an argument could be made that gypsy moth defoliation was more prevalent in siliciclastic watersheds than others, the observed patterns are not consistent with trophic responses to nutrient or light enhancement caused by gypsy moth defoliation. Previous research suggests that biotic uptake of nitrogen by stream communities can be substantial, and shifts in stream trophic structure in response to nutrient fluxes caused by forest disturbances have been observed (Webster and others, 1992; Bernhardt and others, 2003). The efficiency of stream communities in removing nitrogen, however, can be significantly influenced by stream volume and flow (Arheimer and others, 1996; Marti and others, 1997). In particular, the biological uptake of nitrogen has been shown to be relatively unimportant during storm events because of reduced residence time and decreased contact between nutrient-laden water and stream sediment, the site of biological uptake in lotic systems (Arheimer and others, 1996; Marti and others, 1997). Because the effects of gypsy moth defoliation on stream $\mathrm{NO}_{3}^{-}$concentrations were mostly observed during storm events (Eshleman and others, 1998; Scanlon and others, 2010), it is likely that the elevated $\mathrm{NO}_{3}^{-}$- concentrations were not available to headwater communities in the park, although effects could be substantial in larger stream reaches or lakes and ponds farther downstream.
As discussed earlier, the park-wide decline observed in the Leuctra:P\% metric was strongly correlated with temporal increases in water temperatures. Although climate change is probably not implicated, water temperature generally tracked air temperature. Nevertheless, it is possible that forest defoliation caused by the gypsy moth may have contributed to the observed declines in the Leuctra: $\mathrm{P} \%$ metric by enhancing water-temperature increases. In this assessment of temporal patterns in water temperature (fig. 38A), however, no obvious spatial pattern to the increasing water temperature trend that would indicate a gypsy moth effect was found. Specifically, gypsy moth defoliation began in the north section of the park and proceeded south over time; consequently, if defoliation was an important factor in observed water-temperature increases, streams in the north district would be expected to be warmer early in the monitoring period and streams in the south district would be expected to be warmer later in the monitoring period. Instead, the warmest district generally seems to be random in location across years (fig. 38A).

The relation between watershed area and EPT\%, Shredder $\%$, PTV, and Intol\% observed for the most recent 5-year time period (fig. 26) did not appear to correlate with water quality or water temperature. Because the patterns observed for all four of these AM metrics indicate that smaller watersheds showed greater declines in stream condition than larger ones, it is hypothesized that these short-term trends were due to more severe or more frequent flow disturbance events, such as droughts and (or) floods. A rigorous assessment of the relations between AM community structure and temporal variation in flow would require defining flow disturbances in a biologically relevant way, which is beyond the scope of this study. The data needed to conduct this type of analysis are available. The ability to identify and account for the effects of natural disturbances, such as droughts and floods, on biological metrics could substantially improve the power to detect trends associated with anthropogenic disturbances.

\section{Considerations for Future Monitoring}

The current monitoring design in the park is spatially and temporally robust, specifically, in terms of the ability it provides to detect changes in water quality and aquatic fauna and to understand processes related to stream acidification. The current design generates the requisite data to satisfy multiple objectives, including those for which the monitoring program was not originally designed (for example, water-temperature trend analysis). Changes to this design, however, may allow for more efficient accomplishment of monitoring objectives or more complete representation of water-resource and aquatic-fauna conditions throughout the park than is currently possible. Some of these potential changes apply to the entire monitoring program, whereas others apply to specific program components. 
The overall monitoring program in the park could be improved by better integration of the three monitored components, namely, water quality, AM, and fish. Currently, the program is well designed to evaluate spatial and temporal trends in each component, but managers are limited in drawing inferences regarding causal linkages, because each component is monitored using a different set of sites. Thus, one possible improvement to the program would be to co-locate the data-collection efforts for multiple components at more sites. Co-located monitoring stations for water-quality, AM, and fish sampling would improve the ability to perform analyses of interdependencies between these monitored components of the aquatic system.

Five long-term streamgages are operated within the park as part of the SWAS program, generating valuable continuous streamflow data to aid in the interpretation of water-quality and aquatic biota data. Most watersheds in the park do not have a streamgage, however, and although extrapolation methods can be used to represent general hydrologic conditions, the most effective data analysis approaches rely upon streamflow data collected within the watershed of interest. Additionally, few data are available to describe the location and timing of natural disturbance effects, such as those of drought (and consequent periods of no flow) or floods in the park. It is hypothesized that a large fraction of short-term (5-year) temporal variation in AM community structure observed in these analyses was due to the responses of AM communities to flow disturbance events. The ability to account for natural disturbance events may provide more power to detect change caused by anthropogenic stressors, which is the primary purpose of the program. Therefore, additional streamgages in currently ungaged areas would benefit all of the aquatic monitoring programs within the park.

\section{Water-Quality Monitoring Program}

One change to the current water-quality monitoring program that would result in more efficient data collection, while still accomplishing the objective of documenting long-term trends in water quality, is to reduce the frequency of sample collection at the sites currently sampled on a weekly basis. As noted earlier in the temporal-trends discussion, the highest frequency of sampling events that can be used for trend analysis is a monthly time step. Therefore, weekly samples are unnecessary for the evaluation of long-term temporal trends and cost savings would result if the sites sampled weekly were instead sampled monthly. Furthermore, trend analysis of quarterly sampling data has been shown herein (fig. 6) to generate results comparable to those computed from monthly sampling data; therefore, a further reduction in the frequency of sample collection is achievable, while still meeting the objective of documenting long-term trends. These changes could be made to the monitoring program to save costs, if required, or to generate the funding needed to support additional monitoring stations and spatially expand the trend-monitoring network.
Such an expansion would be beneficial, because an expanded monitoring network would provide a more complete picture of long-term trends in water-resource conditions in the park. It is important to recognize, however, that weekly sampling may be valuable to satisfy different objectives of the monitoring effort and that the potential changes described here focused solely on data collection to support long-term trend analysis. For example, studies of contaminant flux require the collection of samples over the entire range of hydrologic conditions, and one approach to generating such a dataset is frequent sampling, particularly during stormflow events (for example, Riscassi and Scanlon, 2011). Although it is difficult to predict future data needs, the potential need for such studies should be carefully considered prior to altering the current monitoring program.

\section{Aquatic Macroinvertebrate Monitoring Program}

Significant spatial and temporal trends in AM metrics were detected, suggesting that sampling effort (number of samples per site, fixed area instead of fixed count sampling), taxonomic level of resolution, and sampling equipment (sampling device and associated net mesh size) were sufficient to meet the status and trends objectives of this study. Therefore, continued use of these methods is expected to continue to provide the requisite data for evaluating trends. The taxonomic identification method used for all samples, however, is described as "lowest practical," but numerous insect taxa are identified to the species level. For quantitative analysis of status and trends, this approach resulted in extensive taxonomic ambiguity at the species level, where, in almost all cases, taxa identified to the species level were also identified to higher levels of taxonomic resolution within the same sample. Thus, quantitative analysis of trends required rolling species level IDs up to the genus level to account for the variability in taxonomic level, thereby reducing the value of identifying some individuals to the species level. Consequently, cost savings potentially could be obtained by identifying taxa no further than genus level. Species-level identification, however, potentially allows park personnel or other scientists to address other research objectives in future studies, and such objectives should be considered prior to changing the identification protocol. For example, the species trait approach for bioassessment described earlier has much greater potential when considering taxa at the species level because there is considerably less variability in traits, including pollution tolerances (Lenat and Resh, 2001), within species than within higher taxonomic groupings. In addition, national parks are important repositories of native biodiversity and species are the fundamental unit of diversity. Thus, even qualitative assessments of species lists over time can have great value in terms of biological conservation.

Park managers currently rely on a set of AM metrics considered to be generalized measures of stream condition or stress. This metric approach is the most common tool 
involving AM data used for bioassessment (Jacobson, 2000; Lücke and Johnson, 2009). Given the scope and quality of the AM data collected in the park, however, it may be possible to develop stress-specific metrics that rely on autecological relations between traits of specific taxa and environmental gradients, such as the Leuctra: $\mathrm{P} \%$ metric used in these analyses, that are designed to be a specific indicator of a specific stressor. Species-traits research is a promising area of research in the field of bioassessment but requires large spatial and temporal databases to establish pertinent linkages; the park's AM (and fish) datasets offer such an opportunity. Several of the current metrics used should be adjusted for the stonefly genus Leuctra. The classification of the genus as both tolerant to acidic conditions and sensitive to most other stressors may serve more to confuse rather than elucidate inferences regarding trends.

The panel approach to site selection used in the park currently employs approximately 26 fixed sites that are sampled annually and another 6 sites sampled on a rotational basis every 3 to 9 years. The rotational sites were initially included so that, over time, all fish-bearing streams would be sampled (J.E.B. Wofford, National Park Service, written commun., 2011). At this point, most, if not all, fish-bearing streams have been sampled. From a status and trends perspective, the rotational sites do not offer much value, because they do not have the same level of temporal representation as the fixed sites. Moreover, it is clear at this point that the selected fixed sites are representative of the pertinent landscape characteristics (geology and watershed area) in the park for detecting changes in stream condition caused by regional and global stressors. Consequently, eliminating rotational sites for cost savings, or redistributing effort to accommodate more fixed sites might be appropriate at this stage of the program.

The current suite of sites sampled for AM represents important landscape gradients. Small first-order headwater streams, however, are under-represented in the Shenandoah National Park AM Program. For example, first-order streams compose nearly 70 percent of the total stream length in the park (conservatively determined from blue lines on 1:24,000scale topographic maps), yet only 30 percent of the AM fixed sites are first order (Snyder and others, 2013). Only 1 of the 24 fixed sites (those used in temporal analyses) drains an area less than 100 ha (site 1F308; table 9). It is clear from comparing results from this effort with those of Snyder and others (2013) that there are distinct differences in AM communities and their relations to landscape factors in streams having a contributing watershed area less than 100 ha compared to those having contributing areas greater than $100 \mathrm{ha}$. These differences are probably due to the relatively high vulnerability of small streams to flow disturbances, especially droughts. Consequently, increasing sampling effort in smaller watersheds would permit more rigorous evaluation of the interaction between natural disturbance and anthropogenic stressors. To be useful, however, more streamgages would be needed to monitor variation in streamflow throughout the park.

\section{Fish Monitoring Program}

The park's fish dataset provides a unique opportunity for understanding spatial and temporal changes in stream fish communities and brook-trout population dynamics. The analysis provided a synthesis of major spatial and temporal patterns and has several implications for the monitoring design and future research needs of the park.

Long-term data were necessary to observe trends in fish communities and brook trout populations. Without exception, different trends were observed for the 5-year and 14-year analyses, because extensive interannual variation in brook trout abundances dominated statistical models for 5 -year timespans, but the inclusion of additional years of data reduced such background variation such that the effects of geology and watershed area could be detected. Therefore, placing the highest priority for additional sampling on the sites with the longest existing records would permit future analysis of long-term trends.

Different trends were observed for YOY and adult brook trout, and a combined analysis may have obscured these fundamental differences. Therefore, continuing the sampling protocol, whereby YOYs are enumerated and distinguished from adult fish in the dataset, would permit such differentiation in the future. Separation of YOY and adult brook trout is a critical component of the park's fish monitoring program.

The 3-pass sampling methodology provides a more accurate sample than would be possible using fewer passes. Preliminary analyses (not shown) indicated that 1-pass data missed present species in 89 ( 15 percent) of the 578 sampling events. On one occasion (2F093 in 1999), 4 species were captured during the second and third passes that were not detected on the first pass. The stream fish community component of monitoring in the park is crucial for understanding and managing the aquatic resources of the park, and given expected increases in fish richness over time, the 3-pass sampling methodology is appropriate and should not be replaced with 1-pass samples.

The current sample reach length $(100 \mathrm{~m})$ may affect the representation of fish population and community dynamics, as these often are influenced by stream network-scale factors (Fausch and others, 2002; Hitt and Angermeier, 2011). The number of mesohabitat sequences included in a given 100-m sample reach may vary by stream size, and this could affect the opportunity to sample low-abundance or rare taxa. For example, it is expected that fewer individual pools, riffles, and runs would be encountered within an equal distance as stream volume increases. Additional sampling to quantify fish community composition surrounding sample sites in a subset of the park sample sites may aid in defining any effect of the reach length on sampling results.

Fish community and brook trout responses to changing water temperature and acidification merit continued research. First, climate-change models predict increasing maximum surface-water temperatures, and long-term park data support this prediction. The implications for fish communities 
and populations, however, are uncertain. Additional research would be necessary to develop spatially explicit models relating air and water temperatures. This work would provide inferences about the role of groundwater and the relative vulnerability of stream segments to increasing air temperatures. In turn, this would also enable spatially explicit predictions for brook trout occupancy in the future. Second, population growth rate is an important parameter for assessing fish population responses to any environmental factor (including acid deposition and temperature change), and such assessment requires sequential years of data. Given the observed spatially synchronous population growth rates park-wide, it is expected that reduction of the currently implemented biannual sampling to an annual sampling protocol would offer important benefits for trend detection without loss of information as a result of sampling fewer locations each year.

\section{Summary}

Three disparate datasets were compiled into a comprehensive database to support the analyses conducted by this study, to support future efforts to evaluate aquatic resources in Shenandoah National Park, and to provide a working database consistent with National Park Service protocols for the storage of data collected in the future. The resulting database, which was created within the NPSTORET framework, contains measurements of water quality, stream habitat, aquatic macroinvertebrates (AM), and fish, from over 600 sites and covering a time span of over 30 years.

The assessment of stream-water quality in the park presented herein found a conflicting picture of acidity trends. Long-term trends in acid-neutralizing capacity (ANC) and $\mathrm{pH}$ suggest some improvement (decreasing acidity), but short-term trends suggest increasing acidity. In addition, the long-term increase in $\mathrm{pH}$ occurred park-wide, although the increases were weak in siliciclastic watersheds. In contrast, the long-term increases in ANC were largely limited to sites in basaltic drainages (figs. 8 and 9). $\mathrm{SO}_{4}^{2-}$ concentration, a constituent of acidic deposition, indicated long-term improvements in basaltic watersheds (decreases in $\mathrm{SO}_{4}^{2-}$ concentrations), increasing concentrations in granitic watersheds, but no trend in siliciclastic or basaltic watersheds (fig. 9). Overall, this analysis demonstrates that watersheds with higher mean elevations, lower land-surface gradients, and greater proportions of basaltic and carbonate geology, are least affected by acidification and tend to be improving over time. The watersheds that are affected by acidification and are experiencing continued degradation in water quality have greater proportions of siliciclastic and granitic geology, with smaller watershed areas and higher minimum watershed elevations.

In terms of water temperature, park-wide increases in mean, median, and maximum water temperatures were detected over the last 20 years (fig. 10), and the magnitude of these trends was substantial and probably biologically meaningful. The average annual increase in mean water temperature park-wide was $0.04{ }^{\circ} \mathrm{C}$, which equates to about $1.2^{\circ} \mathrm{C}$ over the last 30 years. Short-term trends generally coincided with long-term trends, but were more variable. Although increases in water temperatures generally tracked increasing air temperatures, additional analyses of longer-term (more than 80-year) regional air-temperature data showed that the observed increases in air temperature have occurred at other times in the past; therefore, it is not clear what mechanism is responsible for the observed increases over the last 20 years.

Aquatic macroinvertebrate (AM) community metrics showed strong evidence of temporal trends in stream condition. Although the overall condition of streams in the park are considered by most measures to be relatively healthy, there is evidence from spatial and temporal trend assessments that streams in siliciclastic watersheds have been, and continue to be, affected by acidic deposition, despite regional improvements in air quality. Although climate change is not conclusively implicated, streams in the park have warmed significantly over the last 20 years, and there is evidence that $\mathrm{AM}$ communities have responded to the warming trend. The correlation provides some assurance that AM monitoring protocols and metrics are sufficiently sensitive to detect future climate-change effects. There is no clear evidence that trends in AM communities are responding, or have responded, to gypsy moth defoliation.

The quality of the AM data collected over the 20-year period is high (consistent sampling methods employed and taxonomic ID conducted by the same personnel); therefore, confidence in the reported patterns and relations is high. Some of the limitations of the collected data and associated exploratory analyses that were employed are worth noting. First, data for water quality, AM, and fish were derived from different sites, and therefore, relations could not be directly assessed. Thus, although relatively strong inferences were derived from comparing common responses of these different responses to spatial and temporal gradients, better integration of sampling could improve the strength of trend analyses. Second, the selection of the four time periods selected for evaluation in this study essentially was arbitrary, based largely on periods of time for which data for stream water quality, AM, and fish were available. No effort was made to objectively define the boundaries (years) of a consistent trend. For example, only short-term trends for the most recent 5 -year period between 2005 and 2009 were evaluated, although it was clear from plotting the raw metric data by time (not shown) that there were numerous short-term fluctuations in the abundance and diversity of AM communities dispersed throughout the 20 -year monitoring period. It is hypothesized that a large fraction of the short-term variation in AM community structure may be due to the effects of natural disturbances, such as floods and droughts.

This analysis provided several key inferences regarding fish community and brook-trout population dynamics within the park. Increasing trends in species richness from 1996 to 2010 were detected, and these increases were greatest in the 
largest streams. Increases in richness may partially be due to increased water temperatures, but future research would be necessary to test this hypothesis. These increases in richness were detected only in watersheds underlain by granitic and basaltic geology; no trend in richness was detected in siliciclastic watersheds, which also had the lowest richness values. The low richness values and lack of improvement over time in siliciclastic watersheds is further evidence that recovery from acidification is not yet occurring in these watersheds.

Brook trout metrics provided further evidence of the effects of acidification in siliciclastic watersheds, because mean YOY and adult (age 1+) abundances were consistently lower in these watersheds than in others. Long-term (15-year) increases were detected in adult abundances in the siliciclastic watersheds, although YOY abundances showed a declining trend during this same period. These conflicting trends in YOY abundance and adult (age 1+) abundances demonstrate the importance of partitioning YOY and adult fish data in surveys. Increasing water temperatures apparently did not affect brooktrout population growth rates from 1996 to 2010, but continued monitoring would be necessary to evaluate future watertemperature changes and brook trout population responses.

Finally, the monitoring design in the park was found to be generating a spatially and temporally robust dataset, specifically in terms of the ability it provides to detect long-term changes in water quality and aquatic fauna, and to understand processes related to stream acidification. This dataset was found to be sufficient to satisfy multiple objectives, including objectives or data analysis for which the monitoring program was not originally designed (for example, water-temperature trend analysis). Multiple changes to this design that may allow for more efficient accomplishment of monitoring objectives or more complete representation of water-resources and aquatic fauna conditions throughout the park were identified. For example, results of the water-quality trend analysis demonstrate that the quarterly sampling scheme generates the requisite data for long-term trend monitoring, and therefore, savings may be achieved by reducing the sampling frequency for trend monitoring from weekly or monthly to quarterly. Discontinuities in the sampling locations for water-quality, $\mathrm{AM}$, and fish monitoring programs, however, presented challenges for holistic analysis of relations between the three components, and future co-location of monitoring stations would enable more detailed analysis of the relations between water-quality, AM, and fish. Lastly, the scarcity of streamflow data collected within the park presents challenges in evaluating relations between hydrology, water-quality, AM, and fish - a challenge that could be overcome with the operation of additional streamgages.

\section{References Cited}

Arheimer, B., Andersson, L., and Lepistö, A., 1996, Variation of nitrogen concentration in forest streams - Influences of flow, seasonality and catchment characteristics: Journal of Hydrology, v. 179, no. 1-4, p. 281-304.

Atkinson, J.B., 2002, Shenandoah National Park fisheries monitoring protocol: Luray, Va., Shenandoah National Park, $67 \mathrm{p}$.

Barbour, M.T., Gerritsen, J., Snyder, B.D., and Stribling, J.B., 1999, Rapid bioassessment protocols for use in streams and wadeable rivers - Periphyton, benthic macroinvertebrates, and fish: Washington, D.C., U.S. Environmental Protection Agency, Office of Water, $339 \mathrm{p}$.

Berg, L.Y., and Moore, R.B., 1941, Forest cover types of Shenandoah National Park, Virginia: U.S. Department of the Interior, National Park Service, Region One, 132 p.

Bernhardt, E.S., Likens, G.E., Buso, D.C., and Driscoll, C.T., 2003, In-stream uptake dampens effects of major forest disturbance on watershed nitrogen export: Proceedings of the National Academy of Sciences, v. 100, no. 18, p. 10304-10308.

Bowman, M.F., Somers, K.M., Reid, R.A., and Scott, L.D., 2006, Temporal response of stream benthic macroinvertebrate communities to the synergistic effects of anthropogenic acidification and natural drought events: Freshwater Biology, v. 51, no. 4, p. 768-782.

Bricker, O.P., and Rice, K.C., 1989, Acidic deposition to streams - A geology-based method predicts their sensitivity: Environmental Science \& Technology, v. 23, no. 4, p. $379-385$.

Brown, B.L., Swan, C.M., Auerbach, D.A., Campbell Grant, E.H., Hitt, N.P., Maloney, K.O., and Patrick, C., 2011, Metacommunity theory as a multispecies, multiscale framework for studying the influence of river network structure on riverine communities and ecosystems: Journal of the North American Benthological Society, v. 30, no. 1, p. 310-327.

Bulger, A.J., Dolloff, C.A., Cosby, B.J., Eshleman, K.N., Webb, J.R., and Galloway, J.N., 1995, The "Shenandoah National Park: Fish in sensitive habitats" (SNP: FISH) project. An integrated assessment of fish community responses to stream acidification: Water, Air, \& Soil Pollution, v. 85, no. 2, p. 309-314.

Burns, D.A., Lynch, J.A., Cosby, B.J., Fenn, M.E., Baron, J.S., U.S. EPA Clean Air Markets Division, 2011, National Acid Precipitation Assessment Program Report to Congress 2011-An Integrated Assessment: Washington, D.C., National Science and Technology Council, 114 p. 
Burton, J., and Gerritsen, J., 2003, A stream condition index for Virginia non-coastal streams: Owings Mills, Md., Tetra Tech, Inc., 163 p.

Cherry, D.S., Dickson, K.L., Cairns, J., Jr., and Stauffer, J.R., 1977, Preferred, avoided, and lethal temperatures of fish during rising temperature conditions: Journal of the Fisheries Research Board of Canada, v. 34, no. 2, p. 239-246.

Clarke, A., Mac Nally, R., Bond, N., and Lake, P.S., 2008, Macroinvertebrate diversity in headwater streams-A review: Freshwater Biology, v. 53, no. 9, p. 1707-1721.

Clarkson, R.B., 1964, Tumult on the mountains: Lumbering in West Virginia, 1770-1920: Parsons, W. Va., McClain Printing Co., 410 p.

Cosby, B.J., Ryan, P.F., Webb, J.R., Hornberger, G.M., and Galloway, J.N., 1991, Mountains of western Virginia, chap. 10 of Charles, D.F., and Christie, S., eds., Acidic deposition and aquatic ecosystems: New York, Springer-Verlag, p. 297-318.

Cosby, B.J., Webb, J.R., Galloway, J.N., and Deviney, F.A., 2006, Acidic deposition impacts of natural resources in Shenandoah National Park: National Park Service Technical Report NPS/NER/NRTR-2006/066, 35 p.

Cuffney, T.F., Bilger, M.D., and Haigler, A.M., 2007, Ambiguous taxa-Effects on the characterization and interpretation of invertebrate assemblages: Journal of the North American Benthological Society, v. 26, no. 2, p. 286-307.

Cuffney, T.F., and Brightbill, R.A., 2011, User's manual for the National Water-Quality Assessment Program Invertebrate Data Analysis System (IDAS) software, version 5: U.S. Geological Survey Techniques and Methods book 7, chap. C4, 126 p.

Deviney, F.A., Jr., Brown, D.E., and Rice, K.C., 2012, Evaluation of Bayesian estimation of a hidden continuous-time Markov chain model with application to threshold violation in water-quality indicators: Journal of Environmental Informatics, v. 19, no. 2, p. 70-78. (Also available at http:// dx.doi.org/10.3808/jei.201200210.)

Deviney, F.A., Jr., Rice, K.C., and Hornberger, G.M., 2006, Time series and recurrence interval models to predict the vulnerability of streams to episodic acidification in Shenandoah National Park, Virginia: Water Resources Research, v. 42, W09405, (Also available at http://dx.doi. org/10.1029/2005WR004740.)

DeVivo, M.S., 1986, The deforestation of western North Carolina-1900 to 1920: Pioneer America Society Transactions, v. 9, p. 89-94.
Eshleman, K.N., Morgan, R.P., II, Webb, J.R., Deviney, F.A., and Galloway, J.N., 1998, Temporal patterns of nitrogen leakage from mid-Appalachian forested watersheds: Role of insect defoliation: Water Resources Research, v. 34, no. 8, p. 2005-2016.

Fausch, K.D., Torgersen, C.E., Baxter, C.V., and Li, H.W., 2002, Landscapes to riverscapes: Bridging the gap between research and conservation of stream fishes: BioScience, v. 52, no. 6 , p. 483-498.

Fenneman, N.M., and Johnson, D.W., 1946, Physical divisions of the United States (Map): Washington, D.C., U.S. Geological Survey.

Fioletov, V.E., McLinden, C.A., Krotkov, N., Moran, M.D., and Yang, K., 2011, Estimation of $\mathrm{SO}_{2}$ emissions using OMI retrievals: Geophysical Research Letters, v. 38, no. 21, p. L21811.

Fjellheim, A., and Raddum, G.G., 1990, Acid precipitationBiological monitoring of streams and lakes: Science of The Total Environment, v. 96, no. 1-2, p. 57-66.

Fochetti, R., and Tierno de Figueroa, J.M., 2008, Global diversity of stoneflies (Plecoptera; Insecta) in freshwater: Hydrobiologia, v. 595, no. 1, p. 365-377.

Foster, D., Motzkin, G., O’Keefe, J., Boose, E., Orwig, D., Fuller, J., and Hall, B., 2004, The environmental and human history of New England, in Foster, D.R., and Aber, J.D., eds., Forests in Time: The environmental consequences of 1,000 years of change in New England: New Haven, Conn., Yale University Press, p. 43-101.

Griffith, M.B., Perry, S.A., and Perry, W.B., 1995, Macroinvertebrate communities in headwater streams affected by acidic precipitation in the central Appalachians: Journal of Environmental Quality, v. 24, no. 2, p. 233-238.

Haggerty, S.M., Batzer, D.P., and Jackson, C.R., 2002, Macroinvertebrate assemblages in perennial headwater streams of the Coastal Mountain range of Washington, U.S.A.: Hydrobiologia, v. 479, no. 1, p. 143-154.

Heino, J., 2005, Functional biodiversity of macroinvertebrate assemblages along major ecological gradients of boreal headwater streams: Freshwater Biology, v. 50, no. 9, p. 1578-1587.

Helsel, D.R., and Hirsch, R.M., 2002, Statistical methods in water resources: U.S. Geological Survey Techniques of Water-Resources Investigations, book 4, chap. A3, 523 p.

Hem, J.D., 1985, Study and interpretation of the chemical characteristics of natural water ( $3 \mathrm{~d}$ ed.): U.S. Geological Survey Water-Supply Paper 2254, 263 p. 
Herlihy, A.T., Kaufmann, P.R., Church, M.R., Wigington, P.J., Jr., Webb, J.R., and Sale, M.J., 1993, The effects of acidic deposition on streams in the Appalachian Mountain and Piedmont Region of the Mid-Atlantic United States: Water Resources Research, v. 29, no. 8, p. 2687-2703.

Hirsch, R.M., and Slack, J.R., 1984, A nonparametric trend test for seasonal data with serial dependence: Water Resources Research, v. 20, no. 1, p. 727-732.

Hirsch, R.M., Slack, J.R., and Smith, R.A., 1982, Techniques of trend analysis for monthly water quality data: Water Resources Research, v. 18, no. 1, p. 107-121, (Also available at http://dx.doi.org/10.1029/WR018i001p00107.)

Hitt, N.P., and Angermeier, P.L., 2011, Fish community and bioassessment responses to stream network position: Journal of the North American Benthological Society, v. 30, no. 1, p. 296-309.

Hitt, N.P., Eyler, S., and Wofford, J.E.B., 2012, Dam removal increases American Eel abundance in distant headwater streams: Transactions of the American Fisheries Society, v. 141, no. 5, p. 1171-1179.

Hitt, N.P., and Roberts, J.H., 2012, Hierarchical spatial structure of stream fish colonization and extinction: Oikos, v. 121 , no. 1 , p. $127-137$.

Homer, Collin, Huang, Chengquan, Yang, Limin, Wylie, Bruce and Coan, Michael, 2004, Development of a 2001 National Landcover Database for the United States: Photogrammetric Engineering and Remote Sensing, v. 70, no. 7, p. 829-840.

Jacobson, P.T., 2000, Evaluation of multi-metric bioassessment as an approach for assessing impacts of entrainment and impingement under Section 316(b) of the Clean Water Act: Environmental Science \& Policy, v. 3, supplement 1, p. 107-115.

Jenkins, R.E., and Burkhead N.M., 1994, The freshwater fishes of Virginia: Bethesda, M.D., American Fisheries Society, $1079 \mathrm{p}$.

Kalnay, E., and Cai, M., 2003, Impact of urbanization and land-use change on climate: Nature, v. 423, p. 528-531.

Kaushal, S.S., Likens, G.E., Jaworski, N.A., Pace, M.L., Sides, A.M., Seekell, D., Belt, K.T., Secor, D.H., and Wingate, R.L., 2010, Rising stream and river temperatures in the United States: Frontiers in Ecology and the Environment, v. 8 , no. 9, p. 461-466.

Kendall, M.G., 1975, Rank correlation methods: Oxford, U.K., Griffin, 202 p.
Kimmel, W.G., Murphey, D.J., Sharpe, W.E., and DeWalle, D.R., 1985, Macroinvertebrate community structure and detritus processing rates in two southwestern Pennsylvania streams acidified by atmospheric deposition: Hydrobiologia, v. 124 , no. 2 , p. $97-102$.

Klemm, D.J., Blocksom, K.A., Thoeny, W.T., Fulk, F.A., Herlihy, A.T., Kaufmann, P.R., and Cormier, S.M., 2002, Methods development and use of macroinvertebrates as indicators of ecological conditions for streams in the MidAtlantic Highlands Region: Environmental monitoring and assessment, v. 78, no. 2, p. 169-212.

Lenat, D.R., 1993, A biotic index for the southeastern United States: Derivation and list of tolerance values, with criteria for assigning water-quality ratings: Journal of the North American Benthological Society, v. 12, no. 3, p. 279-290.

Lenat, D.R., and Resh, V.H., 2001, Taxonomy and stream ecology - The benefits of genus- and species-level identifications: Journal of the North American Benthological Society, v. 20, no. 2, p. 287-298.

Likens, G.E., 2010, River ecosystem ecology-A global perspective: San Diego, Calif., Academic Press, 425 p.

Lücke, J.D., and Johnson, R.K., 2009, Detection of ecological change in stream macroinvertebrate assemblages using single metric, multimetric or multivariate approaches: Ecological Indicators, v. 9, no. 4, p. 659-669.

Mann, H.B., 1945, Nonparametric tests against trend: Econometrica, v. 13 , no. 3, p. 245-259.

Martí, E., Grimm, N.B., and Fisher, S.G., 1997, Pre- and post-flood retention efficiency of nitrogen in a Sonoran desert stream: Journal of the North American Benthological Society, v. 16, no. 4, p. 805-819.

McCune, B., Grace, J.B., and Urban, D.L., 2002, Analysis of ecological communities: Gleneden Beach, Oreg., MjM Software Design, 304 p.

Merritt, R.W., and Cummins, K.W., 1996, An introduction to the aquatic insects of North America: Dubuque, Iowa, Kendall Hunt, 862 p.

Morgan, B.A., Eaton, L.S., and Wieczorek, G.F., 2003, Pleistocene and Holocene colluvial fans and terraces in the Blue Ridge region of Shenandoah National Park, Virginia: U.S. Geological Survey Open-File Report 03-410, 25 p.

National Oceanic and Atmospheric Administration, 2012, Climate Data Online Database: National Climatic Data Center, accessed March 12, 2012, at http://www.ncdc.noaa. gov/cdo-web/.

National Park Service, 1998, Resource Management Plan: Luray, Va., Shenandoah National Park. 
National Park Service, 2008, Natural resource fact sheet: Luray, Va., Aquatic macroinvertebrate monitoring program.

National Park Service, 2012, Weather-Shenandoah National Park: Accessed February 15, 2012, at http://www.nps.gov/ shen/naturescience/weather.htm.

National Park Service, 2013, Fish—Shenandoah National Park: Accessed April 26, 2013, at http://www.nps.gov/shen/ naturescience/fish.htm

Rice, K.C., Deviney, F.A., and Olson, G., 2007, Acid rain in Shenandoah National Park, Virginia: U.S. Geological Survey Fact Sheet 2007-3057, 4 p. (Also available at http:// pubs.usgs.gov/fs/2007/3057/).

Riscassi, A.L., and Scanlon, T.M., 2011, Controls on stream water dissolved mercury in three mid-Appalachian forested headwater catchments: Water Resources Research, v. 47, no. 12 .

Roberts, J.H., and Hitt, N.P., 2010, Longitudinal structure in temperate stream fish communities-Evaluating conceptual models with temporal data: American Fisheries Society Symposium, v. 73, p. 281-299.

Roghair, C.N., and Dolloff, C.A., 2005, Brook Trout movement during and after recolonization of a naturally defaunated stream reach: North American Journal of Fisheries Management, v. 25, no. 3, p. 777-784.

Rosenberg, D.M., and Resh, V.H., 1993, Freshwater biomonitoring and benthic macroinvertebrates: New York, Chapman \& Hall, 516 p.

Scanlon, T.M., Ingram, S.M., and Riscassi, A.L., 2010, Terrestrial and in-stream influences on the spatial variability of nitrate in a forested headwater catchment: Journal of Geophysical Research, v. 115, no. G2, p. G02022.

Schertz, T.L., Alexander, R.B, and Ohe, D.J., 1991, The computer program EStimate TREND (ESTREND), a system for the detection of trends in water-quality data: U.S. Geological Survey Water-Resources Investigations Report 91-4040, $63 \mathrm{p}$.

Shaw, P.J.A., 2003, Multivariate statistics for the environmental sciences: New York, Oxford University Press, 233 p.

Shreve, R.L., 1966, Statistical law of stream numbers: The Journal of Geology, v. 74, no. 1, p. 17-37.

Slack, J.R., Lorenz, D.L., and others, 2003, USGS library for S-PLUS for Windows-Release 2.1: U.S. Geological Survey Open-File Report 03-357
Snyder, C.D., and Johnson, Z.B., 2006, Macroinvertebrate assemblage recovery following a catastrophic flood and debris flows in an Appalachian mountain stream: Journal of the North American Benthological Society, v. 25, no. 4, p. 825-840.

Snyder, C.D., Webb, J.R., Young, J.A., and Johnson, Z.B., 2013, Significance of headwater streams and perennial springs in ecological monitoring in Shenandoah National Park: U.S. Geological Survey Open-File Report 2013-1178, $46 \mathrm{p}$.

Snyder, C.D., Young, J.A., and Stout, B.M., III, 2006, Aquatic habitats of Canaan Valley, West Virginia: Diversity and environmental threats: Northeastern Naturalist, v. 13, no. 3, p. 333-352.

Sokal, R.R., and Rohlf, F.J., 1995, Biometry (3d ed.): New York, W.H. Freeman and Company, 88 p.

Soucek, D.J., 2007, Sodium sulfate impacts feeding, specific dynamic action, and growth rate in the freshwater bivalve Corbicula fluminea: Aquatic toxicology, v. 83, no. 4, p. 315-322.

Southworth, Scott, Aleinikoff, J.N., Bailey, C.M., Burton, W.C., Crider, E.A., Hackley, P.C., Smoot, J.P., and Tollo, R.P., 2009, Geologic map of the Shenandoah National Park region Virginia: U.S. Geological Survey Open-File Report 2009-1153, 96 p., 1 plate, scale 1:100,000.

Strahler, A.N., 1952, Hypsometric (area-altitude) analysis of erosional topography: Geological Society of America Bulletin, v. 63, no. 11, p. 1117-1142.

Sullivan, T.J., Cosby, B.J., Webb, J.R., Dennis, R.L., Bulger, A.J., and Deviney, F.A., Jr., 2008, Streamwater acid-base chemistry and critical loads of atmospheric sulfur deposition in Shenandoah National Park, Virginia: Environmental Monitoring and Assessment, v. 137, no. 1-3, p. 85-99.

Sweeney, B.W., Jackson, J.K., Newbold, J.D., and Funk, D.H., 1992, Climate change and the life histories and biogeography of aquatic insects in eastern North America, in Firth, P., and Fisher, S.G., eds., Global climate change and freshwater ecosystems: New York, Springer-Verlag Press, 321 p.

Tierno de Figueroa, J., López-Rodríguez, M., Lorenz, A., Graf, W., Schmidt-Kloiber, A., and Hering, D., 2010, Vulnerable taxa of European Plecoptera (Insecta) in the context of climate change: Biodiversity and Conservation, v. 19, no. 5, p. 1269-1277.

U.S. Department of the Interior, 1932, Final report of the Southern Appalachian National Park Commission to the Secretary of the Interior: Washington, D.C., United States Government Printing Office, $39 \mathrm{p}$. 
Vana-Miller, D.L., and Weeks, D.P., 2004, Shenandoah National Park, Virginia, water resources scoping report: Technical Report NPS/NRWRS/NRTR-2004/320, 138 p.

Vannote, R.L., Minshall, G.W., Cummins, K.W., Sedell, J.R., and Cushing, C.E., 1980, The river continuum concept: Canadian Journal of Fisheries and Aquatic Sciences, v. 37, no. 1, p. $130-137$.

Venables, W.N., and Ripley, B.D., 2000, S Programming (1st ed.): New York, Springer-Verlag, 266 p.

Virginia Division of Mineral Resources, 2003, Digital representation of the 1993 geologic map of Virginia: Virginia Division of Mineral Resources Publication 174 [CD-ROM; 2003, December 31]. [Adapted from Virginia Division of Mineral Resources, 1993, Geologic map of Virginia: Virginia Division of Mineral Resources, scale 1:500,000.]

Visbeck, M.H., Hurrell, J.W., Polvani, L., and Cullen, H.M., 2001, The North Atlantic Oscillation: Past, present, and future: Proceedings of the National Academy of Sciences, v. 98 , no. 23 , p. $12876-12877$.
Webster, J.R., Golladay, S.W., Benfield, E.F., Myer, J.L., Swank, W.T., and Wallace, J.B., 1992, Catchment disturbance and stream response-An overview of stream research at Coweeta Hydrologic Laboratory, chap. 15, in Boon, P.J., Calow, P., and Petts, G.E., eds., River conservation and management: Chichester, U.K., John Wiley and Sons, Ltd., $470 \mathrm{p}$.

Wohl, D.L., Wallace, J.B., and Meyer, J.L., 1995, Benthic macroinvertebrate community structure, function and production with respect to habitat type, reach and drainage basin in the southern Appalachians (U.S.A.): Freshwater Biology, v. 34, no. 3, p. 447-464.

Zar, J.H., 1999, Biostatistical analysis (4th ed.): Upper Saddle River, N.J., Prentice Hall, 663 p.

Zipper, C.E., Holtzman, G.I., Darken, P.F., Gildea, J.J., and Stewart, R.E., 2002, Virginia USA water quality, 1978 to 1995: Regional interpretation: Journal of the American Water Resources Association, v. 38, no. 3, p. 789-802. 

Appendix 1. Macroinvertebrate taxa collected at 24 Long Term Ecological Monitoring (LTEM) Program sites between 1990 and 2009, and 54 sites in 1995 (data used in the retrospective analyses contained in this report).

[Table contains taxonomic descriptions as well as taxon-specific ecological characteristics required to compute summary statistics shown in table 10. -, taxa not defined at this level; USGS, U.S. Geological Survey. Functional groups are as follows: CF, Collector filterer; CG, Collector-gatherer; GN, Generalist feeder; MP, Macrophyte piercer; PR, Predator; SC, Scraper; and SH, shredder. Habit codes are as follows: BU, Burrowers; CG, Clingers; CL, Climbers; DV, Divers; GN, Generalist; SK, Skaters; and SP, Sprawlers]

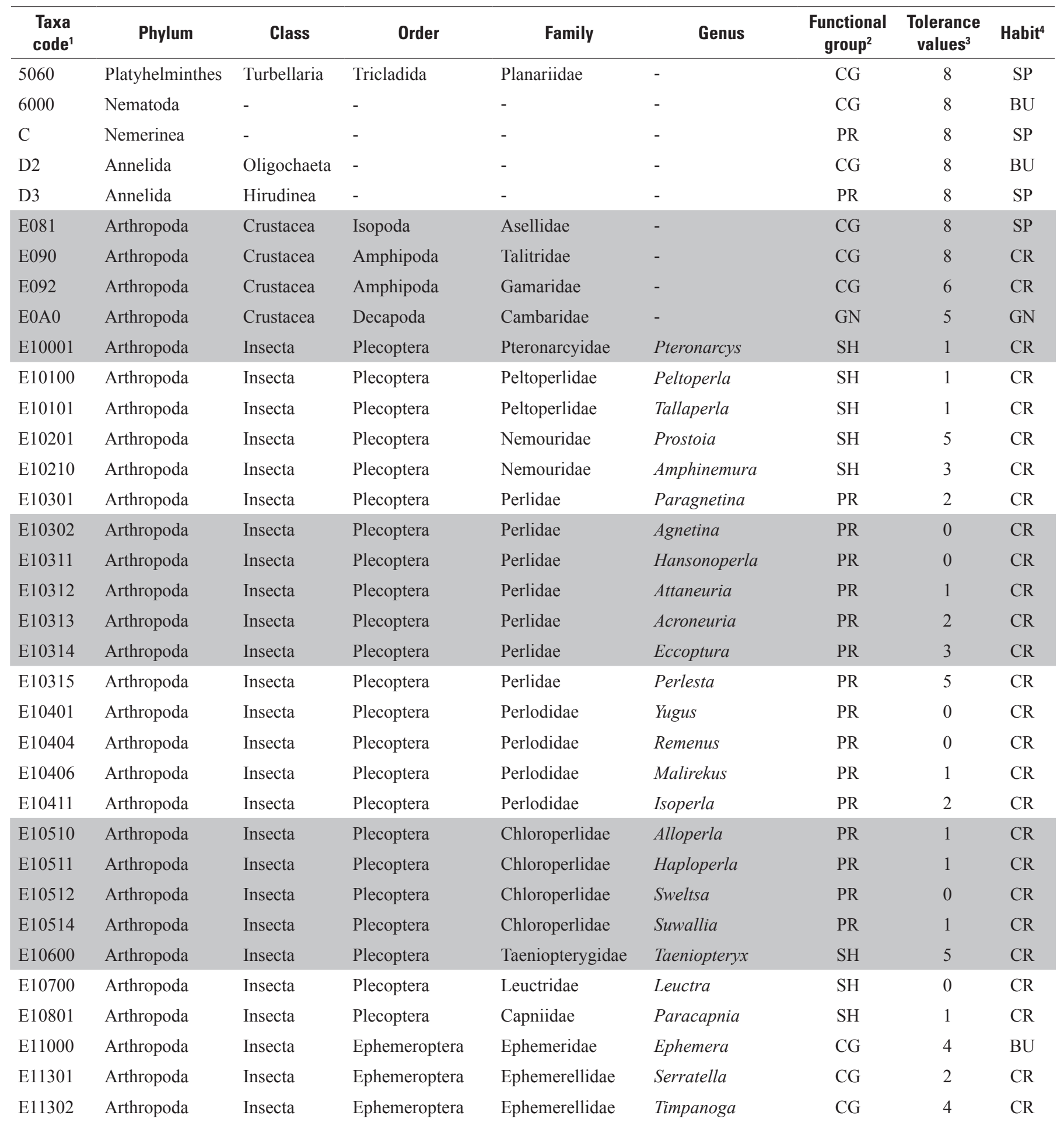


Appendix 1. Macroinvertebrate taxa collected at 24 Long Term Ecological Monitoring (LTEM) Program sites between 1990 and 2009, and 54 sites in 1995 (data used in the retrospective analyses contained in this report).—Continued

[Table contains taxonomic descriptions as well as taxon-specific ecological characteristics required to compute summary statistics shown in table 10. -, taxa not defined at this level; USGS, U.S. Geological Survey. Functional groups are as follows: CF, Collector filterer; CG, Collector-gatherer; GN, Generalist feeder; MP, Macrophyte piercer; PR, Predator; SC, Scraper; and SH, shredder. Habit codes are as follows: BU, Burrowers; CG, Clingers; CL, Climbers; DV, Divers; GN, Generalist; SK, Skaters; and SP, Sprawlers]

\begin{tabular}{|c|c|c|c|c|c|c|c|c|}
\hline $\begin{array}{l}\text { Taxa } \\
\text { code }^{1}\end{array}$ & Phylum & Class & Order & Family & Genus & $\begin{array}{c}\text { Functional } \\
\text { group }^{2}\end{array}$ & $\begin{array}{c}\text { Tolerance } \\
\text { values }^{3}\end{array}$ & Habit \\
\hline E11303 & Arthropoda & Insecta & Ephemeroptera & Ephemerellidae & Drunella & $\mathrm{SC}$ & 0 & $\mathrm{CR}$ \\
\hline E11304 & Arthropoda & Insecta & Ephemeroptera & Ephemerellidae & Ephemerella & CG & 2 & $\mathrm{CR}$ \\
\hline E11305 & Arthropoda & Insecta & Ephemeroptera & Ephemerellidae & Eurylophella & $\mathrm{CG}$ & 4 & $\mathrm{CR}$ \\
\hline E11500 & Arthropoda & Insecta & Ephemeroptera & Ameletidae & Ameletus & $\mathrm{SC}$ & 1 & CG \\
\hline E11600 & Arthropoda & Insecta & Ephemeroptera & Leptophlebiidae & Leptophlebia & CG & 6 & SP \\
\hline E11601 & Arthropoda & Insecta & Ephemeroptera & Leptophlebiidae & Paraleptophlebia & $\mathrm{CG}$ & 1 & $\mathrm{CR}$ \\
\hline E11603 & Arthropoda & Insecta & Ephemeroptera & Leptophlebiidae & Habrophlebia & $\mathrm{CG}$ & 1 & $\mathrm{CR}$ \\
\hline E11604 & Arthropoda & Insecta & Ephemeroptera & Leptophlebiidae & Habrophlebiodes & $\mathrm{SC}$ & 1 & $\mathrm{CR}$ \\
\hline E11701 & Arthropoda & Insecta & Ephemeroptera & Baetidae & Baetis & $\mathrm{CG}$ & 5 & $\mathrm{CG}$ \\
\hline E11702 & Arthropoda & Insecta & Ephemeroptera & Baetidae & Callibaetis & CG & 10 & $\mathrm{CL}$ \\
\hline E11703 & Arthropoda & Insecta & Ephemeroptera & Baetidae & Centroptilum & CG & 7 & CG \\
\hline E11900 & Arthropoda & Insecta & Ephemeroptera & Heptageniidae & Stenonema & $\mathrm{SC}$ & 4 & CG \\
\hline E11901 & Arthropoda & Insecta & Ephemeroptera & Heptageniidae & Stenacron & CG & 4 & CG \\
\hline E11902 & Arthropoda & Insecta & Ephemeroptera & Heptageniidae & Epeorus & CG & 1 & CG \\
\hline E11903 & Arthropoda & Insecta & Ephemeroptera & Heptageniidae & Cinygmula & $\mathrm{SC}$ & 1 & CG \\
\hline E11904 & Arthropoda & Insecta & Ephemeroptera & Heptageniidae & Leucrocuta & $\mathrm{SC}$ & 2 & CG \\
\hline E11905 & Arthropoda & Insecta & Ephemeroptera & Heptageniidae & Heptagenia & $\mathrm{SC}$ & 3 & CG \\
\hline E11907 & Arthropoda & Insecta & Ephemeroptera & Heptageniidae & Rhithrogena & CG & 1 & CG \\
\hline E11B00 & Arthropoda & Insecta & Ephemeroptera & Potomanthidae & Anthopotomus & CG & 2 & $\mathrm{BU}$ \\
\hline E11D04 & Arthropoda & Insecta & Ephemeroptera & Isonychiidae & Isonychia & $\mathrm{CF}$ & 3 & $\mathrm{CG}$ \\
\hline E12000 & Arthropoda & Insecta & Odonata & Cordulegastridae & Cordulegaster & PR & 3 & $\mathrm{BU}$ \\
\hline E12020 & Arthropoda & Insecta & Odonata & Gomphidae & Progomphus & PR & 8 & $\mathrm{BU}$ \\
\hline E12022 & Arthropoda & Insecta & Odonata & Gomphidae & Stylogomphus & PR & 4 & $\mathrm{BU}$ \\
\hline E12023 & Arthropoda & Insecta & Odonata & Gomphidae & Gomphus & PR & 6 & $\mathrm{BU}$ \\
\hline E12029 & Arthropoda & Insecta & Odonata & Gomphidae & Lanthus & PR & 1 & $\mathrm{BU}$ \\
\hline E12041 & Arthropoda & Insecta & Odonata & Aeschnidae & Boyeria & PR & 3 & $\mathrm{CR}$ \\
\hline E12053 & Arthropoda & Insecta & Odonata & Coenagrionidae & - & PR & 9 & $\mathrm{CR}$ \\
\hline E131 & Arthropoda & Insecta & Hemiptera & Nepidae & - & PR & 7 & $\mathrm{CL}$ \\
\hline E13200 & Arthropoda & Insecta & Hemiptera & Gerridae & Gerris & PR & 8 & SK \\
\hline E13400 & Arthropoda & Insecta & Hemiptera & Veliidae & Microvelia & PR & 8 & SK \\
\hline E13A & Arthropoda & Insecta & Hemiptera & Corixidae & - & MP & 9 & DV \\
\hline E14000 & Arthropoda & Insecta & Megaloptera & Sialidae & Sialis & PR & 7 & SP \\
\hline E14100 & Arthropoda & Insecta & Megaloptera & Corydalidae & Corydalus & PR & 5 & $\mathrm{CR}$ \\
\hline E14111 & Arthropoda & Insecta & Megaloptera & Corydalidae & Nigronia & PR & 4 & $\mathrm{CR}$ \\
\hline E16012 & Arthropoda & Insecta & Trichoptera & Hydroptilidae & Hydroptila & MP & 6 & $\mathrm{CR}$ \\
\hline
\end{tabular}


Appendix 1. Macroinvertebrate taxa collected at 24 Long Term Ecological Monitoring (LTEM) Program sites between 1990 and 2009, and 54 sites in 1995 (data used in the retrospective analyses contained in this report).-Continued

[Table contains taxonomic descriptions as well as taxon-specific ecological characteristics required to compute summary statistics shown in table 10. -, taxa not defined at this level; USGS, U.S. Geological Survey. Functional groups are as follows: CF, Collector filterer; CG, Collector-gatherer; GN, Generalist feeder; MP, Macrophyte piercer; PR, Predator; SC, Scraper; and SH, shredder. Habit codes are as follows: BU, Burrowers; CG, Clingers; CL, Climbers; DV, Divers; GN, Generalist; SK, Skaters; and SP, Sprawlers]

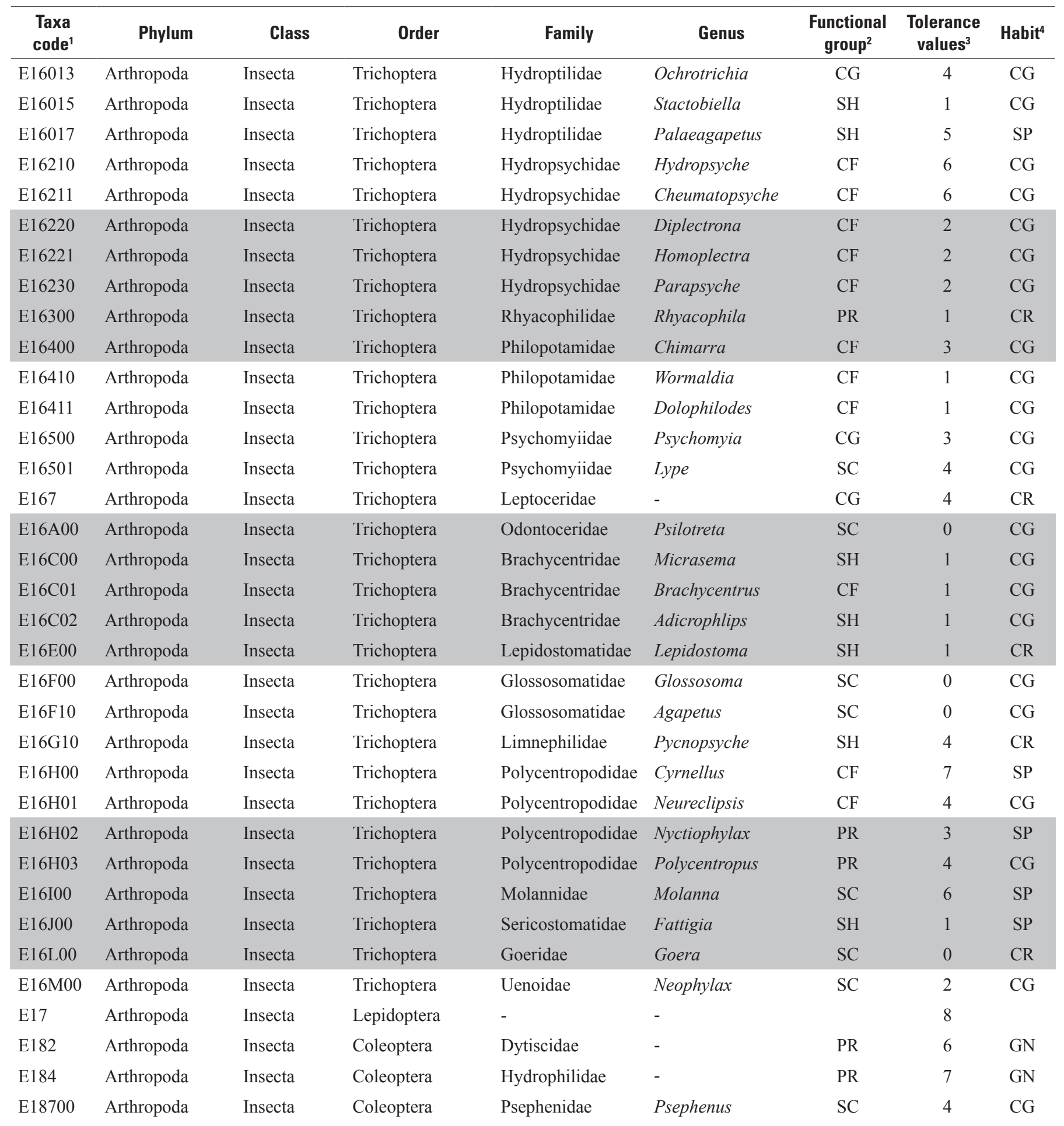


Appendix 1. Macroinvertebrate taxa collected at 24 Long Term Ecological Monitoring (LTEM) Program sites between 1990 and 2009, and 54 sites in 1995 (data used in the retrospective analyses contained in this report).—Continued

[Table contains taxonomic descriptions as well as taxon-specific ecological characteristics required to compute summary statistics shown in table 10. -, taxa not defined at this level; USGS, U.S. Geological Survey. Functional groups are as follows: CF, Collector filterer; CG, Collector-gatherer; GN, Generalist feeder; MP, Macrophyte piercer; PR, Predator; SC, Scraper; and SH, shredder. Habit codes are as follows: BU, Burrowers; CG, Clingers; CL, Climbers; DV, Divers; GN, Generalist; SK, Skaters; and SP, Sprawlers]

\begin{tabular}{|c|c|c|c|c|c|c|c|c|}
\hline $\begin{array}{l}\text { Taxa } \\
\text { code }^{1}\end{array}$ & Phylum & Class & Order & Family & Genus & $\begin{array}{c}\text { Functional } \\
\text { group }^{2}\end{array}$ & $\begin{array}{c}\text { Tolerance } \\
\text { values }^{3}\end{array}$ & Habit \\
\hline E18701 & Arthropoda & Insecta & Coleoptera & Psephenidae & Ectopria & SC & 4 & CG \\
\hline E18800 & Arthropoda & Insecta & Coleoptera & Dryopidae & Helichus & SC & 5 & CG \\
\hline E18900 & Arthropoda & Insecta & Coleoptera & Elmidae & Stenelmis & $\mathrm{SC}$ & 5 & CG \\
\hline E18901 & Arthropoda & Insecta & Coleoptera & Elmidae & Macronychus & $\mathrm{SC}$ & 5 & CG \\
\hline E18902 & Arthropoda & Insecta & Coleoptera & Elmidae & Ancyronyx & $\mathrm{SC}$ & 6 & CG \\
\hline E18904 & Arthropoda & Insecta & Coleoptera & Elmidae & Optioservus & $\mathrm{SC}$ & 5 & CG \\
\hline E18905 & Arthropoda & Insecta & Coleoptera & Elmidae & Dubiraphia & $\mathrm{SC}$ & 5 & CG \\
\hline E18906 & Arthropoda & Insecta & Coleoptera & Elmidae & Promoresia & $\mathrm{SC}$ & 2 & CG \\
\hline E18907 & Arthropoda & Insecta & Coleoptera & Elmidae & Oulimnius & $\mathrm{SC}$ & 2 & CG \\
\hline E18908 & Arthropoda & Insecta & Coleoptera & Elmidae & Gonielmas & $\mathrm{SC}$ & 5 & CG \\
\hline $\mathrm{E} 18 \mathrm{C} 00$ & Arthropoda & Insecta & Coleoptera & Ptilodactylidae & Anchytarsus & SH & 4 & CG \\
\hline E18F0 & Arthropoda & Insecta & Coleoptera & Helophoridae & Helophorus & SH & 8 & $\mathrm{CL}$ \\
\hline E19000 & Arthropoda & Insecta & Diptera & Blephariceridae & Blepharicera & $\mathrm{SC}$ & 0 & CG \\
\hline E19200 & Arthropoda & Insecta & Diptera & Tipulidae & Tipula & SH & 5 & $\mathrm{BU}$ \\
\hline E19210 & Arthropoda & Insecta & Diptera & Tipulidae & Antocha & CG & 3 & CG \\
\hline E19220 & Arthropoda & Insecta & Diptera & Tipulidae & Dicranota & PR & 3 & $\mathrm{CR}$ \\
\hline E19222 & Arthropoda & Insecta & Diptera & Tipulidae & Molophilus & PR & 4 & $\mathrm{BU}$ \\
\hline E19230 & Arthropoda & Insecta & Diptera & Tipulidae & Hexatoma & PR & 3 & $\mathrm{CR}$ \\
\hline E19231 & Arthropoda & Insecta & Diptera & Tipulidae & Limnophila & PR & 4 & $\mathrm{BU}$ \\
\hline E19234 & Arthropoda & Insecta & Diptera & Tipulidae & Pilaria & PR & 3 & $\mathrm{BU}$ \\
\hline E19242 & Arthropoda & Insecta & Diptera & Tipulidae & Ormosia & CG & 4 & $\mathrm{BU}$ \\
\hline E19243 & Arthropoda & Insecta & Diptera & Tipulidae & Erioptera & CG & 3 & $\mathrm{BU}$ \\
\hline E19311 & Arthropoda & Insecta & Diptera & Psychodidae & Pericoma & CG & 10 & $\mathrm{BU}$ \\
\hline E19500 & Arthropoda & Insecta & Diptera & Dixidae & Dixa & CG & 3 & $\mathrm{CR}$ \\
\hline E19700 & Arthropoda & Insecta & Diptera & Simuliidae & Prosimulium & $\mathrm{CF}$ & 4 & CG \\
\hline E19720 & Arthropoda & Insecta & Diptera & Simuliidae & Simulium & $\mathrm{CF}$ & 6 & CG \\
\hline E198 & Arthropoda & Insecta & Diptera & Chironomidae & - & CG & 6 & $\mathrm{BU}$ \\
\hline E199 & Arthropoda & Insecta & Diptera & Ceratopogonidae & - & $\mathrm{SC}$ & 6 & SP \\
\hline E19B10 & Arthropoda & Insecta & Diptera & Tabanidae & Tabanus & PR & 9 & $\mathrm{BU}$ \\
\hline E19C00 & Arthropoda & Insecta & Diptera & Athericidae & Atherix & PR & 2 & $\mathrm{CR}$ \\
\hline E19J00 & Arthropoda & Insecta & Diptera & Empididae & Hemerodromia & PR & 6 & $\mathrm{CR}$ \\
\hline E19J01 & Arthropoda & Insecta & Diptera & Empididae & Chelifera & PR & 6 & SP \\
\hline E19J02 & Arthropoda & Insecta & Diptera & Empididae & Wiedemannia & PR & 6 & CG \\
\hline E19J10 & Arthropoda & Insecta & Diptera & Empididae & Clinocera & PR & 6 & CG \\
\hline E19J30 & Arthropoda & Insecta & Diptera & Empididae & Oreogeton & PR & 6 & SP \\
\hline
\end{tabular}


Appendix 1. Macroinvertebrate taxa collected at 24 Long Term Ecological Monitoring (LTEM) Program sites between 1990 and 2009, and 54 sites in 1995 (data used in the retrospective analyses contained in this report).-Continued

[Table contains taxonomic descriptions as well as taxon-specific ecological characteristics required to compute summary statistics shown in table 10. -, taxa not defined at this level; USGS, U.S. Geological Survey. Functional groups are as follows: CF, Collector filterer; CG, Collector-gatherer; GN, Generalist feeder; MP, Macrophyte piercer; PR, Predator; SC, Scraper; and SH, shredder. Habit codes are as follows: BU, Burrowers; CG, Clingers; CL, Climbers; DV, Divers; GN, Generalist; SK, Skaters; and SP, Sprawlers]

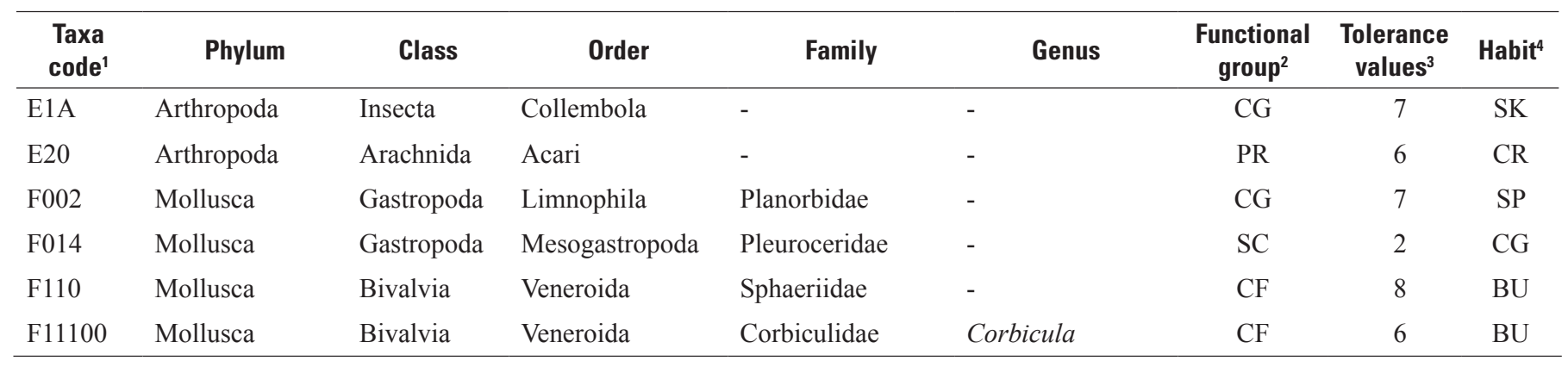

${ }^{1}$ Taxa codes were taken from the Shenandoah National Park long-term monitoring database.

${ }^{2}$ Functional groups were taken from the Shenandoah National Park long-term monitoring database. These characteristics were used to compute community metrics Shredder\% and Scraper\% (see table 10).

${ }^{3}$ Tolerance values were taken from the Shenandoah National Park long-term monitoring database. These values were used to compute community pollution tolerance values (see table 10).

${ }^{4}$ Taxon-specific "habits" were taken from the Shenandoah National Park long-term monitoring database. These characteristics were used to compute the community metric Hapto\% (Haptobenthos), which is the sum of crawlers and clingers (see table 10).

\section{Prepared by: \\ USGS Science Publishing Network \\ Raleigh Publishing Service Center \\ 3916 Sunset Ridge Road \\ Raleigh, NC 27607}

For additional information regarding this publication, contact:

Director

USGS Virginia Water Science Center

1730 East Parham Road

Richmond, Virginia 23228

(804) 261-2600

email: dc_va@usgs.gov

Or visit the Virginia Water Science Center Web site at:

http://va.water.usgs.gov/ 




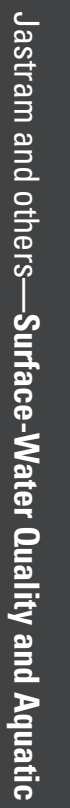

罟

恶

응

蛋

es

$\overrightarrow{\mathrm{T}}$

言

2

휼

일

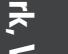

念

os

م

蛋

$\frac{\bar{n}}{\overline{2}}$

ఖ

웅.

항.

के

귱

N

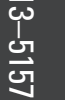

